\title{
Palaeo-dust records: A window to understanding past environments
}

\author{
Samuel K Marx ${ }^{1}$, Balz S Kamber ${ }^{2}$, Hamish A McGowan ${ }^{3}$, Lynda M. Petherick ${ }^{4}$, Grant, H \\ McTainsh $^{5}$, Nicola Stromose ${ }^{6}$, James N. Hooper ${ }^{1}$, Jan-Hendrik May ${ }^{7}$
}

\footnotetext{
${ }^{1}$ GeoQuEST Research Centre - School of Earth and Environmental Sciences, University of Wollongong, New South Wales, 2522, Australia.

${ }^{2}$ Department of Geology, School of Natural Sciences, Trinity College Dublin, 2, Ireland.

${ }^{3}$ School of Earth and Environmental Sciences, The University of Queensland, Brisbane, Queensland, 4072, Australia. ${ }^{4}$ School of Geography, Environment and Earth Sciences, Victoria University of Wellington, Wellington, New Zealand. ${ }^{5}$ Atmospheric Environment Research Centre, Griffith School of Environment, Griffith University, Queensland, 4111, Australia.

${ }^{6}$ School of Engineering Health Science \& Environment, Charles Darwin University, Darwin, Northern Territory 0909 Australia.

${ }^{7}$ School of Geography, University of Melbourne, Australia.
}

\section{Abstract}

Dust entrainment, transport over vast distances and subsequent deposition is a fundamental part of the Earth system. Yet the role and importance of dust has been underappreciated, due largely to challenges associated with recognising dust in the landscape and interpreting its depositional history. Despite these challenges, interest in dust is growing. Technical advances in remote sensing and modelling have improved understanding of dust sources and production, while advances in sedimentology, mineralogy and geochemistry (in particular) have allowed dust to be more easily distinguished within sedimentary deposits. This has facilitated the reconstruction of records of dust emissions through time. A key advance in our understanding of dust has occurred following the development of methods to geochemically provenance (fingerprint) dust to its source region. This ability has provided new information on dust transport pathways, as well as the reach and impact of dust. It has also expanded our understanding of the processes driving dust emissions over decadal to millennial timescales through linking dust deposits directly to source area conditions. Dust provenance studies have shown that dust emission, transport and deposition are highly sensitive to variability in climate. They also imply that dust emissions are not simply a function of the degree of aridity in source areas, but respond to a more complex array of conditions, including sediment availability. As well as recording natural variability, dust records are also shown to sensitively track the impact of human activity. This is reflected by both changing dust emission rates and changing dust chemistry. Specific examples of how dust responds to, and records change, are provided with our work on dust emissions from Australia, the most arid inhabited continent and the largest dust source in the Southern Hemisphere. These case studies show that Australian dust emissions reflect hydro-climate variability, with reorganisation of Australian dust source areas occurring during the mid to late Holocene. Dust emissions are shown to sensitively map the structure of the Last Glacial Maximum in Australia, demonstrating that 
this period was associated with enhanced, but also variable dust emissions, driven by changing sources area conditions. Finally we show how dust emissions have responded to the arrival of Europeans and the associated onset of broad-scale agriculture across the Australian continent.

\section{Introduction: the significance of understanding dust emissions though time}

Long-range dust transport, namely the entrainment, transport and deposition of mineral dust over thousands of kilometres, is a long-standing interest of Earth Scientists, with the first scientific accounts of long-range dust dating from the Mid-16 ${ }^{\text {th }}$ Century, when mysterious red rains, now known to likely have been associated with Saharan dust, fell in Brussels (see Stout et al., 2009). Other significant early accounts of long-range dust includes Charles Darwin's report on encountering dust on the Beagle off the North African coast in 1833 , prompting him to undertake a review of similar observations (Darwin, 1846). In the late $19^{\text {th }}$ Century it was recognised that loess is of aeolian origin (Richthofen, 1882) and furthermore that its formation is dictated by climate (Hardcastle, 1890; also see Smalley et al., 2001). These insights led to numerous investigations of loess deposits and the palaeoclimatic significance of loess/palaeosol sequences, which have improved understanding of past climates and enhanced the appreciation of aeolian processes in the Earth systems. By comparison with loess, which typically represents deposition of local dust, long-range aeolian transport has historically received less attention (although loess and long-range dust can share similar production and transport histories). Dust emissions are considerably less-well studied than fluvial sediment transport, despite the former being of greater or comparable geomorphic significance to fluvial transport in arid/semi-arid landscapes. For example, in Patagonia $30 \mathrm{Mt} / \mathrm{y}$ of dust is estimated to be delivered to the ocean compared to only $2 \mathrm{Mt} / \mathrm{y}$ of suspended river sediment, while African dust emissions are estimated at 517-1,150 Mt/yr (Shao et al., 2011), broadly equivalent to suspended African river sediment loads at 800-1,310 Mt/yr (Syvitski et al., 2005). Similarly in Australia, sediment transport by major rivers is approximately $129 \mathrm{Mt} / \mathrm{yr}(\sim 5 \mathrm{Mt} / \mathrm{yr}$ if tropical rivers are excluded) (Wasson et al., 1996) while dust emissions are estimated to amount to 37-148 $\mathrm{Mt} / \mathrm{yr}$ (Shao et al., 2011). More recently, the advent of high resolution and global remote sensing techniques (Bullard et al., 2008; Ginoux et al., 2012; Washington et al., 2003), in combination with greater understanding of biogeochemical cycles (Bristow et al., 2010; Duce and Tindale, 1991; Jaccard et al., 2013), enhanced analysis methods of dusts (geochemical fingerprinting in particular) (Grousset and Biscaye, 2005; Kamber, 2009; Marx et al., 2005b) and Earth system modelling has led to a greater appreciation of the role of dust, particularly its importance for weather and climate (Arimoto, 2001; Boucher et al., 2013; Huneeus et al., 2011; Peltier and Marshall, 1995). Collectively, these developments have driven increased interest in dust over past decades (Arimoto, 2001; Bullard et al., 2016; Maher et al., 2010; Shao et al., 2011), e.g. the annual number of scientific publications 
examining aeolian processes approximately has doubled after the mid to late 1990s Common Era (CE) (Stout et al., 2009).

Long-range dust transport is of particular significance to a number of Earth system processes due to the magnitude of emissions, the geographical reach of dust plumes and the mode of emission, i.e. directly to the atmosphere (Fig. 1). Within the atmosphere, dust affects climate by altering earth surface-atmosphere radiation exchanges and thereby affecting atmospheric and earth surface heating and cooling; introducing cloud condensation nuclei, which alter precipitation and atmospheric albedo; and influencing atmospheric chemistry (Boucher et al., 2013; Huneeus et al., 2011). In biogeochemistry, the deposition of dust is now also recognised as an important factor, including as a source of nutrients (Bristow et al., 2010; Duce et al., 1991; Duce and Tindale, 1991; Martin et al., 1994), a carrier of pollutants and a vector for pathogens (Garrison et al., 2006; Jaffe et al., 1999; Kellogg and Griffin, 2006; Marx et al., 2008). Dust deposition is known to be an important source of biologically essential trace elements to many environments (Fig. 1). In the ocean, dust deposition contributes toward oceanic primary productivity (Duce et al., 1991; Martin et al., 1994), particularly in High Nutrient, Low Chlorophyll (HNLC) oceanic waters (typically high latitude regions), through supply of biologically essential elements otherwise lacking, e.g. Fe, which is the most studied of these (Ito and Shi, 2016; Jickells et al., 2005; Johnson et al., 2010; Moore et al., 2013). In many parts of the globe, including in the Hawaiian, Canary and Caribbean Islands and the Amazon rainforest, long-range dust deposition is an important component of soil formation and nutrient input (Bristow et al., 2010; Muhs et al., 2010b; Muhs et al., 2012; Porder et al., 2007; Rex et al., 1969; Swap et al., 1992; von Suchodoletz et al., 2013).

There are a number of key feedbacks between dust emissions, biogeochemistry and climate. These constitute the main importance of dust in Earth system dynamics. Increased dust emissions, which in many circumstances results in reduced radiative forcing, contribute to increased effectiveness of the biological C pump (via ecosystem fertilisation) (Falkowski et al., 2000). One illustration of the complex role of dust on glacial-interglacial timescales is that while ocean fertilisation by dust is considered to have resulted in significant atmospheric $\mathrm{CO}_{2}$ drawdown and global cooling, at the same time, dust deposition onto ice results in enhanced ice melt (Maher et al., 2010; Peltier and Marshall, 1995). Similarly, dust emissions, often considered to respond to enhanced aridity, may also increase aridity though suppression of rainfall (Shine and Forster, 1999).

Notwithstanding its importance as a driver of Earth processes, on a more basic level, dust entrainment and transport respond rapidly to changing Earth system dynamics and it is for this reason that reconstructions of past patterns in dust deposition are important palaeoenvironmental and palaeo-climate proxies. The use of dust as an indicator of palaeoenvironmental conditions has several advantages. The generation of large dust plumes 
reflects broad regional environmental conditions, as opposed to globally averaged palaeoclimate proxies (e.g. $\delta \mathrm{O}^{18}$ in ice cores), or specific site conditions, which can influence pollen records for example (e.g. Field et al., 2017). Because dust deposits can be traced to their geographic sources, for example via geochemical fingerprinting, it is possible to link dust emissions to climate/environmental changes within specific areas or even geomorphic processes. Finally, dust is one of the few proxies that can be used to infer windiness and airmass trajectories (circulation) via particle size and source area fingerprinting, respectively (e.g. Bory et al., 2002; Koffman et al., 2014; Petherick et al., 2009; Sun et al., 2004; Zielinski and Mershon, 1997).

Despite the attractive properties of dust deposition records for reconstructing palaeoenvironments, relatively few records have been constructed. This deficit in knowledge about past dust emissions, at a global scale, leads to uncertainty over the role of dust in past, current and future climate change. For example, estimates of the direction and magnitude of current radiative forcing by dust in the atmosphere range between -0.3 and $+0.1 \mathrm{Wm}^{-2}$, because of uncertainty in magnitude of emission estimates, which vary by a factor of 5 (Boucher et al., 2013; Huneeus et al., 2011). This is even more pronounced for the Holocene epoch, where accurate knowledge of dust emissions is arguably of highest importance in terms of understanding climate and biogeochemical cycles. However, despite the recognised importance of dust, empirical data on dust deposition rates from many regions is limited and/or suffers from uncertainty, i.e. different records show contrasting dust emission rates from particular source areas at the same time (see Albani et al., 2015).

Existing records of past dust emission/deposition also show high variability through time in response to changing driving factors (Fig. 2). For illustration, emissions have varied by an order of magnitude in response to changing palaeo-environmental conditions since the late Pleistocene (Fitzsimmons et al., 2013; Harrison et al., 2001). Even within the Holocene, dust emissions have varied by a factor of between 2 and 10 (Marx et al., 2011; Marx et al., 2009; Petherick et al., 2009). Dust is therefore one of the most variable factors of Earth's surface system. In addition, there is evidence that anthropogenic factors have changed both dust emissions and the chemistry of dust (e.g. Marx et al., 2014b) and by implication its effects within Earth systems, e.g. ocean fertilisation.

There are many challenges involved in creating dust emission/deposition records, from the seemingly straightforward task of recognising dust in the landscape, to more advanced goals like determining the origin of dust and interpreting variability in past dust deposition. The purpose of this paper is to provide an overview of dust records and their interpretation for a general readership. First we examine dust sources and the controls on dust production, transport and deposition. Second we provide an overview of the geological repositories that preserve dust flux records and discuss the palaeo-climatic and environmental information which can be extracted from dust records. Third we outline methods of identifying dust 
deposits and, in particular, review approaches for determining the source area provenance of dust. Lastly we illustrate the state of play with example records of dust emissions from Australia, which represents the largest Southern Hemisphere dust source.

\subsection{Dust, sources, production transport and deposition}

\subsection{A global overview of dust production}

Present day global estimates of annual dust emissions to the atmosphere are $>1,500 \mathrm{Mt}$ (see Shao et al., 2011). The major sources of this dust can be broken into two broad, nonexclusive, sources; glacial/cold-climate derived dust and warm arid dust sources (Bullard et al., 2016; Goudie and Middleton, 2006; Pye, 1987). Currently, warm arid dust sources emit most dust (Bullard et al., 2016; Ginoux et al., 2012; Shao et al., 2011). While knowledge of dust sources has historically been based on observational data of dust storm frequency (e.g. Middleton, 1984), over recent decades, satellite imagery has made a major contribution to understanding dust sources and allowed improved mapping of dust sources at a global scale (Ginoux et al., 2012; Prospero et al., 2002; Washington et al., 2003). This has facilitated detailed investigation of dust production areas as well as identification of the specific geomorphic surfaces within these areas which emit dust. Consequently, our understanding of dust sources has expanded significantly over the last two decades.

Warm arid dust sources occur within zone B (Arid) of the Köppen-Geiger climate classification (Peel et al., 2007). They are often associated with large closed drainage (endoreic) basins, that have no (or limited) outflow, instead runoff and associated sediment converges into ephemeral channels, dry (salt) lakes and pans. For example, the Bodélé Depression in North Africa, the Tarim Basin (including the Taklamahan desert) in Asia and the Lake Eyre Basin in central Australia are the largest emitters of dust in Africa, Asia and Australia, respectively (Ginoux et al., 2012; Washington et al., 2003). In addition to these major dust producing basins, there are many other significant dust sources (Fig. 3). These have been mapped using satellite imagery to quantify dust emission frequency in a number of studies, e.g. Ginoux et al. (2012), Prospero, et al. (2002) and Washington et al. (2003). These studies provide a much more detailed discussion of global dust sources than is given here. Broadly, however, significant dust sources occur throughout North Africa, (centred on the Sahara), the largest continuous arid/semi-arid region. Extensive dust sources also occur throughout the Middle East from the upper Tigris-Euphrates Basin to the southern coast of the Arabian Peninsula. In Asia dust sources occur between the Caspian and Aral Seas and throughout the major basins of Iran, Afghanistan and Pakistan. In addition, there are dust sources across the northern Indian sub-continent, including in the Rajasthan Desert and Ganges Basin. In northern East Asia significant dust sources include the Tarim and Qaidam Basins, the Hexi corridor, Gobi Desert and Loess plateau. In North America dust producing regions occur on both the western and eastern side of the central/southern Rocky 
Mountains, while in South America dust sources are centred around western northern Chile, Argentina and Peru, as well in the lee of the Andes across Patagonia. The major dust sources in Australia occur in central and southern eastern Australia, most notably the Lake Eyre Basin and lower Murray-Darling Bain, while in southern Africa dust is produced from the major deserts and pans located in western southern Africa (Ginoux et al., 2012; Prospero et al., 2002).

Within these broad dust producing regions satellite imagery has allowed the identification of specific point sources (hotspots) which emit globally significant volumes of dust (Bullard et al., 2008; Bullard et al., 2011; Washington et al., 2006). These point sources are overwhelmingly associated with ephemeral water bodies (ephemeral lakes, flood plains, and ephemeral river channels) (Ginoux et al., 2012; Prospero et al., 2002; Washington et al., 2003). An example of this is shown by a Moderate Resolution Imaging Spectroradiometer (MODIS) (Terra satellite) image of a dust plume being emitted from the coast of Namibia on the $3 / 11 / 2015$ (Fig. 4A). The image clearly shows that rather than being entrained from across the whole landscape, the dust plumes instead emanate from either east-west draining river channels (dry) or small endoreic basins, such as the well-known Sossusvlei ('dead-end marsh') of the Tsauchab River (Fig. 4B-D). The characteristically red sand dunes of the Namib desert apparently contributed little dust. In a second example, a Eumeteosat image shows a dust storm sweeping from the Sahara over the Atlantic on 3/3/2004 (Fig. 4E). Different sources of dust are evident from the colour contrast of the plumes. The beige to buff dust emanated from focussed hotspot areas is associated with ephemeral water features, whereas the darker, more pink coloured dust, was entrained more broadly from across the Sahara desert. A third example, a MODIS Aqua satellite image captured on $28 / 11 / 2003$, shows a series of dust plumes being transported in an easterly direction from central Australia (Fig. 4F). The plumes are emanating from dust emission hotspots, which include the ephemeral channels of the southern Channel Country region and northern reaches of Lake Eyre, Strzelecki Creek and Lakes Gregory, Blanche and Callabonna and fluvial channels and dune systems south of Lake Frome.

Another notable feature of warm arid dust sources is that most of the sediment available for entrainment as dust appears to be generated outside the emission zones. Typically, the sediment is produced by chemical and physical weathering on the more humid edges of the basins. Transport of sediment into depocentres within the basin (lakes, fans, floodplains, channels etc.) further reduces particle size by comminution and winnowing. For example, the two major dust sources (dust hotspots) within China's Tarim Basin occur on the southern and northern basin edge. In the southern dust hotspot, sediment is produced in the Kunlun Mountains and foothills and transported into the basin via the Tarim, Hotan, Keriya and Niya Rivers, while the northern hotspot receives sediment from south (via the Yarkand River) and from alluvial fans and associated rivers draining the Tien Shan mountains to the north of the basin (Gao and Washington, 2009; Zhang et al., 2008). In the example of the Sossusvlei in Namibia, the Tsauchab River transports very fine pale-grey sediment into 
seasonally flooded inter-dune clay pans (Fig. 4B-C) from where wind entrains the dust-sized fractions under specific conditions. Likewise the rivers that supply sediment to Australia's Lake Eyre Basin have their headwaters in the more humid northern and eastern edges of the basin where sediment production is higher (Heimsath et al., 2010). River flow is fed by rain associated with the Australian summer monsoon, during which sediment may be transported to depocentres lower in the basin (also see section 3.2 and Fig. 7).

Sediment production in glacial/cold climate dust sources has received less attention than warm arid dust sources. This is largely because warm-arid dust sources dominate current global aerosol budgets (Shao et al., 2011). However, the recognition that glacial/cold climate dust sources contribute $>5 \%$ (based on Patagonia, Icelandic and Alaskan data only) of global dust emissions has sparked renewed interest in these dust sources (also referred to as highlatitude dust sources) (Baddock et al., 2017; Bullard, 2017; Bullard et al., 2016). Production of this sediment is associated primarily with glacial grinding although other cold climate and fluvial processes also contribute (Muhs, 2013), with chemical breakdown (weathering) much less important than in warm-arid dust sources (Nesbitt and Young, 1996). Emissions of dust from glacial/cold climate sources are known to have been very significant in the past, as evidenced by extensive loess deposits in glacial or formerly glaciated locations (Pye, 1995), with greatest long-range dust production also occurring during glacial periods (like in some warm arid dust sources) (Harrison et al., 2001). Importantly, the exact timing of peak glacial dust/loess production within glacial periods has not been fully answered, meaning that the relationship between glacier behaviour and dust response is somewhat unclear, i.e. does dust production peak during deglaciation as glaciers retreat exposing sediment, or during periods of highest glacial extent/ice flow leading to greater production of silt from glacial grinding? Like warm arid dust sources, glacially derived dust is overwhelmingly distributed and sorted in fluvial systems. As a result, loess deposits are often extensive along major valleys draining formerly glaciated environments, e.g. the Rhine, Germany or Mississippi, USA (Muhs, 2013).

\subsection{Dust storms: entrainment and transport}

Dust can be defined as a suspension of solid mineral particles in the atmosphere, or their subsequent deposition (Pye, 1995). In terms of size, it is usually confined to being $<100 \mu \mathrm{m}$ in diameter, with smaller grain sizes transported long distances (long range dust) (Lawrence and Neff, 2009) although unexpectedly large grains have been documented undergoing long-range transport (Middleton et al., 2001).

There is a long history of research examining the controls on dust entrainment and transport beginning with the seminal work of Bagnold (1941) which explored the physicals parameters , for example determining the relationships between wind speed (fluid drag), sediment characteristics and sediment cohesion in controlling dust entrainment (the fluid 
threshold velocity). Broadly speaking, dust entrainment occurs when airflow forces are greater than particle inertia forces (mass and inter-particle cohesion). Dust may be transported by a range of modes (Tsoar and Pye, 1987), but only dust transported in suspension is capable of undergoing long-range transport (typically at sizes $<20 \mu \mathrm{m}$; Pye, 1987). Once in suspension, the tendency of dust to remain in suspension and be transported is a function of the settling velocity of dust particles relative to the velocity and turbulence of the airstream (Tsoar and Pye, 1987), however, most deposition from long-range suspension is considered to occur due to precipitation scavenging (Pye, 1987).

At a broad scale, the factors influencing dust emissions can be grouped into three categories (see Fig. 2): 1) climate controls; wind speed and direction, turbulence, precipitation, temperature and humidity; 2 ) vegetation controls; cover, type and transpiration and; 3 ) sediment controls; particle size, shape, density, regolith structure, moisture content, salt content and surface roughness (McTainsh, 1989). A number of studies have explored how these controls interact to influence dust emissions at instantaneous to multi-year time scales (e.g. Marx et al., 2005a; McTainsh et al., 2002; Yang et al., 2007). How these factors interplay over climate-relevant time scales is critical for understanding the palaeoenvironmental significance of dust deposits, however, much remains to be learnt.

A range of dust transport 'event' types have been defined in terms of visibility criteria by the World Meteorological Organisation (O'Loingsigh et al., 2010). Most research has been centred on 'dust storms', which are large events where visibility is $<1000$ to $<200 \mathrm{~m}$. Only exceptionally large dust storms are likely to remain visible after long-range transport. Over recent decades, dust activity has increasingly been mapped by satellite products, e.g. MODIS Deep Blue Aerosol Optical Depth (AIO), Dust Optical Depth (DOD) and earlier SeasWiFS and Total Ozone Mapping Spectrometer (TOMS) absorbing aerosol product (e.g. Ginoux et al., 2012; Prospero et al., 2002; Washington et al., 2003). Although satellite data have greatly increased the spatial coverage of dust observations, the observational time window is still restricted to approximately the last 30 years, therefore ground-level observational data (visibility) remain critical for examining patterns in dust emissions beyond this time period (O'Loingsigh et al., 2015). It is possible to use satellite products to track the long-range trajectories of large dust plumes (e.g. Husar et al., 2001; McTainsh et al., 2005; Shao and Dong, 2006; Uno et al., 2009) but their ability to detect low concentrations of dust is limited. There is the additional limitation that satellite imagery cannot detect dust under cloudy conditions, e.g. in tropical or high latitude regions (Bullard et al., 2016; Gassó et al., 2010). Because even very dispersed low-mass plumes can still have biogeochemical significance, ground-based monitoring, observational data and palaeo-reconstructions remain important for understanding and quantifying long-range dust emissions (Marx et al., 2014a; Prospero, 1999).

\subsection{Dust archives}


Although dust input is nearly universal in sedimentary environments, it is surprisingly difficult to recognise. With the exception of loess, which is deposited close to its source in locations that favour trapping of aeolian sediment (e.g. in the lee of or close to topographic obstacles) (Pye, 1995), dust deposition typically results in extremely dispersed deposits over wide geographical areas (McTainsh, 1989). In arid or semi-arid landscapes, deposited dust is readily re-entrained, and in all environments dust deposits are quickly incorporated into the landscape. Consequently, even following major dust storms little visible sign of dust remains in the environment even after time periods as short as $24-48$ hours after initial deposition, especially when dust storms are followed by rain. The inability to recognise dust deposits in the landscape across many sedimentary environments has curtailed the reconstruction of palaeo-dust deposition records in most locations. Additionally, it has hindered appreciation of the geomorphic significance of dust and its role in Earth systems, particularly in soil formation.

The deposition of small volumes of dust, albeit over large areas, means that in most locations dust is physically overwhelmed by other sedimentary material (alluvial or colluvial deposition) (Fig. 5). However, there are environments that receive sediment input largely or exclusively from dust. Two of the best known of these are the remote ocean, outside the influence of terrigenous and hemipelagic sediment (Rea, 1994), where dust constitutes a major sedimentary component of the sea floor, and ice fields and ice sheets (Delmonte et al., 2008; Lambert et al., 2008; Svensson et al., 2000; Vallelonga et al., 2005). Consequently, our understanding of patterns of dust emissions is still based largely on records from these environments. Oceanic sediment cores provide long temporal records of dust deposition through the Quaternary and beyond. They have demonstrated that, in general, dust emissions are higher during glacial periods. Unfortunately, the distal oceanic records often are from low accumulation rate sediments, offering correspondingly low temporal resolution, e.g. 1-5 cm/kyr (Hesse, 1994; Stuut et al., 2002). Furthermore, they are difficult to date with absolute means instead often relying on indirect chronology, e.g., age control is established with $\delta^{18} \mathrm{O}$ correlation. Finer-scale scale variability in dust emissions are difficult to extract from these records. By comparison, near shore marine records provide both higher temporal resolution and more robust chronology, e.g. they can be dated by ${ }^{14} \mathrm{C}$ as well as $\delta^{18} \mathrm{O}$ correlation (e.g. Collins et al., 2013), but these are more complex sedimentary environments in which dust is intermixed with fluvial and marine sediments requiring well developed approaches to separate a dust signal (Mulitza et al., 2008; Stuut et al., 2002).

Ice cores can provide outstanding high resolution records of dust emissions through time. Their major limitation is that they are geographically restricted to high latitude or mountainous regions, with some exceptions such as the central Andes and Tibetan Plateau. Existing dust records from ice cores are therefore largely from the polar regions. The poles are generally remote from the major dust producing regions, with the exception of the relative close proximity of Patagonia to the Antarctic Peninsula. There is also, however, the potential that long-range dust from multiple sources areas can reach polar latitudes. 
Therefore, sophisticated geochemical tracing work has been undertaken to examine the provenance of dust extracted from polar ice cores (Basile et al., 1997; Bory et al., 2010; De Deckker et al., 2010; Delmonte et al., 2010a; Delmonte et al., 2013; Delmonte et al., 2010b; Delmonte et al., 2004; Delmonte et al., 2017a; Gabrielli et al., 2005; Gili et al., 2017b; Gili et al., 2016; Revel-Rolland et al., 2006; Vallelonga et al., 2010; Vallelonga et al., 2005). For example, dust from both East Asia (Biscaye et al., 1997; Bory et al., 2010) and the Sahara has been identified in central Greenland (VanCuren et al., 2012). In the Southern Hemisphere there is potential for dust to be transported from South America, Australia, southern Africa and New Zealand to the Antarctic. Additionally, it is probable that contribution from these sources has varied through time. While dust deposited in ice cores from East Antarctica has overwhelmingly been provenanced to source regions within Patagonia (Bory et al., 2010; Delmonte et al., 2010a; Gaiero, 2007; Gili et al., 2017b) questions remain about the ability to distinguish between different Southern Hemisphere continental dust sources (Fig. 6). This is because of the presently limited representativeness of dust source area geochemistry databases. For example, there are too few combined $\mathrm{Nd}$ and $\mathrm{Sr}$ isotope data from central Australian dust sources to confidently rule this area out as a substantial contributor to dust in Antarctica. Furthermore, the representativeness of core locations within Antarctica is also limited given the various possible dust transport pathways (Li et al., 2008; Neff and Bertler, 2015). At present, the majority of studies have been undertaken in East Antarctica.

Therefore, the current understanding of the generation of dust and its transport to the polar regions still carries some uncertainty. Finally, it may also also needs to be considered whether the polar regions may are optimal for understanding dust source area changes because transport to these regions may be influenced more strongly by variability in air mass trajectories (e.g. Neff and Bertler, 2015) than other factors. This is highlighted, for example, with transport of dust from the Tarim Basin in northwest China to Greenland (Bory et al., 2002).

The limited spatial distribution of ice core records and the limited temporal resolution of many traditional archives, such as ocean sediment cores, have stimulated growing interest in reconstructing dust deposition records from other environments. Work in these novel setting has additionally benefitted from advancements in geochemical fingerprinting, which has aided dust identification in more complex sedimentary settings. The most widely known studies are those undertaken on cores extracted from peat bogs. These have the advantage of being easily datable by ${ }^{14} \mathrm{C}$ due to their high organic content. Ombrogenous (rain-fed) peat mires can contain pure atmospheric deposition signals. It is worth noting that initially, peat bog sediments were used as archives of atmospheric anthropogenic metal deposition. For example, the pioneering work of Shotyk et al. $(1998 ; 2001)$ constructed contaminant metal loads in peat from the Jura Mountains, Switzerland. In those early studies, it was already realised that climatically-driven mineral dust deposition records might be present. For example, Shotlyk et al. (2001) reported (p. 2337) that: "Elevated soil dust fluxes are observed at 5.3, 8.2 and $10.6 \mathrm{kyr}$; the latter corresponds to the Younger Dryas. Aluminum, 
$\mathrm{Zr}, \mathrm{Hf}$, and $\mathrm{REE} / \mathrm{Sc}$ ratios also are elevated at the same depths, suggesting differences in particle size, wind strength, or source regions". Since then, peat cores have found increasing use for reconstruction of dust records (Kylander et al., 2016; Shotyk et al., 2001; Vanneste et al., 2016; Weiss et al., 2002).

Notwithstanding the many advantages of peat mires for reconstructing dust and metal input, peat records in most locations are restricted to covering the time period between the mid- to late Holocene and the present. Furthermore, the temporal resolution of peat mires is almost always lower than that of ice cores and developing robust geochronology can require considerable analytical effort (e.g. ${ }^{14} \mathrm{C}$ and ${ }^{210} \mathrm{~Pb}$ dating). Similarly, the fidelity and geochronology of some peat mires maybe influenced by internal biological, chemical, or physical processes. Finally, peat mires may contain an extra mineral component (alluvial or colluvial) and may also be influenced by ground water. Overall, however, ombrogenous peats often preserve excellent dust records (e.g., see sections 5.2.and 5.3).

Lake sediments have also been successfully analysed to reconstruct dust input (Ballantyne et al., 2011; Stanley and De Deckker, 2002). They can suffer from many of the same complications as peats. Importantly, as most lakes receive local sediment via runoff in addition to direct dust deposition, greater sophistication in chemically isolating the dust components is required. There are a number of further dust archives that have been proposed, most notably sediment in volcanic craters and maar lakes (Dietrich and Seelos, 2010; Haberzettl et al., 2009; Kylander et al., 2007; Kylander et al., 2006) and soils (Kurtz et al., 2001; May et al., 2015; Muhs et al., 2010a; Muhs et al., 2010b; Muhs et al., 2008; Pye, 1992; Rex et al., 1969).

\subsection{Interpreting dust emissions.}

Dust emissions can provide unique information on palaeo-environments, including on wind speed and wind directions prevailing hundreds of thousands of years ago. Interpretation of palaeo-dust emission records, however, requires careful consideration of the multiple processes which influence entrainment, transport and deposition (illustrated on Figure 2). These can be grouped into four non-exclusive categories: 1) climate controls, 2) sediment availability, 3) human activity and, 4) factors influencing dust deposition. They are discussed in the following subsections, with individual processes summarised in Figure 2.

\subsection{Climate controls}

Variability in dust emission through time has been linked to changes in climate over multiple timescales, from instantaneous through seasonal, multi-annual/decadal to multi-millennial. At multi-decadal to multi-millennial timescales, changing patterns in aridity are widely seen as the most important factor influencing dust emissions. For example, increased dust emissions at or around the last glacial maximum (LGM) have been largely ascribed to increased aridity (Biscaye et al., 1997; Harrison et al., 2001; Kohfeld and Harrison, 2001; 
McGowan et al., 2008; Rea, 1994). Aridity (decreased precipitation relative to evapotranspiration) has the effect of increasing sediment availability by drying sediment (decreasing inter-particle cohesion) and reducing vegetative cover that otherwise would inhibit entrainment. Thus it is generally assumed that periods of elevated dust emissions reflect either an expansion of existing arid areas, the creation of new dust sources, or enhanced sediment availability in marginal dust sources, e.g. due to altered hydrologic regimes (e.g. Harrison et al., 2001; Hesse, 1994; Kohfeld and Harrison, 2001).

Most major contemporary dust sources are already located in arid environments, where moisture rarely inhibits entrainment, therefore it is not obvious why increasing aridity would necessarily result in enhanced dust emissions from these environments. In addition, not all arid regions produce dust, e.g. the hyper-arid Atacama Desert (Ginoux et al., 2012). Similarly the major deserts of Western Australia are not significant dust sources (Ginoux et al., 2012; McTainsh, 1989) despite having a similar climate to eastern Australian arid regions, which are major dust producers. The difference between the two regions is that the eastern Australian arid basins receive periodic drainage from surrounding humid environments (McTainsh, 1989). This implies that sediment recharge is an important control over dust emission.

Dust entrainment from glacial/cold climate dust sources was also more active during cold, and by implication, arid climate phases (Harrison et al., 2001). However, aridity may not be the major control on dust entrainment from cold climate areas in many cases. Current examples of glacial/cold climate dust sources occur in high latitude regions. A number of these sources are not arid, including Iceland, Greenland and New Zealand (Bullard et al., 2016). In some cases, these regions have low precipitation but also low evapotranspiration. However, in other cases they are humid or even super humid. For example, southern Icelandic dust sources experience rainfall $>1,500 \mathrm{~mm} / \mathrm{yr}$ (Bullard, 2017), while on the west coast of the South Island of New Zealand, average local dust deposition rates of 10-143 $\mathrm{g} / \mathrm{m}^{2} / \mathrm{yr}$ (Eger et al., 2012; Marx and McGowan, 2005) were recorded where rainfall of $>5,000 \mathrm{~mm} / \mathrm{yr}$ occurs, resulting in loess formation (Almond and Tonkin, 1999; Eger et al., 2012). Therefore, at least in some environments, dust emissions may not be limited by aridity.

As well as affecting sediment availability, climate also influences dust entrainment through wind speed, wind density and transport pathways. In certain environments, wind speed is the significant controlling factor on dust emissions. In the Bodélé Depression, the world's largest dust source (Warren et al., 2007), extensive deposits (i.e., $>24,000 \mathrm{~km}^{2}$ ) of sediment are available (Bristow et al., 2009) whenever threshold entrainment velocities are exceeded (Warren et al., 2007; Washington et al., 2006). Similarly, in more humid dust sources, e.g. glacial/cold climate dust source areas, wind can be the critical agent in drying surface sediment allowing entrainment (Marx and McGowan, 2005; McGowan and Sturman, 1997). Changes in wind speed in response to changing global energy balances, synoptic system 
migration or teleconnections therefore all have potential to affect dust emissions (Marx et al., 2009; McGowan et al., 2010).

\subsection{Sediment recharge/availability}

Sediment recharge and availability may be a significant control on dust emissions over millennia as well as on shorter time scales. Sediment recharge and availability are interlinked: sediment recharge refers to the supply of fine textured sediments capable of being entrained by the wind to dust source areas. By contrast, sediment availability refers to in situ changes in sediment condition, such as changing vegetative cover or surface crusts, moisture content or sediment volume (which is controlled by sediment supply versus deflation). In order for dust sources to remain active they require either a significant stock of suitable sediment or sustained recharge at a frequency exceeding deflation. The Bodélé Depression is an example of the former case. Although loess deposits represent zones of accumulation they can switch to becoming a dust source if disturbed, e.g., parts of China's loess Plateau have been activated as dust sources following human activity (Sun et al., 2001). By contrast, most of the current dust sources receive sediment resupply from associated fluvial/lacustrine transport systems (Bullard et al., 2011; Ginoux et al., 2012; Prospero et al., 2002). For example, the major dust sources of the Tarim Basin, China, are located on the edge of the Basin where the rivers draining the Kunlun Mountains debouche into the basin. Similarly, dust sources in Patagonia are associated with bajos (deflation basins) or lakes which are seasonally flooded (Gassó and Stein, 2007; Montes et al., 2017). The implication of this is that without alluvial recharge, dust emissions would eventually subside.

The relationship between sediment supply, sediment availability and climate was described by Kocurek (1998) who proposed a model in which aeolian sand systems respond to the interplay of sediment production, during humid climate phases, and sediment availability and therefore aeolian activity during arid climate phases (Fig. 7). Within the context for which the model was developed, namely to explain the preservation of aeolian landforms within the Sahara, this interplay was envisaged to operate at a time scale of multiples of tens of thousands of years (e.g. between marine isotope stages (MIS)). When applied to dust emissions in other environments, the model may be equally applicable over much shorter time scales. Evidence from the Lake Eyre Basin, Australia, implies that sediment recharge and dust emissions are effectively coincident in time. In that setting, sediment is not produced in situ within the basin, but rather transported into dust source areas via river systems sourced from the more humid northern extent of the basin, which receive precipitation following incursions of moist tropical air over the northern ranges during the north Australian monsoon (November to March). This leads to large periodic flow events that reach many hundreds of kilometres down-stream, separated by long periods of no flow 
from late autumn through to spring (Fig. 8) (Knighton and Nanson, 2001; Thoms and Sheldon, 2000).

It was observed in Marx et al., (2005a) that a pattern of elevated atmospheric ${ }^{210} \mathrm{~Pb}$ activity recorded in New Zealand corresponds to the annual discharge patterns in the Lake Eyre Basin, Australia. That study demonstrated that Australian dust scavenges metals, such as ${ }^{210} \mathrm{~Pb}$, from the atmosphere during transport and, therefore, ${ }^{210} \mathrm{~Pb}$ activity could be used as a proxy for dust export. Accordingly, emission of fine dust is greatest following summer recharge of dust sources with sediment, which once dry, is available for transport (Fig. 9). Fine dust emission also appears to be highest following La Niña conditions, when discharge in the rivers of central Australia is enhanced (Kotwicki and Isdale, 1991), although longer data sets will be needed to further test this relationship. Interestingly, in this case, the timing of fine (sub-micron) dust emission, as recorded by ${ }^{210} \mathrm{~Pb}$, does not accord precisely with the peak of dust storm frequency recorded by meteorological observations (i.e., based on observations of visible dust). These have their highest frequency in late spring when meteorological conditions are more favourable for dust storms (McTainsh et al., 1998). By contrast, the ${ }^{210} \mathrm{~Pb}$ proxy matches the favourable meteorological conditions for transport of Australian dust to New Zealand (McGowan and Clark, 2008).

By comparison to Lake Eyre, the Bodélé Depression, in north Africa, receives little significant sediment recharge. There, extensive deposits of very fine-grained diatomite-dominated sediments were formed presumably during high-stands of Lake Mega-Chad in the early-mid Holocene (Bristow et al., 2009; Drake and Bristow, 2006). Thus, fine grained biogenic sediment was produced in situ there, albeit at earlier times and under more humid conditions. Drying of the depression at approximately $1 \mathrm{kyr}$ has exposed the sediments to deflation (Bristow et al., 2009). The north-eastern part of the basin is significantly deflated with inverted topography apparent. Gravel capped ridges representing former drainage channels now protrude above the surrounding landscape because they are resistant to deflation by wind (Bristow et al., 2009), implying that under current climate conditions, without renewed recharge (i.e. a return to a high lake stand), the Bodélé Depression has a finite lifetime as a major dust source.

Even in the most sediment endowed dust source areas, the supply of fine mineral particles will eventually be exhausted (Fig. 7) but the timescales over which sediment starvation sets in is specific to each dust source region. Dust entrainment can also become impeded by the creation of aerodynamically smooth surfaces, surface crusts (Webb and Strong, 2011) or surface armouring, which collectively change the sediment characteristics. For example, in Australia, desert pavements (gibbers) prevent dust entrainment and these can form over thousands years or less (May et al., 2015). In many environments, it is difficult to disentangle whether dust emission is controlled by recharge or climate effects (moisture and vegetation) that restrict dust entrainment, not the least because the two sets of processes occur in close temporal association. Similarly, sediment production and transport 
into depocentres and subsequent sediment availability are themselves linked to climate. Despite these complexities, there is growing evidence that recharge of sediment is critical to maintaining dust emissions from many dust source areas.

\subsection{Factors affecting dust deposition}

Translating empirical records of dust deposition at particular site to records of dust emissions is complicated by several factors. These include the parameters that influence transport of dust from source to sink (the sampling site), processes that control dust deposition (Lawrence and Neff, 2009) as well as internal changes within the sedimentary archive that can impact its fidelity.

Over thousands of years, migration of the mean position of synoptic systems can alter airmass trajectories and/or wind speeds. Both of these influence long-range dust transport potential (Fig. 2) (Marx et al., 2009). This phenomenon can be illustrated by study of marine sediment cores taken along a latitudinal transect to track changing plume pathways. For example, in the Tasman Sea downwind of the eastern Australian dust plume pathway, a series of cores was used to study migration in the mean dust plume export position. It was found that the plume migrated $3-6^{\circ}$ between glacial and interglacial periods between MIS 110 (Hesse, 1994). Similarly, in the eastern Atlantic, off the coast of north-western Africa, Collins et al. (2013) mapped the northward repositioning of the Sahara/Sahel boundary over the past $60 \mathrm{kyr}$ using the changing rate of dust deposition in a series of marine cores. This migration was associated with a general trend of atmospheric cooling and resulting in latitudinal differences in relative dust deposition rates. Periodic rapid northward shifts of the plume pathway were attributed to Heinrich events during which the North Atlantic sea surface temperature cooled, forcing a southerly re-positioning of the Sahara/Sahel boundary and increasing dust flux, i.e. an expansion in the dust plume.

To date, few studies have succeeded in mapping past changes in airmass trajectories, even though they have the potential to influence dust records distant from source and outside of recognised dust transport pathways, such as the transport of dust from the Southern Hemisphere continents to Antarctica.

As precipitation scavenging is the main mechanism of long-range dust deposition (Pye, 1987), changes in the precipitation regime can influence the deposition rate recorded in a geological archive. For example, the long-range dust contribution to soils on the Hawaiian Islands increases with altitude due to orographic precipitation over the high regions of the island, promoting greater dust scavenging (Rex et al., 1969). Similarly, changing vegetation, that influences boundary layer roughness, can also influence deposition rates (see Lawrence and Neff, 2009). Despite this potential, few, if any, studies have attributed the dust flux in archives to changes in the deposition regime rather than changes in dust production and transport. 
Internal processes within the environmental archives can also affect apparent dust deposition records. There are the more obvious sediment reworking processes, such as bioturbation, which should become evident when attempting to derive an age model for a sediment core. However, more subtle processes may also be at work and these may not necessarily become evident from sedimentology or reversed absolute age dates. In marine sediments this can include the shifting of currents that influence the potential for settling and/or advection of dust versus other sediment particles. In lakes, sediment focusing, that is winnowing of sediment due to lake currents and wave action, can influence deposition processes in different parts of a lake basin (e.g. Blais and Kalff, 1995), potentially leading to spurious results when sediment texture is used to isolate a dust component from other sedimentary sources. It could also influence the ability to isolate dust geochemically, i.e. where the focusing of one sedimentary component has the effect of dominating this component over another (Fig. 5). Certain environments such as peat mires do not suffer from sediment focusing effects, but can still be subject to processes such as desiccation and burning, both negatively affecting an accurate dust deposition record (e.g. Marx et al., 2014b) (also see section 3.2).

\subsection{Anthropogenic activity}

There is increasing evidence that human activity has resulted in substantially increased dust emissions from many environments, particularly following the development of industrial methods of agricultural production (Brown et al., 2016; Marx et al., 2014b; McConnell et al., 2007; Mulitza et al., 2010; Neff et al., 2008). The impact of humans on dust output is primarily associated with the conversion of semi-arid wildlands to agricultural landscapes (pastoralism and cropping). Conversion of wildlands to agricultural landscapes has occurred globally on a massive scale over the past $\sim 250$ years. Grasslands, savannas and shrub lands have experienced the greatest degree of modification. Between 1700 and $2000 \mathrm{CE}$, these ecosystems have experienced $>80 \%$ conversion by area (Ellis et al., 2010). This has included conversion of semi-arid wildlands into rangelands and croplands, most notably in North America, Australia and southern South America. Many of these systems have the potential to act as novel (i.e., the initiation of dust emission from regions that did not produce dust prior to human disturbance) or expanded dust sources. Deserts have undergone a lower degree of transformation ( $<20 \%$ conversation) during this period (Ellis et al., 2010), however, this is likely to still have had an impact on dust emissions.

Conversion of wildlands to agricultural results in increased dust emissions via several mechanisms (Marx et al., 2014b). Land clearing exposes soils to the airstream, while the increase in numbers, or introduction, of hard hoofed animals facilitates the break-up of protective soil crusts. Additionally, ploughing further breaks up soil structure and can directly eject dust into the atmosphere (Lal, 2007). At the same time, changes to hydrology (e.g. lowering of groundwater tables) and mechanical modification of river systems that 
often accompanies agricultural development can also facilitate increased wind erosion (Marx et al., 2014b). Despite the undeniable impact of human activity on dust emissions, the anthropogenic effect has remained poorly quantified. However, dramatic examples of the effect of human activity on wind erosion are provided by accounts from the U.S Dust Bowl in the 1930s CE (Cook et al., 2009; Lal, 2007), the Pampas Dust Bowl in the 1930s and 1940s CE (Viglizzo and Frank, 2006), late $19^{\text {th }}$ and early to mid-20 ${ }^{\text {th }}$ Century wind erosion in Australia (Cattle, 2016; O'Loingsigh et al., 2015) and from mid $20^{\text {th }}$ Century from the Aral Sea region (Micklin, 2007; Wiggs et al., 2003). One exception to the general lack of broad-scale data is the study of Ginoux et al. (2012) who estimated the global magnitude of human impacts using MODIS optical depth to examine dust emission frequency from source areas in which agriculture is practised. These authors estimated that $25 \%$ of global dust emissions were anthropogenic in origin. Although anthropogenic activity is likely to result in some novel dust sources, i.e. loess regions and grasslands that may be activated following grazing or cropping, this estimate is complicated by the fact that $\mathrm{CE}$

many anthropogenic dust sources were natural dust sources before human intervention. In addition, the effects of agriculture on dust emissions are likely to vary based on the interaction of landscape sensitivity and the extent/type of agricultural development, e.g. cropping versus low stocking rates. Consequently, the full impact of anthropogenic activity on dust emissions remains uncertain and cannot be characterised by remote sensing data alone. Studies of dust flux in environmental archives that extend beyond the onset of agriculture and have high temporal resolution, i.e. approximately decadal, offer great potential to quantify the effect of human activity on dust emissions. When records extend into pre-historic times, they capture the range of natural dust deposition variability. To date, few such records exist but those that do suggest dust emissions from North Africa, western USA, Patagonia and Australia are likely to have increased between 2-5 times (Marx et al., 2014b; McConnell et al., 2007; Mulitza et al., 2010; Neff et al., 2008). In other key regions, notably, China and the Middle East, the human impact remains largely unquantified.

\section{Identifying and fingerprinting dust}

The ability to accurately identify deposited dust and additionally, the prospect of fingerprinting its provenance (i.e. determining from which source area it was derived) has begun to transform the value of dust as a palaeo-environmental proxy. Identifying longrange dust in a sediment archive is not trivial because, as previously stated, even large events result in extremely thin deposits dispersed over large spatial areas (McTainsh, 1989). Furthermore, dust is rarely the sole mineral component of an environmental archive and, in most settings, is easily overwhelmed by other sources of sediment. The ability to accurately recognise long-range dust is therefore partly a function of the dust deposition rates versus other sediment deposition rates (Fig. 5). Long-range dust has been successfully identified by two approaches; 1 ) either by focussing on locations where atmospheric deposition is the only possible or very much the dominant source of mineral material, or 2 ) differentiating 
dust from within mixed deposits based on a distinctive physical or chemical signature (Fig. 5). In the latter case, success is greatest if the local sediment has a simple and relatively constant composition, ideally of different mineralogy/chemistry from that of the dust component.

A range of sediment parameters has been used to identify long-range dust or determine its provenance. The most widely used approaches include: grain size (e.g. Mulitza et al., 2010; Stuut et al., 2002), mineralogy (e.g. Gaudichet et al., 1988; Gingele et al., 2004) and geochemistry (e.g. Grousset et al., 1992; Le Roux et al., 2012; Marx et al., 2009). In the following subsections, we discuss these grouped into: 1) Transport induced dust signatures; 2) Geochemical and mineralogical dust signatures; 3) Source area fingerprints; and 4) Anthropogenic dust tracers.

\subsection{Transport induced dust signatures}

Transport induced dust signatures are changes in the physical or chemical composition of dust which occur during entrainment and transport. They are the most obvious characteristics to identify dust and include physical properties (e.g. grain size and shape) as well as geochemical attributes. Grainsize has long been used to identify dust because winnowing of dust during entrainment results in a characteristic size range and size distribution (e.g. see Pye, 1987). For example, long-range dust collected from far-travelled plumes at distances of greater than thousands of kilometres is comprised of silt or clay size particles generally <20 $\mu \mathrm{m}$ in size (Lawrence and Neff, 2009; Tsoar and Pye, 1987).

Notwithstanding the simplicity of exploiting the transport-induced dust attributes, it is found that the grain size of dust varies, both with different collection methods and in different environments. For example, suspended dust samples are finer than deposited dust samples collected during the same dust storm event (Hesse and McTainsh, 1999).

Counterintuitively, Australian dust samples collected on New Zealand glaciers were found to be coarser rather than finer-grained than those collected upwind from sediment cores in the Tasman Sea (Hesse and McTainsh, 1999; McGowan et al., 2005a). These differences likely reflect different modes of deposition, i.e. wet versus dry, wind strength and sediment mixing, with additional sediment sources of differing provenance, e.g. locally derived New Zealand dust and hemipelagic sediment contributing to the size distribution in these cited examples. Nonetheless, some studies have successfully used grain size to isolate a dust component (e.g. Alloway et al., 1992; Mulitza et al., 2010; Stanley and De Deckker, 2002; Stuut et al., 2002). Where dust is not the only sedimentary component, it can sometimes still be isolated with statistical unmixing models from grain size populations. For example, (Stuut et al., 2002) succeeded in constructing long-time records of Saharan dust emissions and changing wind strength by studying grain size in marine sediment cores. In certain cases, it has proven possible to attribute particular grain size distributions to the various 
specific sediment components (e.g. dust vs. hemipelagic sediment). This permits linking changes in grain size to waxing and waning inputs of different sediment sources, .e.g. increased grain sizes indicating reduced river discharge and increased dust input implying palaeo-drought events (Mulitza et al., 2008). The use of grain size in this context necessarily assumes that the distance to dust source(s) has remained constant through time, i.e. there was no switching in dominance between distal and proximal dust sources.

The study of physical parameters of dust is not limited to grain size distribution. Abrasion is considered a significant process during aeolian transport and therefore long-range and local dust (or other sediments) can, in some cases, be distinguishable from each other based on their degree of rounding (e.g. McGowan et al., 2005b; Muhs et al., 2008). Grain-shape has additionally been used alongside micro-textures (including surface coatings) to isolate dust in studies reconstructing past dust deposition (An et al., 2012; Muhs et al., 2008; Stanley and De Deckker, 2002).

Although many aspects of the mineralogy and geochemistry of dust remain relatively unchanged during entrainment and transport, there are a few very specific phenomena where transport induces a characteristic change in chemical composition. The first of these is scavenging of atmospheric metals and aerosols onto dust particles. A very specific such example is the isotope ${ }^{210} \mathrm{~Pb}$, which forms within the atmosphere from its progenitor radioactive parent ${ }^{222} \mathrm{Rn}$, a gas that is continuously emitted from the continental land surface (Turekian et al., 1977). The particle reactive metal $\mathrm{Pb}$ has very different physical properties than its progenitor gas and Marx et al. (2005a) found elevated ${ }^{210} \mathrm{~Pb}$ activities in long-range transported dusts from Australia to New Zealand. Thus, elevated ${ }^{210} \mathrm{~Pb}$ activity can be a transport induced chemical attribute of mineral dust. Recognising that the naturally occurring ${ }^{210} \mathrm{~Pb}$ might not be the only atmospheric metal aerosol (Marx et al., 2008) documented that far-travelled dust is enriched in a whole range of industrial metal pollutants (see also section 4.4 and Figs. 10 and 11). This means that enrichment of atmospherically scavenged products in a sedimentary archive implies a dust contribution (see Le Roux et al., 2008; Marx et al., 2010). Density sorting of minerals may also be diagnostic of long-range dust. The most obvious of these is the relative depletion of trace elements hosted in high density minerals such zircon (specific gravity $=4.7$ ) leading to under-abundance in $\mathrm{Zr}$ and $\mathrm{Hf}$ in long-range dust (Gaiero et al., 2004; Marx et al., 2005b). The full application of this phenomenon has yet to be explored.

Although transport induced attributes can be straightforward and powerful identifiers of dust, they can suffer from the multitude of processes by which a particular signature can be created. For example, local dust or fluvial sediment transported long distances in low energy systems may result in deposits of similar physical characteristics (e.g. Fig 5C and D). Therefore, application of these approaches may only be possible in specific, wellunderstood contexts, and is likely to require analysis of various endmember sediment 
populations. Consequently, geochemical approaches are often more powerful for identifying dust in environmental archives.

\subsection{Geochemical and mineralogical dust signatures}

Geochemical and mineralogical dust signatures are widely employed to identify a dust component in sedimentary deposits. Before identification of far-travelled dust can be attempted, the local geochemical inputs needs to be characterised (e.g. Fig. 5). Once the local sediment sources are established, a foreign geochemical or mineralogical component could then imply a dust contribution.

This approach was pioneered in studies of soils in Hawaii. The shield volcanoes of the Hawaiian Islands are exclusively built from the mafic rock type basalt, which is composed of Mg-rich volcanic glass and a very limited range of minerals but devoid of the otherwise common crustal mineral quartz $\left(\mathrm{SiO}_{2}\right)$. Where quartz was found in the basalt derived soils, it was straightforward to conclude that it must represent a component of long-range dust (Jackson et al., 1971; Rex et al., 1969). Beyond the simple recognition of a foreign mineral, these studies further used the $\delta^{18} \mathrm{O}$ isotope composition of the quartz in Hawaiian soils to infer a similar origin for pelagic Pacific sediments, i.e. long-range aeolian transport.

Despite the successful use of quartz to identify a dust component on the Hawaiian Island, it must be recognised that the situation of the simple geology of Hawaii and its isolated position in the Pacific Ocean is uncommon. In more common situations, a range of major and trace element and radiogenic isotope tracers have subsequently been used to identify dust in a variety of sedimentary settings (Ballantyne et al., 2011; Gingele et al., 2007; Kiefert and McTainsh, 1996; Muhs et al., 2010a; Mulitza et al., 2008; Muller et al., 2008; Neff et al., 2008; Shotyk et al., 2000; Weiss et al., 2002). These types of data can be used to construct geochemical mass balance equations to estimate dust contributions. In the most complex of environments (e.g. soils or ancient weathering profiles) these models also consider weathering and other pedogenic processes (see Babechuk et al., 2015; Chadwick et al., 1999; Kurtz et al., 2001; Muhs et al., 2008; Muhs et al., 2007) and have succeeded in quantifying the dust input into soil formation.

\subsection{Source area fingerprinting}

The ultimate aim of reading past dust records is not simply the quantification of the dust deposition rate but to more specifically determine from where the dust was transported. The ability to determine the provenance of dust (source area fingerprinting) provides significantly more information on the drivers of dust emissions and the effect of dust in Earth systems. For example, by linking deposited dust to its source area, changes in dust output can be related directly to changing conditions in the various source areas. Therefore, the fingerprint can provide information on which sources of dust switched on or off in the 
past and how transport pathways from source to sink have changed. Provenancing dust makes use of geochemical tracers that allow dust deposits to be matched with likely source areas. It requires the geochemical characterisation of all (or at least the major) potential dust source areas. The geochemical tracers employed need to meet certain requirements. Most notably, they need to behave conservatively during entrainment, transport and deposition, that is, there is no fractionation, or differential winnowing which may otherwise alter the tracer composition during transport. The tracer should be immune to post depositional modification caused by weathering, radioactive decay, solution/precipitation or other redox processes. The tracer needs to be able to chemically differentiate between the potentially contributing dust sources. The higher the spatial scale at which this can be achieved the more palaeo-environmental information can be extracted from dust records. Finally, the tracer needs to reliably distinguish long-range dust from other sediment sources of material deposited to the study site, e.g. colluvial and alluvial mineral material or locally derived dust (Fig. 5).

Improvements in analytical precision and accuracy and reduction in analytical costs have facilitated the use of various geochemical proxies to fingerprint the source areas of dust (Kamber, 2009). The most widely used tracers to date have been radiogenic isotopes, and trace and minor elements.

\subsubsection{Radiogenic isotopes}

The use of radiogenic isotopes to fingerprint dust origin relies on differences in the antiquity of bedrock lithology (transferred to sediments) between different dust source areas. Radiogenic isotope ratios express the age differences of sediment sources as well as the time-integrated parent/daughter ratios. The most commonly used radiogenic isotope tracers are the $\mathrm{Pb}, \mathrm{Sr}$ and $\mathrm{Nd}$ isotope systems. These were initially developed to understand the evolution of the Earth's continental crust and oceanic mantle. Early applications of these to sediment provenance studies included examination of the origins of oceanic sediment (e.g. Biscaye and Dasch, 1971; Dasch, 1969) before Biscaye and co-workers (1974) specifically attempted to determine the provenance of dust in oceanic sediment. Radiogenic isotopes were subsequently used to fingerprint dust extracted from ice cores, as it was recognised that reconstructing the source(s) of dust to the polar regions held significant palaeoclimatic value (Grousset et al., 1992). Following on from this pioneering work, radiogenic isotopes have been fairly extensively applied to the polar dust source question in particular (Basile et al., 1997; Bory et al., 2010; De Deckker et al., 2010; Delmonte et al., 2010a; Delmonte et al., 2013; Delmonte et al., 2010b; Delmonte et al., 2004; Delmonte et al., 2017a; Gabrielli et al., 2005; Gili et al., 2017b; Gili et al., 2016; Revel-Rolland et al., 2006; Vallelonga et al., 2010; Vallelonga et al., 2005) (Fig. 6). A further system that is widely used in crustal geochemistry are $\mathrm{Hf}$ isotopes, but there are analytical complications rendering this system less suitable to the fingerprinting of dust. 
Radiogenic lead isotopes ( ${ }^{208} \mathrm{~Pb},{ }^{207} \mathrm{~Pb},{ }^{206} \mathrm{~Pb}$ in relation to ${ }^{204} \mathrm{~Pb}$ ) have been used extensively to fingerprint dust. An example of their use has been the demonstration of the Asian origin of dust deposited on the Greenland icesheet (Biscaye et al., 1997). Similarly, they have been applied to investigations of dust provenance in Antarctica (De Deckker et al., 2010; Gili et al., 2016; Vallelonga et al., 2010) (Fig 6D). However, a limitation on the use of Pb isotopes arises from the widespread industrial and older historic contamination of the Earth's surface with $\mathrm{Pb}$ (Patterson, 1965), which in some regions dates back to the mid-Holocene (Marx et al., 2016). Thus, in many environmental dust achieves, $\mathrm{Pb}$ isotopes measured after the onset of human metal use increasingly reflect the composition of major ore bodies mined for industrial $\mathrm{Pb}$ (e.g. Shotyk et al., 1998), rather than the composition of $\mathrm{Pb}$ from natural aerosols and sediment (Fig. 10A). A less appreciated potential issue is that in addition to the $\mathrm{Pb}$ in the archive being contaminated, the $\mathrm{Pb}$ isotope composition of modern dust source sediment samples is also compromised by pollution from atmospheric fallout. Therefore, it may no longer be possible to characterise the source areas of dusts deposited in pre-historic times and the modern dust source areas may be compromised in terms of $\mathrm{Pb}$ isotope composition (Fig. 12; Kamber et al., 2010). An additional complication with using Pb to provenance dust is that $\mathrm{Pb}$ isotope signatures can vary with particle size (Cho et al., 2011; Feng et al., 2010), therefore comparable size fractions need to be analysed in the source area sediments and the dust deposits.

The ${ }^{87} \mathrm{Sr} /{ }^{86} \mathrm{Sr}$ composition of dusts and potential sources sediments is traditionally used in conjunction with the $\mathrm{Nd}$ isotope composition expressed as $\varepsilon \mathrm{Nd}$ (i.e. ${ }^{143} \mathrm{Nd} /{ }^{144} \mathrm{Nd}$ standardised against the CHondritic Uniform Reservoir (CHUR)) or Pb isotopes (Biscaye et al., 1997; Delmonte et al., 2004; Goldstein et al., 1984; Grousset and Biscaye, 2005; Grousset et al., 1992) (Fig. 6C). Similarly to $\mathrm{Pb}$ isotopes, ${ }^{87} \mathrm{Sr} /{ }^{86} \mathrm{Sr}$ ratios vary somewhat with particle size (Biscaye et al., 1997; Meyer et al., 2011). Moreover, Sr concentration and isotope fingerprints in sedimentary environments are not always simply a function of lithologic age, but can be influenced by weathering and primary and secondary evaporite formation (Hagedorn et al., 2011; Kamber et al., 2005; Lyons et al., 1995). Evaporites (e.g. salts or carbonates) can make up a significant component of dust (Pye, 1987), with playa lakes (which often host significant evaporite deposits) a major source of dust (Prospero et al., 2002). Strontium isotope fingerprints of sedimentary deposits are therefore not simply a reflection of bedrock lithology but are also influenced by groundwater and marine aerosols (which are enriched in Sr; Marx et al., 2014a). This adds a further dimension to records of Sr isotope composition of aerosols, as groundwater and sea spray contributions have varied through time and space (Collerson et al., 1988; Dalai et al., 2003; Lu and Meyers, 2003; Lyons et al., 1995; Ullman and Collerson, 1994). Consequently, the composition of Sr isotopes in dust source areas may be expected to change through time as these influences vary (Meyer et al., 2011; Meyer et al., 2013). Some of these issues can be resolved by chemical pre-treatment (e.g. leaching of labile fractions) to remove the non-bedrock derived $\mathrm{Sr}$ but in many cases the small mass of collected dust samples may preclude the pre- 
treatment. In summary, the use of Sr isotopes to provenance dust is not straightforward in many situations and requires detailed and targeted sampling within source areas to understand the full meaning of past variations in this ratio.

By contrast to $\mathrm{Sr}$ and $\mathrm{Pb},{ }^{143} \mathrm{Nd} /{ }^{144} \mathrm{Nd}$ isotopes offer a less complex isotope system for fingerprinting dust sources areas, as they are not greatly affected by size fractionation (Goldstein et al., 1984; Grousset et al., 1988; Kanayama et al., 2005; Meyer et al., 2011), solubility or anthropogenic pollution. Where potential dust sources are characterised by distinctive ${ }^{143} \mathrm{Nd} /{ }^{144} \mathrm{Nd}$ ratios, $\mathrm{Nd}$ isotopes are a powerful geochemical fingerprint of dust sources.

Radiogenic isotopes have been widely applied to determining the origin of dust deposited in Antarctic ice, which is an ongoing question in palaeo-climatic research (e.g. Basile et al., 1997; De Deckker et al., 2010; Delmonte et al., 2010b; Delmonte et al., 2017b; Gili et al., 2017b; Gili et al., 2016; Grousset et al., 1992; Kamber et al., 2010; Revel-Rolland et al., 2006; Vallelonga et al., 2005) and have the potential to differentiate between certain potential dust sources from among the Southern Hemisphere continents, i.e. between some Australian and South American dust sources in ${ }^{143} \mathrm{Nd} /{ }^{144} \mathrm{Nd}$ and ${ }^{87} \mathrm{Sr} /{ }^{86} \mathrm{Sr}$ composition (Fig. $6 \mathrm{~A}, \mathrm{~B}$ and $\mathrm{C}$ ) and more recently between individual South American sources Gili et al. (2017a). A limitation of ${ }^{143} \mathrm{Nd} /{ }^{144} \mathrm{Nd}$ is that there is not a very large amount of spread in upper crustal values (e.g. Gallet et al., 1998) resulting in significant overlap between several potential source areas, some of which (e.g. the Lake Eyre Basin, Australia's major dust producing region) remain to be fully characterised in terms of its $\mathrm{Nd}$ isotope composition.

\subsubsection{Major minor and trace elements}

Unlike radiogenic isotopes, which essentially express the time-integrated difference in the ratio of two trace elements (e.g. $\mathrm{Rb} / \mathrm{Sr}, \mathrm{Sm} / \mathrm{Nd}, \mathrm{U} / \mathrm{Pb}$ ) to differentiate between sediment sources, major, minor and trace elements (including the rare earth elements; REEs) use relatively subtle differences in the inherent geochemistry of the lithologic units, which are transferred to sediments. Minor and trace elements were historically considered too spatially homogenous in upper crustal rock to serve as provenance tools for dust. Indeed the relative homogeneity of dust was originally exploited, via the composition of loess by Goldschmidt $(1933,1954)$ and followers (e.g. Gallet et al., 1998; Taylor et al., 1983) to determine the average composition of upper continental crust with very few samples.

Following from this pioneering work, trace elements began being applied to examining aeolian processes more widely. This included investigations of provenance variability and pedogensis in Chinese (e.g. Gallet et al., 1996; Liu et al., 1993; Sun, 2002) and South American loess and Southern Atlantic Ocean sediments (Gaiero et al., 2004). Trace elements were also used for estimating the Saharan dust contribution to palaeosols on Bermuda (Herwitz et al., 1996) and for examining provenance of East Antarctic dust (Basile et al., 
1997; Gaiero et al., 2004). These early applications of trace elements to dust provenance were conducted at a relatively broad geographic scale. With improving accuracy and precision of geochemical analysis for minor and trace elements (e.g. Eggins et al., 1997), the fine differences in the geochemical makeup started to find its use as a precise fingerprinting tool (e.g. Kamber 2009). For example, a widely known area of application is the fingerprinting of volcanic ash (tephra), in which trace elements have overtaken major elements in their ability to attribute a tephra layer in an environmental archive to a particular volcanic eruption (e.g. Tomlinson et al., 2015). Kamber et al. (2005) were amongst the first to realise that the trace element composition might serve to differentiate dust sources at a sub-basin or even catchment scale when analysed at sufficient resolution.

In this paper, the use of trace elements is demonstrated to differentiate between dust source areas (i.e. fingerprint dust sources), by way of example, for Australian dust source areas. Australia lends itself well to this approach in part because the two major dust producing basins, the Lake Eyre and the Murray-Darling Basin can be distinguished in multiple elements. However, where sufficient lithological (and geochemical) variety exists across dust source areas, the approach illustrated here could be applied to many geographic situations. In the simplest possible way, the geochemistry of sources is examined in terms of a single ratio of two conservative trace elements, e.g. Nb/Ta. The use of such ratios for source discrimination is similar to radiogenic isotopes and widely practised in the field of geo- and cosmochemistry (e.g. Hofmann, 1997). For example, the Lake Eyre Basin is characterised by relatively high $\mathrm{Nb} / \mathrm{Ta}$ ratios, the northern Murray-Darling Basin (the Darling River and its tributaries) by intermediate ratios, and the southern basin MBD by low ratios (Fig. 12). Whereas this type of approach succeeds in discriminating between entire sediment basins and large sub-basins, a more sophisticated method is needed to identify more local, specific dust point sources from one another.

The large anastomosing river systems of the Channel Country, in Australia's Lake Eyre Basin, are the major current Australian (and Southern Hemisphere) dust sources (Bullard and McTainsh, 2003). These large channel systems become periodically inundated as can be seen on the continent-scale map of standing water coverage of Australia since 1987 (Fig. $13 \mathrm{~A}$ and $\mathrm{B})$. As the rivers flow into the basin, the resulting very low gradient results in a reduction of transport velocities and the corresponding deposition of sediment over many hundreds of square kilometres. This results in very homogenous sediment composition along the low gradient stretches of the channels and floodplains. For example, three samples collected along a $>500 \mathrm{~km}$ transect of the Diamantina River display largely identical compositions, with only minor variability in absolute (but not relative) abundance of $\mathrm{Ti}, \mathrm{Nb}$ and Ta attributed to sediment input into the Diamantina system from tributaries (Fig. 13C) (also see Marx and Kamber, 2010). Multi-element compositions of sediment are plotted in 'multi-element-diagrams' in which the composition of samples is typically normalised to (i.e. divided by) that of a reference sample (in this case average upper continental crust (UCC) 
from Kamber et al., (2005)). The Diamantina sediments are ca. $50 \%$ less enriched in most trace elements than global average UCC. To expose the differences between samples, the yaxis of the diagram is shown on linear scale, unlike in traditional geochemical applications where log-scale is used to compare samples that may show many orders of magnitude in concentration range. Importantly, Cooper Creek, approximately $250 \mathrm{~km}$ to the east of Diamantina Creek, displays a subtly different geochemical composition (Fig. 13D). These differences are highlighted further when the trace element chemistry of Diamantina River sediment is normalised against that of Cooper Creek (Fig. 13E).

This example demonstrates that at least in flat-lying sediment-covered dust source regions, geochemical element signatures can be used to fingerprint dust source provenance to within a single large river 'channel'. Dust is provenanced by comparing the pattern of elemental abundance between the sample with all potential source area sediments. The degree of similarity can be quantified by calculating the difference in relative abundance of the elements considered conservative (Gabrielli et al., 2010; Marx et al., 2005b; Muhs et al., 2007). An ideal match between a dust and its sediment source would result in a horizontal line with a value of 1.0 in a diagram like Fig. 13E. If a dust is known to have a local and a fartravelled component, the analysis involves construction of binary or ternary mixing models to calculate the relative contributions of each and the best matching source region for the far-travelled component (Marx et al., 2005b) (Fig. 14).

\subsection{Anthropogenic dust signatures}

The chemistry of modern dust samples universally contains an anthropogenic component. This even includes dust from far from source locations, e.g. Antarctica and from sites in remote New Zealand (De Vleeschouwer et al., 2014; Erel et al., 2007; Marx et al., 2014a; McConnell et al., 2014; Vallelonga et al., 2002). Anthropogenic aerosols have largely become globally pervasive after the Industrial Revolution for metals such as $\mathrm{Pb}$, however, they were present even earlier in locations where (inefficient) metallurgy was practised (the Bronze Age, >3000 yrs BP) (Marx et al., 2016). The complexity and magnitude of anthropogenic emissions increased after the Industrial Revolution, particularly following the Second World War when a whole range of metals, agrochemical compounds and radioactive material have been found associated with dust (most likely via scavenging) (Kinoshita et al., 2011; Lavin et al., 2012; Marx et al., 2010).

Once scavenged by dust, anthropogenic aerosols can be transported and deposited along the same transport routes (Marx et al., 2008). In addition, fallout of anthropogenic aerosols can contaminate surface sediment that may be prone to aeolian entrainment and transport (Erel et al., 2006; Kamber et al., 2010). Contaminants can therefore serve as fingerprints of dust origin. Because $\mathrm{Pb}$ is amongst the most pervasive contaminants, industrially sourced $\mathrm{Pb}$ (the isotopes of which reflect their ore body of origin) has been used via its isotope 
composition to provenance dust origin in a number of studies (e.g. see Erel et al., 2006; McConnell et al., 2014; Vallelonga et al., 2002). Because anthropogenic aerosols are often readily identifiable in sedimentary deposits, their presence in the landscape following initial deposition and/or subsequent redistribution (erosion transport and redeposition) can be used to quantify dust contributions to different landscape environments (e.g. floodplains, lakes, soils, etc.) (e.g. Stromsoe et al., 2015).

An example of the use of metal contaminants to provenance dust is illustrated by dust samples collected on the South Island of New Zealand by deposition traps and from within glacier ice. New Zealand is downwind from Australia's south-eastern dust plume pathway and experiences regular incursions of Australian dust. Although the South Island's West Coast is New Zealand's most sparsely populated region and therefore generates limited local metal contamination, many dust samples collected there contained surprisingly high concentrations of metal contaminants (Fig. 15A and B). These contaminates are likely scavenged from agricultural and mining areas in inland Australia and/or as the dust crossed the eastern Australian seaboard, where the majority of population and industry are located. Therefore high concentrations of industrial metal serve as prima facie evidence of the Australian provenance of dust in this setting. The provenance of these samples was independently estimated using a geochemical trace element model, which also showed that mixed origin dust samples with higher contaminant loads contained a higher proportion of Australia-sourced dust (Fig. 15A and B) (Marx et al., 2008).

Contaminant fingerprinting of dust is not limited to metals. In a separate study to that described above, samples of dust were collected using high volume samplers in New Zealand's Southern Alps (Lavin et al., 2012). Concentrations of semi-volatile organic contaminants (SOCS) were measured alongside the inorganic chemistry. This permitted calculation of the dust load and provenancing of the dust source using the geochemical model. It was found that several dust samples were associated with particular SOCs known to be of Australian origin. Most notably, endosulfan was detected in some of the samples. This organochlorine insecticide had been banned in New Zealand at the time of sampling, but was still being used in Australia (predominately to spray cotton crops), a situation confirming the Australian origin of the agrochemical and dust alike. The concentration of endosulfan was statistically higher on days when atmospheric dust was found to contain a higher Australian dust content (Fig. 15C). Similarly, other SOCs were also found at higher concentration when dust was predominantly sourced from Australia. This included the polycyclic aromatic hydrocarbon (PAH) benzo [g,h,i] perylene (Fig. 15D) (Lavin et al., 2012).

From the perspective of historic pollution reconstruction, sedimentary archives that receive significant dust input are potentially record contamination. In the best cases, the history of past atmospheric contamination/industrial development can be reconstructed in fine detail from such environmental archives (Marx et al., 2010; Shotyk et al., 1998). For Australia, this 
is illustrated via the temporal change in the geochemistry of dust, recording the onset of, and patterns in, industrialisation following European settlement. Changes in the $\mathrm{Pb}$ isotope composition of dust deposited in a peat mire in the Snowy Mountains records the onset of mining/smelting in Australia, as well as subsequent mining and $\mathrm{Pb}$ use patterns (Fig. 10A). Along with $\mathrm{Pb}$, other metals also display changing (increasing) abundance in the peat core for the same reasons, e.g. Zn and Sb (Fig. 10B). As well as recording Australian history of metal use, the changing composition of dust further records changing agricultural patterns in the Australia's primary agricultural area, the Murray-Darling Basin, which is directly upwind of the Snowy Mountains. Evolving agricultural patterns over 150 years are recorded in the chemistry of the dust captured in the peat mire. For example, the use of marine phosphate fertiliser in the basin is reflected by an increase in $\mathrm{Y} / \mathrm{Ho}$ ratios towards the top of the peat core (Fig. 10A).

\subsection{Limitations to identifying and fingerprinting dust}

Although dust deposition influences all landscapes, the primary limitation to identifying it rests with the isolation of a long-range dust component within the matrix of other sedimentary material. Geochemical dust signatures rely on using elements or isotopes which are universally present in mineral material, i.e. all sedimentary material contains the element $\mathrm{Nd}$, each with a specific $\varepsilon N d$ value. Therefore, the ability to identify dust is a function of the proportion of long-range dust relative to other sedimentary material, the chemical distinctiveness of the various sediment components and the analytical precision of the data (measurement error) (Fig. 16). A further limitation to the use of transport derived dust signatures is that they can exist in a continuum and are consequently present to some degree in all sediments. If they are unique to dust, the ability to identify its contribution depends upon the relative mass of dust and on analytical precision.

Once dust has been identified in a sedimentary archive, the spatial resolution of dust provenance depends on how strongly separate potential dust source regions differ from each other in their geochemistry. For example, geographically different areas (e.g. Southern Africa and Australia) can have quite similar geology and average ages, which can limit the geochemical resolution of radiogenic isotopes (see Fig. 6). An advantageous situation exists in the Australian Basins (e.g. Figs. 12 and 13) where relatively narrow corridors of homogenous sediment are deposited in relatively close geographic proximity. Increases in our understanding of which geomorphic environments produce dust at which times may allow for more targeted sampling, reducing geochemical overlap in some systems. Similarly, combining multiple geochemical fingerprints (i.e. the use of multiple trace elements) provides more scope for fingerprinting dust sources at a higher spatial resolution (Fig. 13), provided the selected elements behaved conservatively during transport and during sediment accumulation. 
An additional complication in identifying and fingerprinting dust develops when mixed sediment containing a dust component is recycled. Certain terrestrial settings, which would be otherwise amongst the best locations for constructing dust deposition reconstructions, experience sediment recycling, i.e. humid environments high in the landscape which are directly downwind from dust sources (Fig. 17A). These are also sediment generating environments, meaning sediment is transported fluvially from these settings into arid/semiarid depocentres from where it is entrained as dust and transported back to and deposited in its original source area. This recycling of sediment obviously limits the potential to identify or provenance dust (Marx et al., 2011). In some cases, however, it is possible to still identify dust using subtle downstream changes in geochemistry due to a combination of weathering, sediment sorting and introduction of geochemical variability from tributary streams and erosion of rock and regolith downstream. This is demonstrated for Australia's Murray-Darling Basin, where changes in downstream trace element composition permit distinguishing dust from local sediment (Fig. 17B and C). Because dust source regions often concentrate evaporites, e.g. playas, the problem of sediment recycling can be overcome using geochemical signatures of evaporites (salts and carbonates), at least in some semi-arid environments (e.g. May et al., 2015).

\section{0: Dust as a proxy for palaeo-environmental change:}

In this final section, we show examples of dust reconstruction studies as records of palaeoclimate/palaeo-environmental change for the Australian dust transport system. Australia is the driest and most developed continent and aeolian processes have shaped large regions of its landscape. However, there are many other regions in both hemispheres where similar records could exist. Currently, Australia is considered to be the major dust source in the Southern Hemisphere, resulting in the emission of an estimated 37-148 Mt/yr (Shao et al., 2011). The major dust producing regions are large $\left(>1\right.$ million $\left.\mathrm{km}^{2}\right)$ basins in eastern central Australia; the Lake Eyre and the Murray-Darling Basins (Fig. 18), although other dust sources exist outside these regions (Ginoux et al., 2001; Hesse and McTainsh, 2003; Prospero et al., 2002). Dust is primarily transported along two major plume pathways. Firstly, via the passage of east to west moving cold fronts across southern and central Australian, resulting in dust transport out of south-eastern Australian into the Tasman Sea and often across to New Zealand. Secondly, a lesser pathway out of north-western Western Australia into the Indian Ocean associated with south-easterly anticyclonic winds (Fig. 3) (Bowler, 1976; McTainsh, 1989; Sprigg, 1982). Mapping changes in both dust emission intensity and dust sources through time therefore provides valuable insight into Australia's palaeoenvironment as well as into the drivers of dust emissions.

Three records of dust deposition reconstructed from geologic archives within the eastern Australian dust plume pathway are presented (Fig. 18). They illustrate: 1 ) the role of hydroclimate variability in driving dust emissions; 2 ) large scale re-organisation of dust 
source areas during the Holocene; 3 ) the structure of the last glacial maximum in central Australia; and 4) anthropogenic enhancement of dust emissions. The three examples represent a record of dust deposition in Native Companion Lagoon (NCL), a shallow interdune lagoon on North Stradbroke Island, southeast Queensland (previously described in McGowan et al., 2008; Petherick et al., 2009; Petherick et al., 2008); a record of dust deposition in an Alpine ombrogenous peat bog on the Old Man Range (OMR) in central Otago, New Zealand (previously described in Marx et al., 2009); and an additional dust record reconstructed from an Alpine ombrogenous peat land in the Snowy Mountains, south-eastern NSW, Australia (previously described in Marx et al., 2011; Marx et al., 2014b).

\subsection{Hydroclimate variability as a driver of dust emissions?}

Palaeo-environmental change within the Holocene is often regarded as being minor by comparison with the dramatic changes associated with glacial/interglacial transitions of the Quaternary. Records of dust emissions reflect these patterns, with many dust producing regions, including those of eastern Australia, emitting more dust during glacial periods (Harrison et al., 2001; Hesse, 1994; McGowan et al., 2008; Petherick et al., 2008). Despite the relatively subdued climate variability over the mid- to late Holocene, records of dust emissions from eastern Australia, recorded as dust deposition in sediment cores, vary by a factor of 2-10 within individual records (Marx et al., 2011; Marx et al., 2009; McGowan et al., 2012; Stanley and De Deckker, 2002).

Variability in dust emissions from eastern Australia during the mid-late Holocene is evident in the OMR site, from New Zealand, which records the rate of Australian dust flux to New Zealand over the past 8,000 years (Fig. 19A). In this example, the flux of Australian dust was isolated from New Zealand material geochemically (Marx et al., 2009). The resulting record indicates that Australian dust transport to New Zealand was relatively low prior to $4.5 \mathrm{kyr}$ with deposition rates of approximately $0.35 \mathrm{~g} / \mathrm{m}^{2} / \mathrm{y}$. After $4.5 \mathrm{kyr}$, Australian dust transport to New Zealand increased to an average deposition flux of $0.94 \mathrm{~g} / \mathrm{m}^{2} / \mathrm{yr}$ between 4,000 and $2 \mathrm{kyr}$ Following this, deposition flux decreased to $0.66 \mathrm{~g} / \mathrm{m}^{2} / \mathrm{yr}$, before decreasing further after 0.9 kyr. The record of geochemically modelled long-range dust reconstructed in NCL in southeastern Queensland shows a similar, albeit more subdued, pattern, that is, a pulse of increased dust flux between 7 .7and $2.3 \mathrm{kyr}$ (Fig 19B).

While increased dust emissions are often attributed to increases in aridity in dust source regions, the relatively stable climate of the mid-late Holocene rules out the kind of dramatic large-scale changes which occurred during the late Pleistocene. Therefore variability in dust emissions during this time likely occurred due to more subtle changes. There is evidence that the Lake Eyre Basin, the major dust source at this time (Fig. 20 and 21), became drier after 5 kyr (Magee et al., 2004; McCarthy and Head, 2001; Quigley et al., 2010; Singh and Luly, 1991), however, there is also significant evidence of enhanced pluvial activity, particularly around $3 \mathrm{kyr}$, indicating conditions were still relative humid or at least highly variable (Gliganic et al., 2014). Consequently and counterintuitively, the pulse in dust 
emissions from 4-2 kyr coincides with evidence of wetter conditions in central Australia than at present (Gliganic et al., 2014).

The period after $5 \mathrm{kyr}$ is associated with increased climate instability and, in particular, increased variability in the El Niño Southern Oscillation (ENSO) (Moy et al., 2002; Rodbell et al., 1999; Sandweiss et al., 1996; Shulmeister, 1999). This includes enhanced ENSO amplitude at around 3 kyr (Donders et al., 2008; Gagan et al., 2004; Gomez et al., 2012; Haberle et al., 2001; Tudhope et al., 2001). As previously discussed, modern dust emissions from eastern Australian appear to have an ENSO signal (Fig. 9). This occurs because during wet La Niña conditions, the rivers draining to central Australia experience enhanced discharge, transporting fresh sediment to pans, ephemeral lakes, river channels and other depocentres. During subsequent dry El Niño events, this sediment is available for aeolian transport. Therefore our interpretation is that the pulse of elevated dust export from 4-2 kyr was driven by enhanced climate variability as represented in Figure 7. If this is correct, it would further imply that over the mid- to late Holocene, the Australian dust transport system has become supply limited, i.e. the recharge of source areas with fine fluvial sediments is critical to driving subsequent dust emissions (Bullard and McTainsh, 2003; Marx et al., 2005a).

The more subdued pattern of the $\sim 4-2$ kyr dust pulse in the NCL record by comparison to the OMR record may reflect the location of North Stradbroke Island. The NCL coring site is close to the northern limit of the main eastern Australian dust plume (Hesse, 1994; McTainsh, 1989) and therefore long-range dust was being transported to the site relatively less frequently in the early Holocene by comparison to the OMR site from New Zealand. This may imply that cold fronts and associated westerly winds, which entrain and transport dust from eastern Australia (Sprigg, 1982; Strong et al., 2011) remained further south th th time, resulting in less frequent dust transport of dust laden to the NCL site in southeast Queensland.

\subsection{Reorganisation of Australia's dust producing regions during the Holocene}

Interpretations of past dust flux records often assume that the source areas supplying the deposited dust have remained constant through time. However, dust emissions studied over seasons and decades show high temporal variability in emissions (McTainsh et al., 2002), implying that dust sources may switch on or off over relatively short timescales in response to environmental change. Shifts in the relative importance of different dust sources through time have been inferred in some studies of dust flux reconstruction, where geochemical fingerprinting allows tracing of such changes (e.g. Marx et al., 2009; Petherick et al., 2009; Revel-Rolland et al., 2006).

Records of dust emission from eastern Australia indicates that significant re-organisation of dust supply regions has occurred at different times in the past (e.g. Petherick et al., 2009). While is some cases this may be related to shifts in dominant dust pathways, in other cases 
the factors that control dust emissions from within a particular region appear to have changed. A striking example of this is provided by Australian dust production during the Holocene. In the early to mid-Holocene the provenance of Australian dust deposited in New Zealand geochemically matched sediments from the southern Murray-Darling Basin (MDB) (Fig. 20). Similarly, long-range dust deposited at the same time in the NCL site also produces a good match with sediment from the southern MDB (Fig. 21). This consistent dust fingerprint occurs at sites $\sim 2,400 \mathrm{~km}$ distant. Importantly, despite the Lake Eye Basin being Australia's current major dust source (Ginoux et al., 2012), it did not appear to be a dominant dust producing region in the early to mid-Holocene.

Dust supply from the southern MDB started to wain from around $5 \mathrm{kyr}$ after which time a major re-organisation in dust producing regions appears to have occurred. The geochemical fingerprint of deposited dust becomes more variable, but generally shifted to the north. Most notably the Lake Eyre Basin becomes an increasingly prominent source of dust deposited in both the OMR and NCL records, as did the northern MDB (Fig. 20 and 21). This shift in Australian Holocene dust production has been argued to reflect re-organisation of the synoptic systems influencing Australian hydroclimate patterns (Marx et al., 2009). The Australian summer monsoon was more active during the early part of the Holocene, possibly associated with more southerly positioning of the Intertropical Convergence Zone (e.g. Denniston et al., 2013; Field et al., 2017; Nanson et al., 2005; Proske et al., 2014; Shulmeister and Lees, 1995), resulting in wetter conditions in the Lake Eyre Basin (Gliganic et al., 2014) and inhibiting dust entrainment. For example, the Lake Eyre experienced a perennial lake-full phase between 12 and 4 kyr (Magee et al., 2004). Simultaneously, an associated southward repositioning of the baric ridge (which is centred in central Australia during the austral winter) would have resulted in drier conditions in southern Australia, promoting enhanced dust entrainment from the southern MDB, while also reducing the frequency with which dust transporting winds (dry cold fronts) were affecting the Lake Eyre Basin (Marx et al., 2011; Marx et al., 2009).

These examples demonstrate the sensitivity of dust emissions to relatively subtle, yet broadscale, environmental and climatic change within dust source areas. In this case, the geological context permits detailed dust source fingerprinting within a continent, the result of which has progressed understanding of Australia's palaeo-environments.

\subsection{The structure of the LGM in Australia as defined by dust emission}

The Last Glacial Maximum (LGM) was the most significant global cooling event of the last $130 \mathrm{kyr}$ and possibly beyond. Characterising its precise timing and temporal structure is therefore important for understanding Quaternary climate variability. As the most arid inhabited continent, Australia experienced only minor glaciation, and the precise structure of the LGM has remained difficult to reconstruct. However, important information about the 
LGM can be reconstructed from dust emissions because they are sensitive to changes in climate (i.e. climate forced landscape responses) and reflect broad environmental conditions in arid and semi-arid environments. These conditions can otherwise be difficult to discern due to the subtle geomorphic response of arid environments and low preservation potential of past climate records by comparison with temperate environments.

The NCL sediment core extends back to approximately $40 \mathrm{kyr}$ and therefore encompasses the LGM (Petherick et al., 2008), which is defined here as the most pronounced climate perturbations within Marine Isotope Stage 2 (MIS2). The flux of long-range dust recorded in the core at the end of MIS3 was variable but relatively low (average flux $=0.67 \mathrm{~g} / \mathrm{m}^{2} / \mathrm{yr}$ ) (Fig. 22). A small dust pulse between $\sim 33-31$ kyr denotes the transition into MIS2 and the LGM; the onset of which is marked by a rapid transition to significantly enhanced long-range dust flux between 31.7 and $29.8 \mathrm{kyr}$ and peaking at $11.1 \mathrm{~g} / \mathrm{m}^{2} / \mathrm{yr}$. Interestingly, in continental Australia, the LGM was apparently not characterised by one sustained period of generally enhanced dust emission, but rather by two pronounced peaks separated by about 5 kyr, between which dust emission was reduced (Fig. 22). Following the first LGM pulse, dust flux in the $\mathrm{NCL}$ decreased to $<0.12 \mathrm{~g} / \mathrm{m}^{2} / \mathrm{yr}$ at $\sim 29.3 \mathrm{kyr}$, that is, lower than was recorded during the mid to late-Holocene (Fig. 19B). From this very low level, dust flux then increased slowly until $23.6 \mathrm{kyr}$, from which point flux accelerated, peaking abruptly at $22.1 \mathrm{kyr}$ at 14.2 $\mathrm{g} / \mathrm{m}^{2} / \mathrm{yr}$. After this peak, dust flux decreased rapidly to $1.2 \mathrm{~g} / \mathrm{m}^{2} / \mathrm{yr}$ at $21 \mathrm{kyr}$. This was followed by further more minor pulses up until $18 \mathrm{kyr}$, after which dust emissions decreased to the low levels of the early Holocene.

On a global scale, atmospheric dust loads increased during the LGM (Harrison et al., 2001). Much of this increase was likely associated with enhanced cold climate sediment production and, possibly, increases in aridity and wind speed (Kohfeld and Harrison, 2001). The behaviour of warm arid dust sources during MIS2 is more uncertain. For example, the Sahara seems to have emitted less dust during the LGM by comparison to the Holocene (Collins et al., 2013). The NCL record therefore corroborates earlier evidence from Tasman Sea cores (Hesse, 1994) suggesting enhanced dust emissions from Australia during the LGM. Importantly the NCL record also demonstrates that the LGM was not simply a period of sustained high dust emissions. Rather long-range dust transport varied by three orders of magnitude during MIS2, implying significant variability in locally relevant climate factors, e.g. variable hydroclimate.

The dust deposited in the NCL site throughout the LGM period originated predominately from the Darling River and its catchments as well as the Lake Eyre Basin. Existing records for these regions for MIS2 and the LGM imply an increase in aridity by comparison to MIS3 (Fitzsimmons et al., 2013). However, despite being generally drier, there is also evidence of significant fluvial activity at this time (e.g. Cohen et al., 2010; Fitzsimmons et al., 2013). Variable moisture availability and potentially associated punctuated sediment supply are possible drivers of the increased dust emissions from central Australian not only during the 
Holocene (Marx et al., 2009), but also during the LGM. Importantly moisture availability was unlikely to have inhibited dust emissions during the protracted period of low dust emissions between the major LGM pulses, because there is little evidence of enhanced pluvial conditions in central Australia during this period. Dust entrainment was therefore more likely to be impeded by sediment starvation. That is, deflation during the first LGM dust pulse (31.7-29.8 kyr) appears to have removed available fine sediment impeding subsequent dust entrainment until sediment reserves were replenished during the approximately $5 \mathrm{kyr}$, leading to the subsequent LGM dust pulse. Alternatively, or in addition, changing windiness or transport trajectories may have limited dust transport to the NCL site during that period. Regardless the NCL long-range dust flux record implies that MIS2 and the LGM were marked by significant variability in hydroclimate.

\subsection{The human dust fingerprint: agriculture as a driver of dust emissions}

Australia was amongst the last landmasses to be settled by Europeans. Its colonisation coincided with the beginning of the Industrial Revolution and the associated development of industrial agriculture, that is, large scale land clearing, mechanisation and use of fertilisers. Following European settlement, large areas of Australia were converted into agricultural landscapes, including very marginal lands. The MDB is Australia's largest agricultural region and $67 \%$ of its land surface has been developed for grazing, $10 \%$ for cropping and $1.8 \%$ is irrigated (Leblanc et al., 2012). On a continent-wide scale, grazing land occupies $43 \%$ of Australia (McAlpine et al., 2009), i.e. 3.3 million $\mathrm{km}^{2}$. After more than 40 kyr of traditional land use (Bowler et al., 2003) this transformation can be expected to have affected dust emissions.

A high-resolution record of dust flux was reconstructed from a peat bog in the Snowy Mountains (USC), which are located downwind from the MDB and which form its eastern divide. Data from the most recent 300 years of dust accumulation in that peat bog are plotted in Figure 23. In the period before significant European settlement (1700 to $1880 \mathrm{CE}$ ), dust flux in the peat bog was relatively low (average $=33 \mathrm{~g} / \mathrm{m}^{2} / \mathrm{yr}$ ), with only minor pulses in elevated dust flux. These are attributable to natural variability in dust emissions. However, from 1880 CE dust flux increased by more than double (average $=80 \mathrm{~g} / \mathrm{m}^{2} / \mathrm{yr}$ ).

Agriculture had begun in the eastern reaches of the MDB from $1820 \mathrm{CE}$, but did not apparently adversely affect dust emissions. Rather, the increase in dust flux is evident from 1880 CE coinciding with expansion of grazing into central and western parts of the basin, which are more arid, and the onset of intensive cropping on floodplains (Henzell, 2007; Lewis et al., 2007). Interestingly, the expansion of agriculture in Australia was, in part, driven by the American Civil War, which resulted in increased demand for wool in Britain due to a reduction in cotton supply (Lewis et al., 2007). Unsurprisingly, this land use and dust flux was also reflected in the source areas supplying dust to the USC site (Fig. 24). Prior to 1880 
$\mathrm{CE}$, the sources of dust were mainly floodplains in the southern part of the basin, however, after $1880 \mathrm{CE}$ the source areas expanded to include the semi-arid grazing lands between the major MDB rivers (Fig. 24). These regions became novel dust sources, following the clearing of native vegetation and the introduction of hard hooved stock. Soon after agricultural conversion, major drought episodes were experienced and these resulted in significant hardship for farmers and agricultural communities. They include the Federation Drought (1895-1903), the 1911-1915 drought and major drought in the late 1930s and early 1940s (often called the Australian Dust Bowl). There are dramatic accounts of dust storms within the MDB during these droughts (Cattle, 2016; Marx et al., 2014b), which are all evident in the USC core as spikes in dust input (Fig. 23).

After $\sim 1990$ CE dust flux to the USC site decreased to levels similar to those which occurred prior to the agricultural development of the MDB (Fig. 23). One possible explanation for this decrease in dust flux after is sediment starvation. That is, the novel source areas which switched on after agricultural development may have become depleted in easily entrainable sediment following a century of wind erosion. This is supported by a generalised trend of decreasing dust flux in the USC site in the period between 1880 and 2006 CE. It is further supported by geomorphic evidence of significant landscape change as a result of aeolian and fluvial erosion during that period and by historic oral accounts of dramatic erosion collected during major drought episodes (Cattle, 2016; Fanning, 1999; Marx et al., 2014b; Wasson and Galloway, 1986). More optimistically, or in addition, the sudden drop in dust flux may also reflect improved soil conservation measures introduced from the late $1980 \mathrm{~s}$ (McTainsh and Leys, 1993).

\subsection{Conclusions and future directions in dust research}

Significant advances have been made in understanding the role of dust in Earth systems over recent decades. Satellite imagery and observational data have allowed detailed mapping of dust sources and emissions and, as a consequence, our understanding of the controls on dust emissions has increased significantly. Similarly, the development of physical and geochemical dust signatures have advanced our ability to trace dust throughout sedimentary systems. In particular, the ability to fingerprint the potential sources of deposited dust has greatly enhanced the utility of reconstructed dust records for providing novel information on palaeoclimatic conditions as well as tracking the imprints of human activity.

Despite these advances, the full value of dust as a tool to understand Earth processes remains to be explored. It is not surprising that the role of dust in palaeo-climatic studies is perhaps more advanced in areas that currently experience dust storms and where there is a greater societal awareness of dust, for example in China (e.g. Chen et al., 2007; Kohfeld and Harrison, 2003; Xiao et al., 1999; Yang et al., 2007). Nonetheless, there are still relatively few palaeo-records of dust emissions, yet dust offers significant untapped potential for 
understanding past climates and landscapes. For example, many landscapes that have produced limited dust in the Holocene would have been very prone to dust transport and deposition during the LGM and they hold great promise to reconstruct in more detail the supply, entrainment, transport and deposition of aeolian sediment in times of pronounced climatic change. Expanding both the number and spatial distribution of dust records therefore remains a priority for the future.

The use of palaeo-dust records to aid reconstructing air-mass trajectories and past wind speeds also remains to be fully developed. Dust is one of the few direct indictors of wind, better knowledge of its past transport therefore holds great potential for understanding palaeo wind regimes. Despite this, there is significant complexity in how wind speed, entrainment mechanisms and dust particle characteristics interact (see Újvári et al., 2016), therefore using dust to reconstruct wind speed remains an ongoing challenge. Similarly, our understanding of the drivers of dust emissions through time remains incomplete. What appears clear is that dust emissions responded non-linearly to climate and that dust producing regions can respond differently (and surprisingly quickly) to environmental change. Better interpretation of the palaeo-climatic significance of dust emissions will require an improved understanding of how dust responds to different climate and landscape processes. Therefore linking dust emissions to source area conditions is a critical part of advancing understanding of dust emissions. The contribution of dust to ecosystems, e.g. via fertilisation and soil development, also remains a relatively unexplored aspect of the role of dust, yet it is potentially of high significance, especially given the role of anthropogenic activity in increasing dust emissions. Key components of addressing these challenges are the continued improvement of dust fingerprinting techniques and the search for new deep-time sedimentary archives of dust deposition.

\section{Acknowledgements}

We would like to thank Tim Horscroft for inviting us to write this paper, which developed out of a talk at the 2016 European Geosciences Union titled "Natural variability versus human impact: Hydroclimate variability and the role of agriculture in changing dust emissions from Australia". We would also like to thank all the individuals who have contributed to field work and data production which have underpinned our work. In addition we thank our collaborators whose ideas and creativity have helped shape various aspects of this work. Finally we thank two reviewers whose constructive comments benefitted this paper.

\section{References:}

Albani, S., Mahowald, N.M., Winckler, G., Anderson, R.F., Bradtmiller, L.I., Delmonte, B., François, R., Goman, M., Heavens, N.G., Hesse, P.P., Hovan, S.A., Kohfeld, K.E., Lu, H., Maggi, V., Mason, J.A., Mayewski, P.A., McGee, D., Miao, X., OttoBliesner, B.L., Perry, A.T., 2015. Twelve thousand years of dust: the Holocene global dust cycle constrained by natural archives. Climate of the Past 11, 869-903. 
Alloway, B.V., Stewart, R.B., Neall, V.E., Vucetich, C.G., 1992. Climate of the last glaciation in New Zealand, based on aerosolic quartz influx in an Andesitic terrain. Quaternary Research 38, 170-179.

Almond, P.C., Tonkin, P.J., 1999. Pedogenesis by upbuilding in an extreme leaching and weathering environment, and slow loess accretion, south Westland, New Zealand. Geoderma 92, 1-36.

An, F., Ma, H., Wei, H., Lai, Z., 2012. Distinguishing aeolian signature from lacustrine sediments of the Qaidam Basin in northeastern Qinghai-Tibetan Plateau and its palaeoclimatic implications. Aeolian Research 4, 17-30.

Arimoto, R., 2001. Eolian dust and climate: relationships to sources, tropospheric chemistry, transport and deposition. Earth-Science Reviews 54, 29-42.

Babechuk, M.G., Widdowson, M., Murphy, M., Kamber, B.S., 2015. A combined Y/Ho, high field strength element (HFSE) and Nd isotope perspective on basalt weathering, Deccan Traps, India. Chemical Geology 396, 25-41.

Baddock, M.C., Mockford, T., Bullard, J.E., Thorsteinsson, T., 2017. Pathways of highlatitude dust in the North Atlantic. Earth and Planetary Science Letters 459, 170182.

Bagnold, R.A., 1941. The Physics of Blown Sand and Desert Dunes. Methuen, London.

Ballantyne, A.P., Brahney, J., Fernandez, D., Lawrence, C.L., Saros, J., Neff, J.C., 2011. Biogeochemical response of alpine lakes to a recent increase in dust deposition in the Southwestern, US. Biogeosciences 8, 689-2706.

Basile, I., Grousset, F.E., Revel, M., Petit, J.R., Biscaye, P.E., Barkov, N.I., 1997. Patagonian origin of glacial dust deposited in East Antarctica (Vostok and Dome C) during glacial stages 2, 4 and 6. Earth and Planetary Science Letters 146, 573-589.

Biscaye, P.E., Chesselet, R., Prospero, J.M., 1974. Rb-Sr, $87 \mathrm{Sr} / 86 \mathrm{Sr}$ isotope system as an index of provenance of continental dusts in the open Atlantic ocean. Journal de Recherches Atmospheriques 8, 819-829.

Biscaye, P.E., Dasch, E.J., 1971. The rubidium, strontium, strontium-isotope system in deepsea sediments: Argentine Basin. Journal of Geophysical Research 76, 5087-5096.

Biscaye, P.E., Grousset, F.E., Revel, M., Van der Gaast, S., Zielinski, G.A., Vaars, A., Kukla, G., 1997. Asian provenance of glacial dust (stage 2) in the Greenland Ice Sheet Project 2 Ice Core, Summit, Greenland. Journal of Geophysical Research-Oceans 102, 26765-26781.

Blais, J.M., Kalff, J., 1995. The influence of lake morphometry on sediment focusing. Limnology and Oceanography 40, 582-588.

Bory, A., Wolff, E., Mulvaney, R., Jagoutz, E., Wegner, A., Ruth, U., Elderfield, H., 2010. Multiple sources supply eolian mineral dust to the Atlantic sector of coastal Antarctica: Evidence from recent snow layers at the top of Berkner Island ice sheet. Earth and Planetary Science Letters 291, 138-148.

Bory, A.J.M., Biscaye, P.E., Svensson, A., Grousset, F.E., 2002. Seasonal variability in the origin of recent atmospheric mineral dust at NorthGRIP, Greenland. Earth and Planetary Science Letters 196, 123-134.

Boucher, O., Randall, D., Artaxo, P., Bretherton, C., Feingold, G., Forster, P., Kerminen, V.M., Kondo, Y., Liao, H., Lohmann, U., Rasch, P., Satheesh, S.K., Sherwood, S., Stevens, B., Zhang, X.Y., 2013. Clouds and Aerosols in: Stocker, T.F., Qin, D., Plattner, G.-K., Tignor, M., Allen, S.K., Boschung, J., Nauels, A., Xia, Y., Bex, V., Midgley, P.M. (Eds.), The Physical Science Basis. Contribution of Working Group I to the Fifth Assessment Report of the Intergovernmental Panel on Climate Change. Cambridge University Press, Cambridge, United Kingdom and New York, NY, USA., pp. 571-657. 
Bowler, J.M., 1976. Aridity in Australia: Age, origin and expression in aeolian landforms and sediments. Earth Science Reviews 12, 279-310.

Bowler, J.M., Johnston, H., Olley, J.M., Prescott, J.R., Roberts, R.G., Shawcross, W., Spooner, N.A., 2003. New ages for human occupation and climatic change at Lake Mungo, Australia. Nature 421, 837-840.

Bristow, C.S., Drake, N., Armitage, S., 2009. Deflation in the dustiest place on Earth: The Bodélé Depression, Chad. Geomorphology 105, 50-58.

Bristow, C.S., Hudson-Edwards, K.A., Chappell, A., 2010. Fertilizing the Amazon and equatorial Atlantic with West African dust. Geophysical Research Letters 37, L14807.

Brown, A.G., Tooth, S., Bullard, J.E., Thomas, D.S.G., Chiverrell, R.C., Plater, A.J., Murton, J., Thorndycraft, V.R., Tarolli, P., Rose, J., Wainwright, J., Downs, P., Aalto, R., 2016. The geomorphology of the Anthropocene: emergence, status and implications. Earth Surface Processes and Landforms, 71-90.

Bullard, J.E., 2017. The distribution and biogeochemical importance of high-latitude dust in the Arctic and Southern Ocean-Antarctic regions. Journal of Geophysical Research: Atmospheres 122, 3098-3103.

Bullard, J.E., Baddock, M., Bradwell, T., Crusius, J., Darlington, E., Gaiero, D., Gassó, S., Gisladottir, G., Hodgkins, R., McCulloch, R., McKenna-Neuman, C., Mockford, T., Stewart, H., Thorsteinsson, T., 2016. High-latitude dust in the Earth system. Reviews of Geophysics 54, 447-485.

Bullard, J.E., Baddock, M., McTainsh, G.H., Leys, J., 2008. Sub-basin scale dust source geomorphology detected using MODIS. Geophysical Research Letters 35, L15404.

Bullard, J.E., Harrison, S.P., Baddock, M.C., Drake, N., Gill, T.E., McTainsh, G., Sun, Y., 2011. Preferential dust sources: A geomorphological classification designed for use in global dust-cycle models. Journal of Geophysical Research 116, F04034.

Bullard, J.E., McTainsh, G.H., 2003. Aeolian-fluvial interactions in dryland enviroments: examples, concepts and Australian case study. Progress in Physical Geography 27, 471-501.

Cattle, S.R., 2016. The case for a southeastern Australian Dust Bowl, 1895-1945. Aeolian Research 21, 1-20.

Chadwick, O.A., Derry, L.A., Vitousek, P.M., Huebert, B.J., Hedin, L.O., 1999. Changing sources of nutrients during four million years of ecosystem development. Nature 397, 491-497.

Chen, J., Li, G., Yang, J., Rao, W., Lu, H., Balsam, W., Sun, Y., Ji, J., 2007. Nd and Sr isotopic characteristics of Chinese deserts: Implications for the provenances of Asian dust. Geochimica Et Cosmochimica Acta 71, 3904-3914.

Cho, S.H., Richmond-Bryant, J., Thornburg, J., Portzer, J., Vanderpool, R., Cavender, K., Rice, J., 2011. A literature review of concentrations and size distributions of ambient airborne $\mathrm{Pb}$-containing particulate matter. Atmospheric Environment 45, 5005-5015.

Cohen, T.J., Nanson, G.C., Larsen, J.R., Jones, B.G., Price, D.M., Coleman, M., Pietsch, T.J., 2010. Late Quaternary aeolian and fluvial interactions on the Cooper Creek Fan and the association between linear and source-bordering dunes, Strzelecki Desert, Australia. Quaternary Science Reviews 29, 455-471.

Collerson, K.D., Ullman, W.J., Torgersen, T., 1988. Ground waters with unradiogenic ${ }^{87} \mathrm{Sr} /{ }^{86} \mathrm{Sr}$ ratios in the Great Artesian Basin, Australia. Geology 16, 59-63.

Collins, J.A., Govin, A., Mulitza, S., Heslop, D., Zabel, M., Hartmann, J., Röhl, U., Wefer, G., 2013. Abrupt shifts of the Sahara-Sahel boundary during Heinrich stadials. Clim. Past 9, 1181-1191. 
Cook, B.I., Miller, R.L., Seager, R., 2009. Amplification of the North American "Dust Bowl" drought through human-induced land degradation. Proceedings of the National Academy of Sciences 106, 4997-5001.

Dalai, T.K., Krishnaswami, S., Kumar, A., 2003. Sr and ${ }^{87} \mathrm{Sr} /{ }^{86} \mathrm{Sr}$ in the Yamuna River System in the Himalaya: Sources, fluxes, and controls on sr isotope composition. Geochimica Et Cosmochimica Acta 67, 2931-2948.

Darwin, C.E., 1846. An account of fine dust which often falls on vessels in the Atlantic Ocean. Quarterly Journal of the Geological Society 2, 26-30.

Dasch, E.J., 1969. Strontium isotopes in weathering profiles, deep-sea sediments, and sedimentary rocks. Geochimica Et Cosmochimica Acta 33, 1521-1552.

De Deckker, P., Norman, M., Goodwin, I.D., Wain, A., Gingele, F.X., 2010. Lead isotopic evidence for an Australian source of aeolian dust to Antarctica at times over the last 170,000 years. Palaeogeography, Palaeoclimatology, Palaeoecology 285, 205223.

De Vleeschouwer, F., Vanneste, H., Mauquoy, D., Piotrowska, N., Torrejón, F., Roland, T., Stein, A., Le Roux, G., 2014. Emissions from pre-Hispanic metallurgy in the South American atmosphere. PloS one 9, e111315.

Delmonte, B., Andersson, P.S., Hansson, M., Schöberg, H., Petit, J.R., Basile-Doelsch, I., Maggi, V., 2008. Aeolian dust in East Antarctica (EPICA-Dome C and Vostok): Provenance during glacial ages over the last 800 kyr. Geophysical Research Letters 35.

Delmonte, B., Andersson, P.S., Schöberg, H., Hansson, M., Petit, J.R., Delmas, R., Gaiero, D.M., Maggi, V., Frezzotti, M., 2010a. Geographic provenance of aeolian dust in East Antarctica during Pleistocene glaciations: preliminary results from Talos Dome and comparison with East Antarctic and new Andean ice core data. Quaternary Science Reviews 29, 256-264.

Delmonte, B., Baroni, C., Andersson, P.S., Narcisi, B., Salvatore, M.C., Petit, J.R., Scarchilli, C., Frezzotti, M., Albani, S., Maggi, V., 2013. Modern and Holocene aeolian dust variability from Talos Dome (Northern Victoria Land) to the interior of the Antarctic ice sheet. Quaternary Science Reviews 64, 76-89.

Delmonte, B., Baroni, C., Andersson, P.S., Schoberg, H., Hansson, M., Aciego, S., Petit, J.R., Albani, S., Mazzola, C., Maggi, V., Frezzotti, M., 2010b. Aeolian dust in the Talos Dome ice core (East Antarctica, Pacific/Ross Sea sector): Victoria Land versus remote sources over the last two climate cycles. Journal of Quaternary Science 25, 1327-1337.

Delmonte, B., Basile-Doelsch, I., Petit, J.R., Maggi, V., Revel-Rolland, M., Michard, A., Jagoutz, E., Grousset, F., 2004. Comparing the Epica and Vostok dust records during the last 220, 000 years: Stratigraphical correlation and provenance in glacial periods. Earth Science Reviews 66, 63-87.

Delmonte, B., Paleari, C.I., Andò, S., Garzanti, E., Andersson, P.S., Petit, J.R., Crosta, X., Narcisi, B., Baroni, C., Salvatore, M.C., Baccolo, G., Maggi, V., 2017a. Causes of dust size variability in central East Antarctica (Dome B): Atmospheric transport from expanded South American sources during Marine Isotope Stage 2. Quaternary Science Reviews 168, 55-68.

Delmonte, B., Paleari, C.I., Andò, S., Garzanti, E., Andersson, P.S., Petit, J.R., Crosta, X., Narcisi, B., Baroni, C., Salvatore, M.C., Baccolo, G., Maggi, V., 2017b. Causes of dust size variability in central East Antarctica (Dome B): Atmospheric transport from expanded South American sources during Marine Isotope Stage 2. Quaternary Science Reviews 168, 55-68. 
Denniston, R.F., Wyrwoll, K.-H., Polyak, V.J., Brown, J.R., Asmerom, Y., Wanamaker, A.D., LaPointe, Z., Ellerbroek, R., Barthelmes, M., Cleary, D., Cugley, J., Woods, D., Humphreys, W.F., 2013. A Stalagmite record of Holocene IndonesianAustralian summer monsoon variability from the Australian tropics. Quaternary Science Reviews 78, 155-168.

Dietrich, S., Seelos, K., 2010. The reconstruction of easterly wind directions fo rthe Eifel region (CentralEurope) during the period 40.3-12.9 ka BP. Climate of the Past 6, 145-165.

Donders, T.H., Wagner-Cremer, F., Visscher, H., 2008. Integration of proxy data and model scenarios for the mid-Holocene onset of modern ENSO variability. Quaternary Science Reviews 27, 571-579.

Drake, N., Bristow, C., 2006. Shorelines in the Sahara; geomorphological evidence for an enhanced monsoon from Palaeolake Megachad. Holocene 16, 901-911.

Duce, R.A., Tindale, N., Zhuang, G., 1991. Atmospheric Iron and Its Impact on Marine Biological Productivity and Chemical Cycling. Abstracts of Papers of the American Chemical Society 201, 20-NUCL.

Duce, R.A., Tindale, N.W., 1991. Atmospheric Transport of Iron and Its Deposition in the Ocean. Limnology and Oceanography 36, 1715-1726.

Eger, A., Almond, P.C., Condron, L.M., 2012. Upbuilding pedogenesis under active loess deposition in a super-humid, temperate climate - quantification of deposition rates, soil chemistry and pedogenic thresholds. Geoderma 189-190, 491-501.

Eggins, S.M., Woodhead, J.D., Kinsley, L.P.J., Mortimer, G.E., Slyvester, M.T., McCulloch, M.T., Hergt, J.M., Handler, M.R., 1997. A simple method for the precise determination of $>40$ trace elements in geological samples by ICPMS using enriched isotope internal standardisation Chemical Geology 134, 311-326.

Ellis, E.C., Goldewijk, K.K., Siebert, S., Lightman, D., Ramankutty, N., 2010. Anthropogenic transformation of the biomes, 1700 to 2000. Global Ecology and Biogeography 19, 589-606.

Erel, Y., Dayan, U., Rabi, R., Rudich, Y., Stein, M., 2006. Trans boundary transport of pollutants by atmospheric mineral dust. Environmental Science \& Technology 40, 2996-3005.

Erel, Y., Kalderon-Asael, B., Dayan, U., Sandler, A., 2007. European atmospheric pollution imported by cooler air masses to the Eastern Mediterranean during the summer. Environmental Science \& Technology 41, 5198-5203.

Falkowski, P., Scholes, R.J., Boyle, E., Canadell, J., Canfield, D., Elser, J., Gruber, N., Hibbard, K., Högberg, P., Linder, S., Mackenzie, F.T., Moore III, B., Pedersen, T., Rosenthal, Y., Seitzinger, S., Smetacek, V., Steffen, W., 2000. The Global Carbon Cycle: A Test of Our Knowledge of Earth as a System. Science 290, 291-296.

Fanning, P.C., 1999. Recent landscape history in arid western New South Wales, Australia: a model for regional change. Geomorphology 29, 191-209.

Feng, J.L., Hu, Z.G., Cui, J.Y., Zhu, L.P., 2010. Distributions of lead isotopes with grain size in aeolian deposits. Terra Nova 22, 257-263.

Field, E., McGowan, H., A., Moss, P.T., Marx, S.K., 2017. A late Quaternary record of monsoon variability in the northwest Kimberley, Australia. Quaternary International In Press.

Fitzsimmons, K.E., Cohen, T.J., Hesse, P.P., Jansen, J., Nanson, G.C., May, J.-H., Barrows, T.T., Haberlah, D., Hilgers, A., Kelly, T., Larsen, J., Lomax, J., Treble, P., 2013. Late Quaternary palaeoenvironmental change in the Australian drylands. Quaternary Science Reviews. 
Gabrielli, P., Planchon, F.A.M., Hong, S.M., Lee, K.H., Do Hur, S., Barbante, C., Ferrari, C.P., Petit, J.R., Lipenkov, V.Y., Cescon, P., Boutron, C.F., 2005. Trace elements in Vostok Antarctic ice during the last four climatic cycles. Earth and Planetary Science Letters 234, 249-259.

Gabrielli, P., Wegner, A., Petit, J.R., Delmonte, B., De Deckker, P., Gaspari, V., Fischer, H., Ruth, U., Kriews, M., Boutron, C., Cescon, P., Barbante, C., 2010. A major glacialinterglacial change in aeolian dust composition inferred from Rare Earth Elements in Antarctic ice. Quaternary Science Reviews 29, 265-273.

Gagan, M.K., Hendy, E.J., Haberle, S.G., Hantoro, W.S., 2004. Post-glacial evolution of the Indo-Pacific Warm Pool and El Nino-Southern Oscillation. Quaternary International 118-19, 127-143.

Gaiero, D.M., 2007. Dust provenance in Antarctic ice during glacial periods: From where in southern South America? Geophysical Research Letters 34, L17707.

Gaiero, D.M., Brunet, F., Probst, J.-L., Depetris, P.J., 2007. A uniform isotopic and chemical signature of dust exported from Patagonia: Rock sources and occurrence in southern environments. Chemical Geology 238, 107-120.

Gaiero, D.M., Depetris, P.J., Probst, J.L., Bidart, S.M., Leleyter, L., 2004. The signature of river- and wind-borne materials exported from Patagonia to the southern latitudes: a view from REEs and implications for paleoclimatic interpretations. Earth and Planetary Science Letters 219, 357-376.

Gallet, S., Jahn, B.M., Torii, M., 1996. Geochemical characterization of the Luochuan loesspaleosol sequence, China, and paleoclimatic implications. Chemical Geology 133, 67-88.

Gallet, S., Jahn, B.M., Van Vilet Lanoë, B., Dia, A., Rossello, E., 1998. Loess geochemistry and its implications for particle origin and composition of the upper continental crust. Earth and Planetary Science Letters 156, 157-172.

Gao, H., Washington, R., 2009. The spatial and temporal characteristics of TOMS AI over the Tarim Basin, China, Atmospheric Environment. Atmospheric Environment 43, 1106-1115.

Garrison, V.H., Foreman, W.T., Genualdi, S., Griffin, D.W., Kellogg, A.C., Majewski, M.S., Mohammed, A., Ramsubhag, A., Shinn, E.A., Simonich, S.L., Smith, G.W., 2006. Saharan dust - a carrier of persistent organic pollutants, metals and microbes to the Caribbean? Revista De Biologia Tropical 54, 9-21.

Gassó, S., Stein, A., Marino, F., Castellano, E., Udisti, R., Ceratto, J., 2010. A combined observational and modeling approach to study modern dust transport from the Patagonia desert to East Antarctica. Atmos. Chem. Phys. 10, 8287-8303.

Gassó, S., Stein, A.F., 2007. Does dust from Patagonia reach the sub-Antarctic Atlantic Ocean? Geophysical Research Letters 34, L01801.

Gaudichet, A., De Angelis, M., Lefevre, R., Petit, J.R., Korotkevitch, Y.S., Petrov, V.N., 1988. Mineralogy of insoluble particles in the Vostok Antarctic ice core over the last climatic cycle (150 kyr). Geophysical Research Letters 15, 1471-1474.

Gili, S., Gaiero, D.M., Goldstein, S.L., Chemale, F., Jweda, J., Kaplan, M.R., Becchio, R.A., Koester, E., 2017a. Glacial/interglacial changes of Southern Hemisphere wind circulation from the geochemistry of South American dust. Earth and Planetary Science Letters 469, 98-109.

Gili, S., Gaiero, D.M., Goldstein, S.L., Chemale, F., Jweda, J., Kaplan, M.R., Becchio, R.A., Koester, E., 2017b. Glacial/interglacial changes of Southern Hemisphere wind circulation from the geochemistry of South American dust. Earth and Planetary Science Letters 469, 98-109. 
Gili, S., Gaiero, D.M., Goldstein, S.L., Chemale Jr, F., Koester, E., Jweda, J., Vallelonga, P., Kaplan, M.R., 2016. Provenance of dust to Antarctica: A lead isotopic perspective. Geophysical Research Letters 43, 2291-2298.

Gingele, F., De Deckker, P., Norman, M., 2007. Late Pleistocene and Holocene climate of SE Australia reconstructed from dust and river loads deposited offshore the River Murray Mouth. Earth and Planetary Science Letters 255, 257-272.

Gingele, F.X., De Deckker, P., Hillenbrand, C.D., 2004. Late Quaternary terrigenous sediments from the Murray Canyons area, offshore South Australia and their implications for sea level change, palaeoclimate and palaeodrainage of the MurrayDarling Basin. Marine Geology 212, 183-197.

Ginoux, P., Chin, M., Tegen, I., Prospero, J.M., Holben, B., Dubovik, O., Lin, S.J., 2001. Sources and distributions of dust aerosols simulated with the GOCART model. Journal of Geophysical Research-Atmospheres 106, 20255-20273.

Ginoux, P., Prospero, J.M., Gill, T.E., Hsu, N.C., Zhao, M., 2012. Global-scale attribution of anthropogenic and natural dust sources and their emission rates based on MODIS Deep Blue aerosol products. Reviews of Geophysics 50.

Gliganic, L.A., Cohen, T.J., May, J.H., Jansen, J.D., Nanson, G.C., Dosseto, A., Larsen, J.R., Aubert, M., 2014. Late-Holocene climatic variability indicated by three natural archives in arid southern Australia. Holocene 24, 104-117.

Goldschmidt, V.M., 1933. Grundlagen der quantitativen. Geochemie. Fortschr. Mienral 17, 122.

Goldschmidt, V.M., 1954. Geochemistry. Oxford University Press.

Goldstein, S.L., O'Nions, R.K., Hamilton, P.J., 1984. A Sm-Nd isotopic study of atmospheric dusts and particulates from major river systems. Earth and Planetary Science Letters 70, 221-236.

Gomez, B., Carter, L., Orpin, A.R., Cobb, K.M., Page, M.J., Trustrum, N.A., Palmer, A.S., 2012. ENSO/SAM interactions during the middle and late holocene. Holocene 22, 23-30.

Goudie, A.S., Middleton, N.J., 2006. Desert dust in the global system. Springer, Berlin, Heidelberg, New York.

Grousset, F.E., Biscaye, P.E., 2005. Tracing dust sources and transport patterns using Sr, Nd and $\mathrm{Pb}$ isotopes Chemical Geology 222, 149-167.

Grousset, F.E., Biscaye, P.E., Revel, M., Petit, J.R., Pye, K., Joussaume, S., Jouzel, J., 1992. Antarctic (Dome C) ice-core dust at 18 K.y. B.P.: Isotopic constraints on origins. Earth and Planetary Science Letters 111, 175-182.

Grousset, F.E., Biscaye, P.E., Zindler, A., Prospero, J., Chester, R., 1988. Neodymium Isotopes as Tracers in Marine-Sediments and Aerosols - North-Atlantic. Earth and Planetary Science Letters 87, 367-378.

Haberle, S.G., Hope, G.S., van der Kaars, S., 2001. Biomass burning in Indonesia and Papua New Guinea: natural and human induced fire events in the fossil record. Palaeogeography Palaeoclimatology Palaeoecology 171, 259-268.

Haberzettl, T., Anselmetti, F.S., Bowen, S.W., Fey, M., Mayr, C., Zolitschka, B., Ariztegui, D., Mauz, B., Ohlendorf, C., Kastner, S., Lücke, A., Schäbitz, F., Wille, M., 2009. Late Pleistocene dust deposition in the Patagonian steppe - extending and refining the paleoenvironmental and tephrochronological record from Laguna Potrok Aike back to 55ka. Quaternary Science Reviews 28, 2927-2939.

Hagedorn, B., Cartwright, I., Raveggi, M., Maas, R., 2011. Rare earth element and strontium geochemistry of the Australian Victorian Alps drainage system: Evaluating the dominance of carbonate vs. aluminosilicate weathering under varying runoff. Chemical Geology 284, 105-126. 
Hardcastle, J., 1890. On the Timaru less as a climate register. Transactions and Proceedings of the New Zealand Institute 23, 324-332.

Harrison, S.P., Kohfeld, K.E., Roelandt, C., Claquin, T., 2001. The role of dust in climate changes today, at the last glacial maximum and in the future. Earth-Science Reviews 54, 43-80.

Heimsath, A.M., Chappell, J., Fifield, K., 2010. Eroding Australia: rates and processes from Bega Valley to Arnhem Land, in: Bishop, P., Pillans, B. (Eds.), Australian Landscapes Geological Societhly, London, Special Publication, pp. 225-241.

Henzell, T., 2007. Australian agriculture: its history and challenges. CSIRO Publishing, Collingwood VIC Australia, p. 308.

Herwitz, S.R., Muhs, D.R., Prospero, J.M., Mahan, S., Vaughn, B., 1996. Origin of Bermuda's clay-rich Quaternary paleosols and their paleoclimatic significance. Journal of Geophysical Research-Atmospheres 101, 23389-23400.

Hesse, P.P., 1994. The record of continental dust from Australia in Tasman Sea sediments. Quaternary Science Reviews 13, 257-272.

Hesse, P.P., McTainsh, G.H., 1999. Last glacial maximum to early Holocene wind strength in the mid-latitudes of the Southern Hemisphere from aeolian dust in the Tasman Sea. Quaternary Research 52, 343-349.

Hesse, P.P., McTainsh, G.H., 2003. Australian dust deposits: modern processes and the Quaternary record. Quaternary Science Reviews 22, 2007-2035.

Hofmann, A.W., 1997. Mantle geochemistry: the message from oceanic volcanism. Nature 385, 219-229.

Huneeus, N., Schulz, M., Balkanski, Y., Griesfeller, J., Prospero, J., Kinne, S., Bauer, S., Boucher, O., Chin, M., Dentener, F., Diehl, T., Easter, R., Fillmore, D., Ghan, S., Ginoux, P., Grini, A., Horowitz, L., Koch, D., Krol, M.C., Landing, W., 2011. Global dust model intercomparison in AeroCom phase I. Atmospheric Chemistry \& Physics 11, 7781-7816.

Husar, R.B., Tratt, D.M., Schichtel, B.A., Falke, S.R., Li, F., Jaffe, D., Gasso, S., Gill, T., Laulainen, N.S., Lu, F., Reheis, M.C., Chun, Y., Westphal, D., Holben, B.N., Gueymard, C., McKendry, I., Kuring, N., Feldman, G.C., McClain, C., Frouin, R.J., Merrill, J., DuBois, D., Vignola, F., Murayama, T., Nickovic, S., Wilson, W.E., Sassen, K., Sugimoto, N., Malm, W.C., 2001. Asian dust events of April 1998. Journal of Geophysical Research-Atmospheres 106, 18317-18330.

Ito, A., Shi, Z., 2016. Delivery of anthropogenic bioavailable iron from mineral dust and combustion aerosols to the ocean. Atmos. Chem. Phys. 16, 85-99.

Jaccard, S.L., Hayes, C.T., Martínez-García, A., Hodell, D.A., Anderson, R.F., Sigman, D.M., Haug, G.H., 2013. Two Modes of Change in Southern Ocean Productivity Over the Past Million Years. Science 339, 1419-1423.

Jackson, M.L., Levelt, T.W.M., Syers, J.K., Rex, R.W., Clayton, R.N., Clayton, G.D., Sherman G.D., Uehara, G., 1971. Geomorphological relationships of tropospherically derived quartz in soils on the Hawaiian Islands. Soil Science Society, American Proceedings 35, 515-525.

Jaffe, D., Anderson, T., Kotchenruther, R., Trost, B., Danielson, J., Simpson, W., Brentsen, T., Karlsdottir, S., Blake, D., Harris, J.M., Carmichael, G., Uno, I., 1999. Transport of Asian air pollution to North America. Geophysical Research Letters 26, 711714.

Jickells, T.D., An, Z.S., Andersen, K.K., Baker, A.R., Bergametti, G., Brooks, N., Cao, J.J., Boyd, P.W., Duce, R.A., Hunter, K.A., Kawahata, H., Kubilay, N., laRoche, J., Liss, P.S., Mahowald, N., Prospero, J.M., Ridgwell, A.J., Tegen, I., Torres, R., 
2005. Global iron connections between desert dust, ocean biogeochemistry, and climate. Science 308, 67-71.

Johnson, M.S., Meskhidze, N., Solmon, F., Gassó, S., Chuang, P.Y., Gaiero, D.M., Yantosca, R.M., Wu, S., Wang, Y., Carouge, C., 2010. Modeling dust and soluble iron deposition to the South Atlantic Ocean. Journal of Geophysical Research: Atmospheres 115, D15202.

Kamber, B.S., 2009. Geochemical fingerprinting: 40 years of analytical development and real world applications. Applied Geochemistry 24, 1074-1086.

Kamber, B.S., Greig, A., Collerson, K.D., 2005. A new estimate for the composition of weathered young upper continental crust from alluvial sediments, Queensland, Australia. Geochimica Et Cosmochimica Acta 69, 1041-1058.

Kamber, B.S., Marx, S.K., McGowan, H., A., 2010. Comment on: "Lead isotopic evidence for an Australian source of aeolian dust to Antarctic at times over the last 170,000 years". Palaeogeography Palaeoclimatology Palaeoecology 298, 432-436.

Kanayama, S., Yabuki, S., Zeng, F., Liu, M., Shen, Z., Liu, L., Yanagisawa, F., Abe, O., 2005. Size-dependent geochemical characteristics of Asian dust - Sr and $\mathrm{Nd}$ isotope compositions as tracers for source identification. Journal of the Meteorological Society of Japan 83, 107-120.

Kellogg, C.A., Griffin, D.W., 2006. Aerobiology and the global transport of desert dust. Trends in Ecology \& Evolution 21, 638-644.

Kiefert, L., McTainsh, G.H., 1996. Oxygen isotope abundance in the quartz fraction of aeolian dust: Implications for soil and ocean sediment formation in the Australasian region. Australian Journal of Soil Research 34, 467-473.

Kinoshita, N., Sueki, K., Sasa, K., Kitagawa, J., Ikarashi, S., Nishimura, T., Wong, Y.S., Satou, Y., Handa, K., Takahashi, T., Sato, M., Yamagata, T., 2011. Assessment of individual radionuclide distributions from the Fukushima nuclear accident covering central-east Japan. PNAS 108, 19526-19529.

Knighton, A.D., Nanson, G.C., 2001. An event-based approach to the hydrology of arid zone rivers in the Channel Country of Australia. Journal of Hydrology 254, 102-123.

Kocurek, G., 1998. Aeolian system response to external forcing factors - a sequence stratigraphic view of the Saharan region, in: Alsharan, A.S., Glennie, K.W., Whittle, G.L., Kendall, C.G.S.C. (Eds.), Quaternary Deserts and Climatic Change. Balkema, Rotterdam/Brookfield, pp. 327-338.

Koffman, B.G., Kreutz, K.J., Breton, D.J., Kane, E.J., Winski, D.A., Birkel, S.D., Kurbatov, A.V., Handley, M.J., 2014. Centennial-scale variability of the Southern Hemisphere westerly wind belt in the eastern Pacific over the past two millennia. Climate of the Past, Vol 10, Iss 3, Pp 1125-1144 (2014), 1125.

Kohfeld, K.E., Harrison, S.P., 2001. DIRTMAP: the geological record of dust. Earth-Science Reviews 54, 81-114.

Kohfeld, K.E., Harrison, S.P., 2003. Glacial-interglacial changes in dust deposition on the Chinese Loess Plateau. Quaternary Science Reviews 22, 1859-1878.

Kotwicki, V., Isdale, P., 1991. Hydrology of Lake Eyre, Australia: El Niño link. Palaeogeography Palaeoclimatology Palaeoecology 84, 87-98.

Kurtz, A.C., Derry, L.A., Chadwick, O.A., 2001. Accretion of Asian dust to Hawaiian soils: Isotopic, elemental, and mineral mass balances. Geochimica Et Cosmochimica Acta 65, 1971-1983.

Kylander, M.E., Martínez-Cortizas, A., Bindler, R., Greenwood, S.L., Mörth, C.M., Rauch, S., 2016. Potentials and problems of building detailed dust records using peat archives: An example from Store Mosse (the "Great Bog"), Sweden. Geochimica Et Cosmochimica Acta 190, 156-174. 
Kylander, M.E., Muller, J., Wüst, R.A.J., Gallagher, K., Garcia-Sanchez, R., Coles, B.J., Weiss, D.J., 2007. Rare earth element and $\mathrm{Pb}$ isotope variations in a $52 \mathrm{kyr}$ peat core from Lynch's Crater (NE Queensland, Australia): Proxy development and application to paleoclimate in the Southern Hemisphere. Geochimica Et Cosmochimica Acta 71, 942-960.

Kylander, M.E., Weiss, D.J., Peiteado Varela, E., Taboada Rodriguez, T., Martínez Cortizas, A., 2006. Chapter 21 Archiving natural and anthropogenic lead deposition in peatlands, in: I.P. Martini, A.M.C., Chesworth, W. (Eds.), Developments in Earth Surface Processes. Elsevier, pp. 479-497.

Lal, R., 2007. Evolution of the plow over 10,000 years and the rationale for no-till farming. Soil \& Tillage Research 93, 1-12.

Lambert, F., Delmonte, B., Petit, J.R., Bigler, M., Kaufmann, P.R., Hutterli, M.A., Stocker, T.F., Ruth, U., Steffensen, J.P., Maggi, V., 2008. Dust-climate couplings over the past 800,000 years from the EPICA Dome C ice core. Nature 452, 616-619.

Lavin, K.S., Hageman, K.J., Marx, S.K., Dillingham, P.W., Kamber, B.S., 2012. Using trace elements in particulate matter to identify the sources of semi-volatile organic contaminants in air at an alpine site. Environmental Science \& Technology 46, 268-276.

Lawrence, C.R., Neff, J.C., 2009. The contemporary physical and chemical flux of aeolian dust: A synthesis of direct measurements of dust deposition. Chemical Geology 267, 46-63.

Le Roux, G., Fagel, N., De Vleeschouwer, F., Krachler, M., Debaille, V., Stille, P., Mattielli, N., van der Knaap, W.O., van Leeuwen, J.F., Shotyk, W., 2012. Volcano- and climate-driven changes in atmospheric dust sources and fluxes since the late glacial in Central Europe. Geology 40, 335-338.

Le Roux, G., Pourcelot, L., Masson, O., Duffa, C., Vray, F., Renaud, P., 2008. Aerosol deposition and origin in the Frency mountains estimated with soil inventories of ${ }^{210} \mathrm{~Pb}$ and artificial radionuclides. Atmospheric Environment 42, 1517-1525.

Leblanc, M., Tweed, T., Van Dijk, A., Timbal, B., 2012. A review of historic and future hydrological changes in the Murray-Darling Basin. Global and Planetary Change 80-81, 226-248.

Lewis, S.E., Shields, G.A., Kamber, B.S., Lough, J.M., 2007. A multi-trace element coral record of land-use changes in the Burdekin River catchment, NE Australia. Palaeogeography Palaeoclimatology Palaeoecology 246, 471-487.

Li, F., Ginoux, P., Ramaswamy, V., 2008. Distribution, transport, and deposition of mineral dust in the Southern Ocean and Antarctica: Contribution of major sources. Journal of Geophysical Research D: Atmospheres 113.

Liu, C.Q., Masuda, A., Okada, A., Yabuki, S., Zhang, J., Fan, Z.L., 1993. A geochemical study of loess and desert sand in northern China: implications for continental crust weathering and compostion. Chemical Geology 106.

Lu, F.H., Meyers, W.J., 2003. Sr, S and $\mathrm{O}_{\mathrm{SO} 4}$ isotopes and the depositional environments of the Upper Miocene evaporites, Spain. Journal of Sedimentary Research 73, 444450.

Lyons, W.B., Tyler, S.W., Gaudette, H.E., Long, D.T., 1995. The use of strontium isotopes in determining groundwater mixing and brine fingering in a playa spring zone, Lake Tyrrell, Australia. Journal of Hydrology 167, 225-239.

Magee, J.W., Miller, G.H., Spooner, N.A., Questiaux, D., 2004. Continuous 150 k.y. monsoon record from Lake Eyre, Australia: Insolation-forcing implications and unexpected Holocene failure. Geology 32, 885-888. 
Maher, B.A., Prospero, J.M., Mackie, D., Gaiero, D., Hesse, P.P., Balkanski, Y., 2010. Global connections between aeolian dust, climate and ocean biogeochemistry at the present day and at the last glacial maximum. Earth-Science Reviews 99, 61-97.

Martin, J.H., Coal, K.H., Johnson, K.S., Fitzwater, S.E., Gordon, R.M., Tanner, S.J., Hunter, C.N., Elrod, V.A., Nowicki, J.L., Coley, T.L., Barber, R.T., Lindley, S., Watson, A.J., Van Scoy, K., Law, C.S., Liddicoat, M.I., Ling, R., Stanton, T., Stockel, J., Collins, C., Anderson, A., Bidigare, R., Ondrusek, M., Latasa, M., Millero, F.J., Lee, K., Yao, W., Zhang, J.H., Friederich, G., Sakamoto, C., Chavez, F., Buck, K., Kolber, Z., Grenne, R., Falkowski, P., Chisholm, S.W., Hoge, F., Swift, R., Yungel, J., Turner, S., Nightingale, P., Hatton, A., Liss, P., Tindale, N.W., 1994. Testing the iron hypothesis in ecosystems of the equatorial Pacific-Ocean. Nature 371, 123-129.

Marx, S.K., Kamber, B.S., 2010. High-precision trace-element systematics of sediments in the Murray-Darling Basin, Australia: sediment tracing and palaeo-climate implications of fine scale chemical heterogeneity of the upper continental crust. Applied Geochemistry 25, 1221-1237.

Marx, S.K., Kamber, B.S., McGowan, H., A.,, Denholm, J., 2011. Holocene dust deposition rates in Australia's Murray-Darling Basin record the interplay between aridity and the position of the mid-latitude westerlies. Quaternary Science Reviews 30, 32903305.

Marx, S.K., Kamber, B.S., McGowan, H.A., 2005a. Estimates of Australian dust flux into New Zealand: Quantifying the eastern Australian dust plume pathway using trace element calibrated ${ }^{210} \mathrm{~Pb}$ as a monitor. Earth and Planetary Science Letters 239, 336-351.

Marx, S.K., Kamber, B.S., McGowan, H.A., 2005b. Provenance of long travelled dust determined with ultra-trace-element composition: A pilot study with samples from New Zealand glaciers. Earth Surface Processes and Landforms 30, 699-716.

Marx, S.K., Kamber, B.S., McGowan, H.A., 2008. Scavenging of trace metal pollutants by mineral dust: Inter-regional transport of trace metal pollution to New Zealand. Atmospheric Environment 42, 2460-2478.

Marx, S.K., Kamber, B.S., McGowan, H.A., Zawadzki, A., 2010. Atmospheric pollutants in alpine peat bogs record a detailed chronology of industrial and agricultural development on the Australian continent. Environmental Pollution 158, 1615-1628.

Marx, S.K., Lavin, K.J., Hageman, K.J., Kamber, B.S., O'Loingsigh, T., Mctainsh, G.H., 2014a. Trace elements and metal pollution in aerosols at an alpine site, New Zealand: Sources, concentrations and implications. Atmospheric Environment 82, 206-217.

Marx, S.K., McGowan, H., A., Kamber, B.S., Knight, J., Denholm, J., Zawadzki, A., 2014b. Unprecedented wind erosion and perturbation of surface geochemistry marks the Anthropocene in Australia. Journal of Geophysical Research-Earth Surface 119, 45-61.

Marx, S.K., McGowan, H.A., 2005. Dust transport and deposition in a superhumid environment. CATENA 59, 147-171.

Marx, S.K., McGowan, H.A., Kamber, B.S., 2009. Long-range dust transport from eastern Australia: a proxy for Holocene aridity and ENSO-induced climate variability. Earth and Planetary Science Letters 282, 167-177.

Marx, S.K., Rashid, S., Stromsoe, N., 2016. Global-scale patterns in anthropogenic $\mathrm{Pb}$ contaimnination reconstructed from natural archives. Environmental Pollution 213, 283-298. 
May, J.-H., Wells, S.G., Cohen, T.J., Marx, S.K., Nanson, G.C., Baker, S.E., 2015. A soil chronosequence on Lake Mega-Frome beach ridges: implications for late Quaternary pedogenesis and palaeoenvironmental conditions in the drylands of southern Australia. Quaternary Research 83, 150-156.

McAlpine, C.A., Etter, A., Fearnside, P.M., Seabrook L., Laurance, W.F., 2009. Increasing world consumption of beef as a driver of regional and global change: a call for policy action based on evidence from Queensland (Australia), Colombia and Brazil. Global Environmental Change 19, 21-33.

McCarthy, L., Head, L., 2001. Holocene variability in semi-arid vegetation; new evidence from Leporillus middens from the Flinders Ranges, South Australia. Holocene 11, 681-689.

McConnell, J.R., Aristarain, A.J., Banta, J.R., Edwards, P.R., Simões, J.C., 2007. 20thCentury doubling in dust archived in an Antarctic Peninsula ice core parallels climate change and desertification in South America. Proceedings of the National Academy of Sciences 104, 5743-5748.

McConnell, J.R., Maselli, O.J., Sigl, M., Vallelonga, P., Neumann, T., Anschütz, H., Bales, R.C., Curran, M.A.J., Das, S.B., Edwards, R., Kipfstuhl, S., Layman, L., Thomas, E.R., 2014. Antarctic-wide array of high-resolution ice core records reveals pervasive lead pollution began in 1889 and persists today. Scientific Reports 4.

McGowan, H., A., Marx, S.K., Moss, P., Hammond, A.P., 2012. Evidence of ENSO megadrought triggered collapse of prehistory Aboriginal society in northwest Australia. Geophysical Research Letters 39, L22702.

McGowan, H.A., Clark, A., 2008. Identification of dust transport pathways from Lake Eyre, Australia using Hysplit. Atmospheric Environment 42, 6915-6925.

McGowan, H.A., Kamber, B.S., Marx, S.K., 2005a. Geochemical characterisation of east Australian dusts: A tool for provenance of aeolian sediments from geological archives, Drylands: Linking landscape processes to sedimentary envornments. A joint BGRG/BSRG International Conference., London.

McGowan, H.A., Kamber, B.S., McTainsh, G.H., Marx, S.K., 2005b. High resolution provenance of long travelled dust deposition in the Southern Alps, New Zealand. Geomorphology 69, 208-221.

McGowan, H.A., Marx, S.K., Soderholm, J., Denholm, J., 2010. Evidence of solar and tropical-ocean forcing of hydroclimate in southeastern Australia for the past 6500 years. Geophysical Research Letters 37, L10705.

McGowan, H.A., Petherick, L.M., Kamber, B.S., 2008. Aeolian sedimentation and climate variability during the late Quaternary in southeast Queensland, Australia. Palaeogeography Palaeoclimatology Palaeoecology 265, 171-181.

McGowan, H.A., Sturman, A.P., 1997. Characteristics of aeolian grain transport over a fluvio-glacial lacustrine braid delta, Lake Tekapo, New Zealand. Earth Surface Processes and Landforms 22, 773-784.

McTainsh, G.H., 1989. Quaternary Aeolian Dust Processes and Sediments in the Australian Region. Quaternary Science Reviews 8, 235-253.

McTainsh, G.H., Chan, Y., McGowan, H.A., Leys, J.F., Tews, K., 2005. The 23rd October, 2002 dust storm in eastern Australia: characteristics and meteorological conditions. Atmospheric Environment 39, 1227-1236.

McTainsh, G.H., Leys, J.F., 1993. Soil erosion by wind, in: McTainsh, G.H., Boughton, W.C. (Eds.), Land degredation processes in Australia. Longman Cheshire Pty Ltd, Melbourne, pp. 188-230.

McTainsh, G.H., Love, B.M., Leys, J.F., Strong, C., 2002. Wind erodibility of arid lands in the Channel Country of western Queensland, Australia, a sequel (1994-2000), in: 
Lee, J.A., Zobeck, T.M. (Eds.), ICAR5/GCTE-SEN Joint conference. International Center for Arid and Semiarid Lands Studies, Texas Tech University, Texas, USA, pp. 179-183.

McTainsh, G.H., Lynch, A.W., Tews, E.K., 1998. Climatic controls upon dust storm occurrence in eastern Australia. Journal of Arid Environments 39, 457-466.

Meyer, I., Davies, G.R., Stuut, J.B.W., 2011. Grain size control on Sr-Nd isotope provenance studies and impact on paleoclimate reconstructions: An example from deep-sea sediments offshore NW Africa. Geochemistry, Geophysics, Geosystems 12.

Meyer, I., Davies, G.R., Vogt, C., Kuhlmann, H., Stuut, J.B.W., 2013. Changing rainfall patterns in NW Africa since the Younger Dryas. Aeolian Research 10, 111-123.

Micklin, P., 2007. The Aral Sea Disaster. Annual Review of Earth and Planetary Sciences 35, 47-72.

Middleton, N.J., 1984. Dust storms in Australia: Frequency, distribution and seasonality. Search 15, 46-47.

Middleton, N.J., Betzer, P.R., Bull, P.A., 2001. Long-range transport of 'giant' aeolian quartz grains: linkage with discrete sedimentary sources and implications for protective particle transfer. Marine Geology 177, 411-417.

Montes, A., Rodríguez, S.S., Domínguez, C.E., 2017. Geomorphology context and characterization of dunefields developed by the southern westerlies at drying Colhué Huapi shallow lake, Patagonia Argentina. Aeolian Research 28, 58-70.

Moore, C.M., Mills, M.M., Arrigo, K.R., Berman-Frank, I., Bopp, L., Boyd, P.W., Galbraith, E.D., Geider, R.J., Guieu, C., Jaccard, S.L., Jickells, T.D., La Roche, J., Lenton, T.M., Mahowald, N.M., Maranon, E., Marinov, I., Moore, J.K., Nakatsuka, T., Oschlies, A., Saito, M.A., Thingstad, T.F., Tsuda, A., Ulloa, O., 2013. Processes and patterns of oceanic nutrient limitation. Nature Geoscience 6, 701-710.

Moy, C.M., Seltzer, G.O., Rodbell, D.T., Anderson, D.M., 2002. Variability of El Niño/Southern Oscillation activity at millennial timescales during the Holocene epoch. Nature 420, 162-165.

Muhs, D.R., 2013. The geologic records of dust in the Quaternary. Aeolian Research 9, 3-48.

Muhs, D.R., Budahn, J., Avila, A., Skipp, G., Freeman, J., Patterson, D., 2010a. The role of African dust in the formation of Quaternary soils on Mallorca, Spain and implications for the genesis of Red Mediterranean soils. Quaternary Science Reviews 29, 2518-2543.

Muhs, D.R., Budahn, J., Skipp, G., Prospero, J.M., Patterson, D., Bettis Iii, E.A., $2010 \mathrm{~b}$. Geochemical and mineralogical evidence for Sahara and Sahel dust additions to Quaternary soils on Lanzarote, eastern Canary Islands, Spain. Terra Nova 22, 399410.

Muhs, D.R., Budahn, J.R., Johnson, D.L., Reheis, M., Beann, J., Skipp, G., Fisher, E., Jones, J.A., 2008. Geochemical evidence for airborne dust additions to soils in Channel Islands National Park, California. Geological Society of America Bulletin 120, 106-126.

Muhs, D.R., Budahn, J.R., Prospero, J.M., Carey, S.N., 2007. Geochemical evidence for African dust inputs to soils of western Atlantic islands: Barbados, the Bahamas, and Florida. Journal of Geophysical Research-Earth Surface 112, F02009.

Muhs, D.R., Budahn, J.R., Prospero, J.M., Skipp, G., Herwitz, S.R., 2012. Soil genesis on the island of Bermuda in the Quaternary: The importance of African dust transport and deposition. Journal of Geophysical Research: Earth Surface 117.

Mulitza, S., Heslop, D., Pittauerova, D., Fischer, H.W., Meyer, I., Stuut, J.-B., Zabel, M., Mollenhauer, G., Collins, J.A., Kuhnert, H., Schulz, M., 2010. Increase in African 
dust flux at the onset of commercial agriculture in the Sahel region. Nature 466, 226-228.

Mulitza, S., Prange, M., Stuut, J.B., Zabel, M., von Dobeneck, T., Itambi, A.C., Nizou, J., Schulz, M., Wefer, G., 2008. Sahel megadroughts triggered by glacial slowdowns of Atlantic meridional overturning. Paleoceanography 23.

Muller, J., Kylander, M., Martinez-Cortizas, A., Wuest, R.A.J., Weiss, D., Blake, K., Coles, B., Garcia-Sanchez, R., 2008. The use of principle component analyses in characterising trace and major elemental distribution in a $55 \mathrm{kyr}$ peat deposit in tropical Australia: Implications to paleoclimate. Geochimica Et Cosmochimica Acta 72, 449-463.

Nanson, G.C., Jones, B.G., Price, D.M., Pietsch, T.J., 2005. Rivers turned to rock: Late Quaternary alluvial induration influencing the behaviour and morphology of an anabranching river in the Australian monsoon tropics. Geomorphology 70, 398420.

Neff, J.C., Ballantyne, A.P., Farmer, G.L., Mahowald, N.M., Conroy, J.L., Landry, C.C., Overpeck, J.T., Painter, T.H., Lawrence C. R., L., R., 2008. Increasing eolian dust deposition in the western United States linked to human activity. Nature Geoscience 1, 189-195.

Neff, P.D., Bertler, N.A.N., 2015. Trajectory modeling of modern dust transport to the Southern Ocean and Antarctica. Journal of Geophysical Research: Atmospheres 120, 9303-9322.

Nesbitt, H.W., Young, G.M., 1996. Petrogenesis of sediments in the absence of chemical weathering: effects of abrasion and sorting on bulk compositoin and mineralogy. Sedimentology 43, 341-358.

O'Loingsigh, T., McTainsh, G.H., Parsons, K., Strong, C.L., Shinkfield, P., Tapper, N.J., 2015. Using meteorological observer data to compare wind erosion during two great droughts in eastern Australia; the World War II Drought (1937-1946) and the Millennium Drought (2001-2010). Earth Surface Processes and Landforms 40, 123-130.

O'Loingsigh, T., McTainsh, G.H., Tapper, N.J., Shinkfield, P., 2010. Lost in code: A critical analysis of using meteorological data for wind erosion monitoring. Aeolian Research 2, 49-57.

Patterson, C.C., 1965. Contaiminated and natural lead environments of man. Archives of Environmental Health 11, 344-360.

Peel, M.C., Finlayson, B.L., McMahon, T.A., 2007. Updated world map of the KöppenGeiger climate classification. Hydrol. Earth Syst. Sci. 11, 1633-1644.

Peltier, W.R., Marshall, S., 1995. Coupled energy-balance/ice-sheet model simulations of the glacial cycle: a possible connection between terminations and terrigenous dust. Journal of Geophysical Research 100, 14,269-214,289.

Petherick, L.M., McGowan, H.A., Kamber, B.S., 2009. Reconstructing transport pathways for late Quaternary dust from eastern Australia using the composition of trace elements of long traveled dusts. Geomorphology 105, 67-79.

Petherick, L.M., McGowan, H.A., Moss, P.T., 2008. Climate variability during the Last Glacial Maximum in eastern Australia: evidence of two stadials? Journal of Quaternary Science 23, 787-802.

Porder, S., Hilley, G.E., Chadwick, O.A., 2007. Chemical weathering, mass loss, and dust inputs across a climate by time matrix in the Hawaiian Islands. Earth and Planetary Science Letters 258, 414-427. 
Proske, U., Heslop, D., Haberle, S., 2014. A Holocene record of coastal landscape dynamics in the eastern Kimberley region, Australia. Journal of Quaternary Science 29, 163 174.

Prospero, J.M., 1999. Long-term measurements of the transport of African mineral dust to the southeastern United States: Implications for regional air quality. Journal of Geophysical Research-Atmospheres 104, 15917-15927.

Prospero, J.M., Ginoux, P., Omar, T., Nicholson, S.E., Gill, T.E., 2002. Environmental characterization of global sources of atmospheric soil dust identified with the NIMBUS 7 total ozone mapping spectrometer (TOMS) absorbing aerosol product. Reviews of Geophysics 40, 1-31.

Pye, K., 1987. Aeolian dust and dust deposits. Academic Press Inc, London.

Pye, K., 1992. Aeolian dust transport and deposition over Crete and adjacent parts of the Mediterranean Sea. Earth Surface Processes and Landforms 17, 271-288.

Pye, K., 1995. The nature, origin and accumulation of loess. Quaternary Science Reviews 14, 653-667.

Quigley, M.C., Horton, T., Hellstrom, J.C., Cupper, M.L., Sandiford, M., 2010. Holocene climate change in arid Australia from speleothem and alluvial records. Holocene 20, 1093-1104.

Rea, D.K., 1994. The paleoclimatic record provided by eolian deposition in the deep sea: The geologic history of wind. Reviews of Geophysics 32, 159-195.

Revel-Rolland, M., De Deckker, P., Delmonte, B., Hesse, P.P., Magee, J.W., BaisileDoelsch, I., Grousset, F., Bosch, D., 2006. Eastern Australia: a possible source of dust in east Antarctic interglacial ice. Earth and Planetary Science Letters 249, 113.

Rex, R.W., Syers, J.K., Jackson, M.L., Clayton, R.N., 1969. Eolian origin of quartz in soils of Hawaiian Islands and in Pacific pelagic sediments. Science 163, 277-279.

Richthofen, F.v., 1882. On the mode and origin of the loess. Geology Magazine 9, 293-305.

Rodbell, D.T., Seltzer, G.O., Anderson, D.G., Abbott, M.B., Enfield, D.B., Newman, J.H., 1999. An 15,000-year record of El Niño-driven alluviation in southwestern Ecuador. Science 283, 516-520.

Sandweiss, D.H., Richardson III, J.B., Reitz, E., Rollins, H.B., Maasch, K.A., 1996. Geoarchaeological evidence from Peru for a 5000 years B.P. onset of El Niño. Science 273, 1531-1533.

Shao, Y., Dong, C.H., 2006. A review on East Asian dust storm climate, modelling and monitoring. Global and Planetary Change 52, 1-22.

Shao, Y., Wyrwoll, K.-H., Chappell, A., Huang, J., Lin, Z., McTainsh, G.H., Mikami, M., Tanaka, T.Y., Wang, X., Yoon, S., 2011. Dust cycle: An emerging core theme in Earth system science. Aeolian Research 2, 181-204.

Shine, K.P., Forster, P.M.D., 1999. The effect of human activity on radiative forcing of climate change: A review of recent developments. Global and Planetary Change 20, 205-225.

Shotyk, W., Blaser, P., Grünig, A., Cheburkin, A.K., 2000. A new approach for quantifying cumulative, anthropogenic, atmospheric lead deposition using peat cores from bogs: $\mathrm{Pb}$ in eight Swiss peat bog profiles. Science of the Total Environment 249, 281-295.

Shotyk, W., Weiss, D., Appleby, P.G., Cheburkin, A., Gloor, M., Kramers, J.D., Reese, S., Van Der Knaap, W.O., 1998. History of atmospheric lead deposition since 12,370 14C yr BP from a peat bog, Jura Mountains, Switzerland. Science 281, 1635-1640.

Shotyk, W., Weiss, D., Kramers, J.D., Frei, R., Cheburkin, A.K., Gloor, M., Reese, S., 2001. Geochemistry of the peat bog at Etang de la Gruere, Jura Mountains, Switzerland, 
and its record of atmospheric $\mathrm{Pb}$ and lithogenic trace metals $\mathrm{Sc}, \mathrm{Ti}, \mathrm{Y}, \mathrm{Zr}$, and REE) since 12,370 C-14 yr BP. Geochimica Et Cosmochimica Acta 65, 23372360.

Shulmeister, J., 1999. Australasian evidence for mid-holocene climate change implies precessional control of Walker Circulation in the Pacific. Quaternary International 57-58, 81-91.

Shulmeister, J., Lees, B.G., 1995. Pollen evidence from tropical Australia for the onset of an ENSO-dominated climate at c. 4000 B.P. The Holocene 5, 10-18.

Singh, G., Luly, J.G., 1991. Changes in vegetation and seasonal climate since the last full glacial at Lake Frome, South Australia. Palaeogeography Palaeoclimatology Palaeoecology 84, 75-86.

Smalley, I.J., Jefferson, I.F., Dijkstra, T.A., Derbyshire, E., 2001. Some major events in the development of the scientific study of loess. Earth-Science Reviews 54, 5-18.

Sprigg, R.C., 1982. Alternating wind cycles of the Quaternary era and their influence on aeolian sedimentation in and around the dune deserts of south eastern Australia, in: Wasson, R.J. (Ed.), Quaternary Dust Mantels of China, New Zealand, and Australia. Proceedings of the INQUA loess commission workshop, INQUA, Canberra, pp. 211-240.

Stanley, S., De Deckker, P., 2002. A Holocene record of allochthonous, aeolian mineral grains in an Australian alpine lake; implications for the history of climate change in southeastern Australia. Journal of Paleolimnology 27, 207-219.

Stout, J.E., Warren, A., Gill, T.E., 2009. Publication trends in aeolian research: An analysis of the Bibliography of Aeolian Research. Geomorphology 105, 6-17.

Stromsoe, N.J., Marx, S.K., McGowan, H., A., Callow, J.N., Zawadzki, A., Heijnis, H., 2015. A landscape-scale approach to examining the fate of atmospheric derived toxic metals in the surficial environment. Science of the Total Environment 505, 962980.

Strong, C.L., Parsons, K., McTainsh, G.H., Sheehan, A., 2011. Dust transporting wind systems in the lower Lake Eyre Basin, Australia: A preliminary study. Aeolian Research 2, 205-214.

Stuut, J.W., Prins, M.A., Schneider, R.R., Weltje, G.J., Jansen, J.H.F., Postma, G., 2002. A 300-kyr record of aridity and wind strength in southwestern Africa: Inferences from grain-size distributions of sediments on Walvis Ridge, SE Atlantic. Marine Geology 180, 221-233.

Sugden, D.E., McCulloch, R.D., Bory, A.J.M., Hein, A.S., 2009. Influence of Patagonian glaciers on Antarctic dust deposition during the last glacial period. Nature Geoscience 2, 281-285.

Sun, D., Bloemendal, J., Rea, D.K., An, Z., Vandenberghe, J., Lu, H., Su, R., Liu, T., 2004. Bimodal grain-size distribution of Chinese loess, and its palaeoclimatic implications. CATENA 55, 325-340.

Sun, J., Zhang, M., Liu, T., 2001. Spatial and temporal characteristics of dust storms in China and its surrounding regions, 1960-1999. Journal-of-Geophysical-Research-D:Atmospheres 106, 10325-10333.

Sun, J.M., 2002. Provenance of loess material and formation of loess deposits on the Chinese Loess Plateau. Earth and Planetary Science Letters 203, 845-859.

Svensson, A., Biscaye, P.E., Grousset, F.E., 2000. Characterization of late glacial continental dust in the Greenland Ice Core Project ice core. Journal of Geophysical ResearchAtmospheres 105, 4637-4656.

Swap, R., Garstang, M., Greco, S., Talbot, R., Kallberg, P., 1992. Saharan dust in the Amazon Basin Tellus Series B-Chemical and Physical Meteorology 44, 133-149. 
Syvitski, J.P.M., Vörösmarty, C.J., Kettner, A.J., Green, P., 2005. Impact of Humans on the Flux of Terrestrial Sediment to the Global Coastal Ocean. Science 308, 376-380.

Taylor, S.R., McLennan, S.M., McCulloch, M.T., 1983. Geochemistry of loess, continental crustal composition and crustal model ages. Geochimica Et Cosmochimica Acta 47, 1897-1905.

Thoms, M.C., Sheldon, F., 2000. Lowland rivers: An Australian introduction. Regulated Rivers: Reseach and Management 16, 375-383.

Tomlinson, E.L., Smith, V.C., Albert, P.G., Aydar, E., Civetta, L., Cioni, R., Çubukçu, E., Gertisser, R., Isaia, R., Menzies, M.A., Orsi, G., Rosi, M., Zanchetta, G., 2015. The major and trace element glass compositions of the productive Mediterranean volcanic sources: tools for correlating distal tephra layers in and around Europe. Quaternary Science Reviews 118, 48-66.

Townsend, A.T., Snape, I., 2002. The use of $\mathrm{Pb}$ isotope ratios determined by magnetic sector ICP-MS for tracing $\mathrm{Pb}$ pollution in marine sediments near Casey Station, East Antarctica. Journal of Analytical Atomic Spectrometry 17.

Tsoar, H., Pye, K., 1987. Dust Transport and the Question of Desert Loess Formation. Sedimentology 34, 139-153.

Tudhope, A.W., Chilcott, C.P., McCulloch, M.T., Cook, E.R., Chappell, J., Ellam, R.M., Lea, D.W., Lough, J.M., Shimmield, G.B., 2001. Variability in the El Niño-Southern Oscillation Through a Glacial-Interglacial Cycle. Science 291, 1511-1517.

Turekian, K.K., Nozaki, Y., Benninger, K., 1977. Geochemistry of atmospheric radon and radon products. Annual Review Earth Planetary Sciences 5, 227-255.

Újvári, G., Kok, J.F., Varga, G., Kovács, J., 2016. The physics of wind-blown loess: Implications for grain size proxy interpretations in Quaternary paleoclimate studies. Earth-Science Reviews 154, 247-278.

Ullman, W.J., Collerson, K.D., 1994. The Sr - isotope record of late quaternary hydrologic changes around Lake Frome, South Australia. Australian Journal of Earth Sciences 41, 37-45.

Uno, I., Eguchi, K., Yumimoto, K., Takemura, T., Shimizu, A., Uematsu, M., Liu, Z.Y., Wang, Z.F., Hara, Y., Sugimoto, N., 2009. Asian dust transported one full circuit around the globe. Nature Geoscience 2, 557-560.

Vallelonga, P., Gabrielli, P., Balliana, E., Wegner, A., Delmonte, B., Turetta, C., Burton, G., Vanhaecke, F., Rosman, K.J.R., Hong, S., Boutron, C.F., Cescon, P., Barbante, C., 2010. Lead isotopic compositions in the EPICA Dome $C$ ice core and Southern Hemisphere Potential Source Areas. Quaternary Science Reviews 29, 247-255.

Vallelonga, P., Gabrielli, P., Rosman, K.J.R., Barbante, C., Boutron, C.F., 2005. A 220 kyr record of $\mathrm{Pb}$ isotopes at Dome $\mathrm{C}$ Antarctica from analyses of the EPICA ice core. Geophysical Research Letters 32.

Vallelonga, P., Van de Velde, K., Candelone, J.P., Morgan, V.I., Boutron, C.F., Rosman, K.J.R., 2002. The lead pollution history of Law Dome, Antarctica, from isotopic measurements on ice cores: 1500 AD to 1989 AD. Earth and Planetary Science Letters 204, 291-306.

VanCuren, R.A., Cahill, T., Burkhart, J., Barnes, D., Zhao, Y., Perry, K., Cliff, S., McConnell, J., 2012. Aerosols and their sources at Summit Greenland - First results of continuous size- and time-resolved sampling. Atmospheric Environment 52, 82-97.

Vanneste, H., De Vleeschouwer, F., Bertrand, S., Martínez-Cortizas, A., Vanderstraeten, A., Mattielli, N., Coronato, A., Piotrowska, N., Jeandel, C., Roux, G.L., 2016. Elevated dust deposition in Tierra del Fuego (Chile) resulting from Neoglacial Darwin Cordillera glacier fluctuations. Journal of Quaternary Science 31, 713-722. 
Viglizzo, E.F., Frank, F.C., 2006. Ecological interactions, feedbacks, thresholds and collapses in the Argentine Pampas in response to climate and farming during the last century. Quaternary International 158, 122-126.

von Suchodoletz, H., Glaser, B., Thrippleton, T., Broder, T., Zang, U., Eigenmann, R., Kopp, B., Reichert, M., Ludwig, Z., 2013. The influence of Saharan dust deposits on La Palma soil properties (Canary Islands, Spain). CATENA 103, 44-52.

Warren, A., Chappell, A., Todd, M.C., Bristow, C., Drake, N., Engelstaedter, S., Martins, V., M'Bainayel, S., Washington, R., 2007. Dust-raising in the dustiest place on earth. Geomorphology 92, 25-37.

Washington, R., Todd, M., Middleton, N.J., Goudie, A.S., 2003. Dust storm source areas determined by the Total Ozone Monitoring Spectrometer and Surface Observations. Annuals of the Association of American Geographers 93, 297-313.

Washington, R., Todd, M.C., Lizcano, G., Tegen, I., Flamant, C., Koren, I., Ginoux, P., Engelstaedter, S., Bristow, C.S., Zender, C.S., Goudie, A.S., Warren, A., Prospero, J.M., 2006. Links between topography, wind, deflation, lakes and dust: The case of the Bodélé Depression, Chad. Geophysical Research Letters 33, n/a-n/a.

Wasson, R.J., Galloway, R.W., 1986. Sediment yeild in the Barrier Range before and after European settlement. Australian Rangelands Journal 8, 79-80.

Wasson, R.J., Olive, L.J., Rosewell, C.J., 1996. Rates of erosion and sediment transport in Australia, in: Walling, D.E., Webb, B.W. (Eds.), Erosion and Sediment Yield: Global and Regional Perspectives. Proceedings of the Exeter Symposium, July 1996, Exeter, UK, IAHS Publication 236., pp. 139-148.

Webb, N.P., Strong, C.L., 2011. Soil erodibility dynamics and its representation for wind erosion and dust emission models. Aeolian Research 3, 165-179.

Weiss, D., Shotyk, W., Rieley, J., Page, S., Gloor, M., Reese, S., Martinez-Cortizas, A., 2002. The geochemistry of major and selected trace elements in a forested peat bog, Kalimantan, SE Asia, and its implications for past atmospheric dust deposition. Geochimica Et Cosmochimica Acta 66, 2307-2323.

Wiggs, G.F.S., O'Hara, S.L., Wegerdt, J., Van Der Meer, J., Small, I., Hubbard, R., 2003. The dynamics and characteristics of aeolian dust in dryland Central Asia: possible impacts on human exposure and respiratory health in the Aral Sea basin. Geographical Journal 169, 142-157.

Xiao, J.L., An, Z.S., Liu, T.S., Inouchi, Y., Kumai, H., Yoshikawa, S., Kondo, Y., 1999. East Asian monsoon variation during the last 130,000 Years: evidence from the Loess Plateau of central China and Lake Biwa of Japan. Quaternary Science Reviews 18, 147-157.

Yang, B., Bräuning, A., Zhang, Z., Dong, Z., Esper, J., 2007. Dust storm frequency and its relation to climate changes in Northern China during the past 1000 years. Atmospheric Environment 41, 9288-9299.

Zhang, B., Tsunekawa, A., Tsubo, M., 2008. Contributions of sandy lands and stony deserts to long-distance dust emission in China and Mongolia during 2000-2006. Global and Planetary Change 60, 487-504.

Zielinski, G.A., Mershon, G.R., 1997. Paleoenvironmental implications of the insoluble microparticle record in the GISP2 (Greenland) ice core during the rapidly changing climate of the Pleistocene-Holocene transition. Geological Society of America Bulletin 109, 547-559. 


\section{Figure Captions}

Figure 1: Schematic diagram illustrating the impact of dust on Earth's systems. Dust influences atmospheric heating and cooling through its effect on radiation exchanges, both directly (1) and by influencing cloud development, i.e. acting as condensation nuclei (2). It therefore also impacts precipitation (3). Another potentially significant impact of dust over glacial timeframes is the role of deposited dust in reducing ice albedo and therefore enhancing ice melting (4). The deposition of dust fertilises both marine (5) and terrestrial (6) ecosystems, as well as contributing to soil formation. The role of dust in marine fertilisation is of most significance in High Nutrient Low Chlorophyll (HNLC) regions of the ocean. Through these processes dust also contributes indirectly to the biological C pump (e.g. 7) (see text for further details).

Figure 2: Environmental controls on the emission and deposition of dust. These include processes that influence dust entrainment, including shifts in wind regimes and dust plume pathways, and processes which influence sediment availability, such as rainfall, evapotranspiration and associated vegetation cover. In addition to these, hydroclimate variability, which influences sediment recharge in dust source areas, is also an important control on dust emissions in many areas. These factors are influenced by large scale climate variability, such as the migration in the position of synoptic scale circulation systems, which exert broad-scale control on dust emissions. Dust deposition is also influenced by many of the same processes, e.g. migration of plume pathways and precipitation at the deposition zone.

Figure 3: Major global dust sources, as mapped by the TOMS AAI frequency, and associated transport trajectories. Dark brown = high frequency of dust events (21-31 days/year), light brown = moderate frequency (7-21 days/year) (Modified after; Muhs, 2013; Prospero et al., 2002).

Figure 4. Satellite and field photographs of dust storms and dust supply areas. Panel (A) shows a Moderate Resolution Imaging Spectroradiometer (MODIS) image (Terra satellite) of a 3/11/2015 dust storm off the coast of Namibia (length of field of view ca. 1,100 km). Note the specific point sources supplying dust to the airstream. White box shows area of detail depicted in panel (B), which sows the Sossusvlei endorehic drainage basin ('Dead-end marsh') of the Tsauchab River from where a significant dust plume was emitted (length of view ca. $135 \mathrm{~km}$ ). White box shows area seen in the photograph in panel (C), that is, a westward-looking view over an inter-dune clay pan. The black box shows the area of detail photograph in panel (D), that is, desiccation cracked beige mud on the pan surface. Panel (E) is an Eumeteosat image from 3/03/2004 showing a dust being transported from the Sahara over the Atlantic (the Canary Islands are covered by the dust plume (Calima)). Note the colour contrast between the beige to buff dust and darker Sahara desert background. Length of field of view is ca. 2,150 km. Panel (F) shows MODIS image from Aqua satellite from 28/10/2003 showing dust being transported from central Australia towards the Pacific. Lake Eyre is in the top left of the image, and a large dust plume is being emitted from the northern section of the lake bed and the lower Channel Country Rivers. Note three main dust point sources in the image all have their own characteristic colour (Length of field of view is ca. $800 \mathrm{~km}$ ).

Figure 5: Conceptual diagram demonstrating the utility of different geomorphic positions for recording long-range dust. Panel $\boldsymbol{A}$ ). geologic archives in different geomorphic positions (denoted by letters). Panel $\boldsymbol{B}$ ). indicates the relative input from different sedimentary processes to each geomorphic setting. Panel $\boldsymbol{C}$ ). indicates the sedimentary (textual) composition (the sedimentary 
signature) in each geomorphic setting, while panel $\boldsymbol{D}$ ). indicates the geochemical composition/fingerprint. Position A , high in the landscape, is remote from local alluvial and aeolian sediment sources (panel $\boldsymbol{A}$ ).). It receives dominantly long-range dust input, but also local dust and trace amounts of colluvium (panel B).). In this setting, long-range dust and local dust cannot be distinguished using sedimentary composition because local dust is winnowed to a similar size of that of long-range dust (panel $\boldsymbol{C}$ ).), however the three sedimentary sources may be distinguished geochemically (panel $D$ ).). In position $B$ which receives long-range, local dust and colluvium, longrange dust can be distinguished using either its texture or geochemistry. In position C, alluvial input dominates while there is also significant local dust input. Long-range dust in this setting is overwhelmed by local material and is identifiable only if its input is significant enough to influence the geochemical or textual composition of the alluvium/local dust. Position D receives alluvial, local and long-range dust. Due to winnowing the three sources may have the same textual fingerprint, however long-range dust is geochemically distinctive.

Figure 6: Radiogenic isotopes signatures of potential dust source sediments from Southern Hemisphere dust sources in Australia, southern Africa, South America and New Zealand. Grey boxes denote the region of geochemical overlap between the different continents. Panel $\boldsymbol{A}$ ). shows ${ }^{143} \mathrm{Nd} /{ }^{144} \mathrm{Nd}$ ratios and $\left.\boldsymbol{B}\right) .{ }^{87} \mathrm{Sr} /{ }^{86} \mathrm{Sr}$ ratios. Panel $\boldsymbol{C}$ ). displays the same data plotted against each other, i.e. ${ }^{87} \mathrm{Sr} /{ }^{86} \mathrm{Sr}$ versus ${ }^{143} \mathrm{Nd} /{ }^{144} \mathrm{Nd}$ (expressed as $\varepsilon \mathrm{Nd}$ ). In panel $\boldsymbol{D}$.) ${ }^{208} \mathrm{~Pb} /{ }^{204} \mathrm{~Pb}$ versus ${ }^{207} \mathrm{~Pb} /{ }^{206} \mathrm{~Pb}$ ratios are plotted for different Southern Hemisphere dust sources (note that some of Australian $\mathrm{Pb}$ data are known to be contaminated, see Figure 11). Pb data from Marx et al., (2010), Kamber et al., (2010), Gili et al., (2016), Vallelonga et al., (2010) and De Deckker et al., (2010). Sr and Nd data from Kamber et al., (2005), Gingele et al., (2005), Grousset et al. (1992), Revel-Rolland et al., (2006), Delmonte et al., (2004), Gaiero et al., (2007), Sugden et al., (2009), Gili et al., (2017) and Basile et al., (1997).

Figure 7: Conceptual model showing the temporal relationship between $\boldsymbol{A}$ ). climate phase, $\boldsymbol{B})$. sediment recharge/production and sediment availability and, C). corresponding dust emissions (modified after Kocurek, 1998).

Figure 8: Discharge regime for rivers in the Lake Eyre Basin. The annual discharge regime displays a distinctive summer maximum separated by either low or no flow during between Autumn and Spring (After Knighton and Nanson, 2002).

Figure 9: Australian dust concentration, determined using ${ }^{210} \mathrm{~Pb}$ activity, measured at Hokitika, South Island, New Zealand. A) Monthly data smoothed with a 3-point running mean. Grey bars indicate the months December to March. During this period the rivers of the Channel Country in Australia's Lake Eyre Basin typically record discharge (see Fig., 8), recharging dust source areas with fine sediment (After Marx et al., 2005). B). Concentration of Australian dust in New Zealand (as shown in panel A) plotted alongside the Southern Oscillation Index (SOI).

Figure 10: Changing dust composition as recorded in a peat core from the Snowy Mountains, Australia. A). $\mathrm{Pb}$ isotopes $\left({ }^{206} \mathrm{~Pb} /{ }^{204} \mathrm{~Pb}\right)$ record the decrease in radiogenic ratios after $1850 \mathrm{CE}$ associated with onset of mining and smelting in Australia (note the reverse $y$-axis). Letters on the plot indicate; $\mathrm{A}$ early Australian $\mathrm{Pb}$ mining, $\mathrm{B}$ the start of $\mathrm{Pb}$ mining at Broken Hill (which was to become the Worlds' largest $\mathrm{Pb}$ mine), $\mathrm{C}$ the introduction of leaded gasoline and, $\mathrm{D}$ its subsequent phasing out. The $\mathrm{Y} / \mathrm{Ho}$ ratio of the deposited dust is also plotted on the figure. The increase in this 
ratio after 1900 CE reflects the beginning of widespread fertiliser use in the Murray Darling Basin, which became more pronounced from the $1980 \mathrm{~s}$ CE. The grey bar indicates the natural range of $\mathrm{Y} / \mathrm{Ho}$ in upper continental curst (modified after Marx et al., 2014b). In panel B) increasing industrial metal concentrations in the deposited dust is demonstrated by the increasing concentration of $\mathrm{Zn}$ and Sb plotted as a ratio against Sc, which is not influenced by anthropogenic activity (Marx et al., 2010).

Figure 11: Lead contamination overprinting the geochemical signature of both dust and dust source sediments in eastern Australia. A). $\mathrm{Pb}$ isotope ratios of dust deposited in peat mires in the Snowy Mountains (Marx et al., 2010) plotted alongside the composition of Broken Hill ore (Townsend and Snape, 2002). Dust deposited after 1850 CE plots along a linear mixing array between uncontaminated pre 1850 CE dust and Broken Hill ore. By comparison dust deposited before $1850 \mathrm{CE}$ is free from contamination and plots in a cluster, reflecting the natural $\mathrm{Pb}$ composition of dust from the Murray-Darling Basin (MBD). In panel $\boldsymbol{B}$ ), surface sediment samples collected from dust source areas in the MDB (data from De Deckker et al., 2010) plot along the same linear mixing array between pre 1850 CE dust and Broken Hill ore, indicating they are contaminated with industrial $\mathrm{Pb}$. Other potential dust source sediments from South Australia are also plotted on the figure (data from Vallelonga et al., 2010). Some of these samples again plot along the linear mixing array, implying they are also contaminated with Broken Hill $\mathrm{Pb}$, others, however plot outside of the array, indicating they free from significant $\mathrm{Pb}$ contamination (see Kamber et al., 2010).

Figure 12: Map showing the $\mathrm{Nb} / \mathrm{Ta}$ ratio of potential dust source sediments from eastern Australia. The position of the two major dust producing basins in Australia, the Lake Eyre Basin, in the north, and the Murray-Darling Basin (MDB), in the southeast, are indicated on the map. The figure demonstrates the ability to separate different dust source regions from each other, where the Lake Eyre Basin is characterised by high Nb/Ta ratios, the Darling River in the north of the MDB is characterised by intermediate ratios and the southern MDB by low ratios.

Figure 13: Satellite images of the Channel Country in the Lake Eyre Basin and extended trace element plots for selected samples. Panel A) shows a continent-scale summary map of standing water coverage in Australia since 1987 (Water Observations from Space (WOfs); warm colours indicate relatively infrequent water coverage, green to blue colours indicate frequent water coverage (Compiled by Geoscience Australia from water coverage observed on Landsat satellite imagery (Commonwealth of Australia (Geoscience Australia) 2017). The white rectangle indicates the area shown in panel B). Panel B) displays the region known as the 'Channel Country' and covers an area of approximately $1,200 \mathrm{~km}$. It shows water inundation frequency overlaying a Google Earth satellite image. The location of four surface sediment samples from the Diamantina River $(u, m, l)$ and one from the Cooper Creek (c) are indicated on the image. Panel C) shows an extended trace element diagram for the three Diamantina sediment samples normalised to upper continental crust (UCC; values are MuQ from Kamber et al.; 2005). Panel (D) shows a comparison of the average Diamantina River sediments (from panel C) with 1SD errors plotted alongside the Cooper Creek sample. Panel (E) shows the average trace element chemistry of the three Diamantina samples ratio against the Cooper Creek sample, where the ratio deviates significantly from 1 indicates resolvable differences in chemical composition between the two rivers. 
Figure 14: The use of geochemical modelling to unmix the contribution of different dust sources to a collected dust sample. In Panel $\boldsymbol{A}$ ). the trace element chemistry of two potential dust source sediments from New Zealand (a New Zealand loess) and Australian source sediment (from the Murray-Darling Basin) are shown normalised against a dust sample collected from a high volume sampler located in New Zealand's Southern Alps on 7/2/2009. Overall the chemistry of the dust sample is best approximated by the sediment from the Murray Darling Basin, as indicated by the $\sum_{D}$, the sum of deviates between the dust sample and the potential source sediments. For many elements, i.e. those indicated by the grey panels on the figure, the chemistry of the dust is intermediate between that of the NZ loess and the Murray-Darling Basin sediment. This implies the dust sample represents a mixture of these two sources. The mixture that best approximates the chemistry of the collected dust is indicated on the provenance diagram in panel $\boldsymbol{B})$. In that diagram 0 $\%$ Australian dust equates to $100 \%$ NZ loess. The inflection point represented by the vertical line represents the optimal mixture of these two sources with the lowest $\sum_{D}$ equating to a mixture of 0.8/0.2 Murray-Darling Basin sediment to NZ loess. This dust sample shown in this example was collected following a period of dust activity in Australia, during which airmass trajectories were conducive to the transport of dust to New Zealand (see Marx et al., 2014a).

Figure 15: Contaminants in dust as an indicator of provenance. Panels $\boldsymbol{A}$ ). and $\boldsymbol{B}$ ). show $\mathrm{Pb}$ and $\mathrm{Cu}$ concentrations in dust samples collected from ice ('Red Dusts' and 'Grey Dusts') on the Fox and Franz Josef Glaciers, West Coast, South Island, New Zealand, and from dust traps located along the coastal plain of West Coast, New Zealand. As the metal contaminate concentration increases, the percentage of Australian dust, as independently estimated using a trace element provenance model, also increases (after Marx et al., 2008). Panels $\boldsymbol{C}$ ). and $\boldsymbol{D}$ ). show semi-volatile organic contaminants (SOCs) collected alongside dust samples at Temple Basin, Arthur's Pass, Southern Alps New Zealand. Similar to metal contaminants as the SOC increases, the independently estimated Australian dust content increases. The $p$ value was calculated using Spearman's rho (after Lavin et al., 2012).

Fig. 16: Conceptual diagram showing the effect of various admixtures of sediment on the ability to identify dust geochemically. When the mass of long-range dust in a sedimentary deposit is high, relative to other sources of sediment, a unique identifiable geochemical signature is produced. This allows the contribution of long-range dust to be quantified. If the input of long-range dust is low, however, its geochemical signature may not appreciably alter that of the resulting admixture. Therefore a long-range dust component cannot be identified geochemically.

Figure 17: Panel $\boldsymbol{A}$ ). Conceptual diagram illustrating sediment recycling within dust transport systems. Panel B) shows the outline and digital elevation model for Australia's MBD. Sediment is generated in the elevated humid fringes (dark shading) of the basin (e.g. the Snowy Mountains) before being transported by rivers into the drier centre and western regions of the Basin (light shading). From there, sediment be entrained by the wind and transported, by the prevailing westerly winds in this case, back over its protosouce region. The humid fringes of large dust producing basins often contain excellent geologic dust repositories, e.g. alpine cirque lakes and peat bogs. However, differentiating dust geochemically in these environments can be complicated by sediment recycling. In the case of Australia's MDB, despite sediment recycling occurring, dust sourced from the lower Basin can still be geochemically identified in the sediments of the upper basin. This is demonstrated in panel $\mathrm{C}$ ) where the $\mathrm{Ba} / \mathrm{Lu}$ and $\mathrm{Tm} / \mathrm{Li}$ ratios of Snowy Mountains sediment is distinctive from that of downstream dust sources (the Murray and Murrumbidgee Rivers and their floodplains in this 
case) (after Marx et al., 2011). Note the location of the sediments plotted in panel $\boldsymbol{C}$ ) is indicated on panel B).

Figure 18: Location of the reconstructed dust records mentioned in the text and the position of the major dust producing basins in Australia. Details of the NCL record are provided in McGowan et al., (2008) and Petherick et al., (2008), the USC record in Marx et al., (2014b) and the OMR record in Marx et al., (2009).

Figure 19: Australian dust flux during the mid to late Holocene, as recorded in the OMR record from New Zealand (panel $\boldsymbol{A}$ ) and the NCL record from south-eastern, Queensland, Australia (panel $\boldsymbol{B}$ ). Major deposition phases are indicated on each panel. The numbers on both panels indicate the position of samples for where the source area fingerprints are indicated in Figures 20 and 21 . Note the geochemically modelled Australian dust component is plotted in panel A (see Marx et al., 2009) and the long-range dust component is shown in panel B (see McGowan et al., 2008).

Figure 20: The geochemically modelled source area fingerprint for selected dust samples deposited in the OMR site, New Zealand. Each panel shows the most likely source regions for a specific dust sample from the OMR core. The position in the OMR core from where the sample is from indicated by the corresponding letters in Figure 19A. The ten best matching potential source sediments (from a database of $>200$ samples) is shown plotted for each dust sample. The size of the circles indicates the relative degree of match for each potential dust source sediment; larger circles indicate a stronger geochemical match.

Figure 21: The geochemically modelled source area fingerprint of dust samples deposited in the NCL site, southeastern Queensland. Each panel shows the most likely source regions for a specific dust sample from the NCL core. The position in the NCL core from where the sample is from indicated by the corresponding letters in Figure 19B. The ten best matching potential source sediments (from a database of $>200$ samples) is shown plotted for each dust sample. The size of the circles indicates the relative degree of match for each potential dust source sediment; larger circles indicate a stronger geochemical match. Note the geochemical provenance of sample has been re-modelled from those originally presented in Petherick et al., (2009).

Figure 22: Long range dust flux recorded in the NCL record from North Stradbroke Island, southeast Queensland (modified after Petherick et al., 2008). The plotted data represents the long-range dust component as geochemically separated from local sand input using the approach outlined in McGowan et al., (2008).

Figure 23: Dust flux in the USC site, Snowy Mountains, Australia, between 1700 and 2006 CE. Three main deposition phases are indicated on the figure. Letters on the plot indicate; $A$ dust pulses during the Little Ice Age; $B$ the onset of agriculturally induced wind erosion; $C$ the Federation Drought; $D$ the 1914 drought; $E$ the Dust Bowl era; $F$ the early 1970s and $G$ 1980s CE droughts; and $H$ implementation of soil conservation measures (after Marx et al., 2014b).

Figure 24: The source area fingerprint match of dust deposited in the UCS site in the Snowy Mountains. The three phases refer to; Phase 1, pre-agricultural, 1700-1879 CE. Phase 2, agricultural dust emissions, 1880-1989 CE. Phase 3, dust emissions following the implementation of improved 
soil conservation measures, 1990-2006. Figure 23 shows the dust flux during each phase (modifed after Marx et al., 2014b). 
Highlights:

- Mineral dust is critical part of the Earth system, therefore reconstructing dust records is important.

- Dust is a very sensitive proxy of both past and current climatic and environmental conditions.

- Fingerprinting dust sources allows significantly more information to be gained from dust records.

- Dust emissions record broad-scale landscape change, particularly hydro-climate variability.

- Dust sensitively tracks anthropogenic impacts through changing emission rates and chemistry.

- Examples from Australia show how dust emissions respond to palaeo-environmental and human induced change. 
1 Radiation

Budget

Cloud

Formation

2

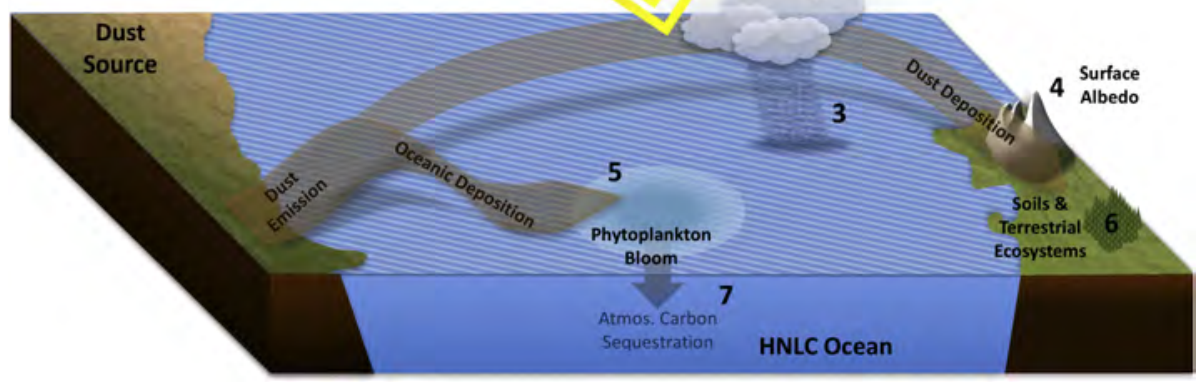

Figure 1 


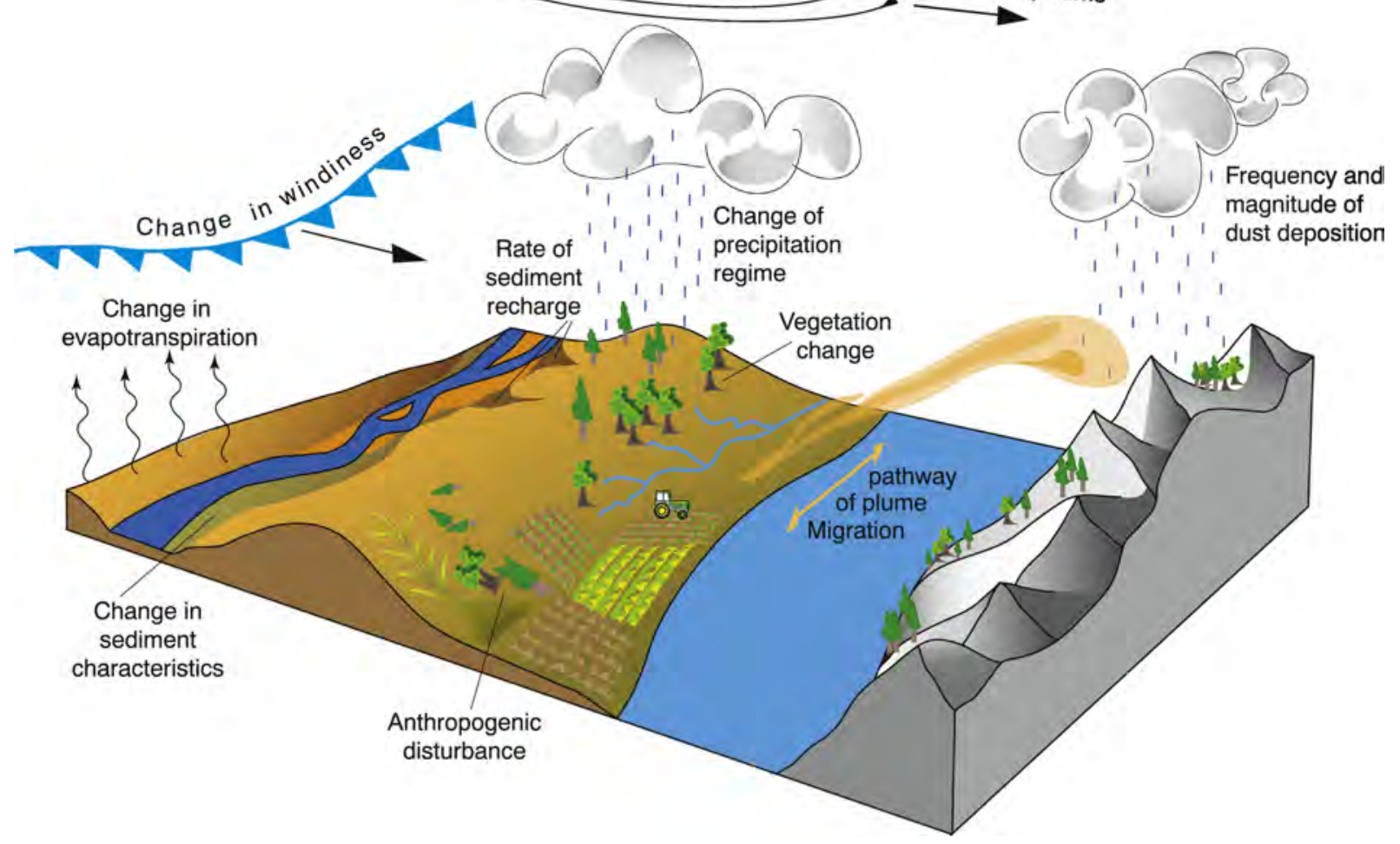

Figure 2 


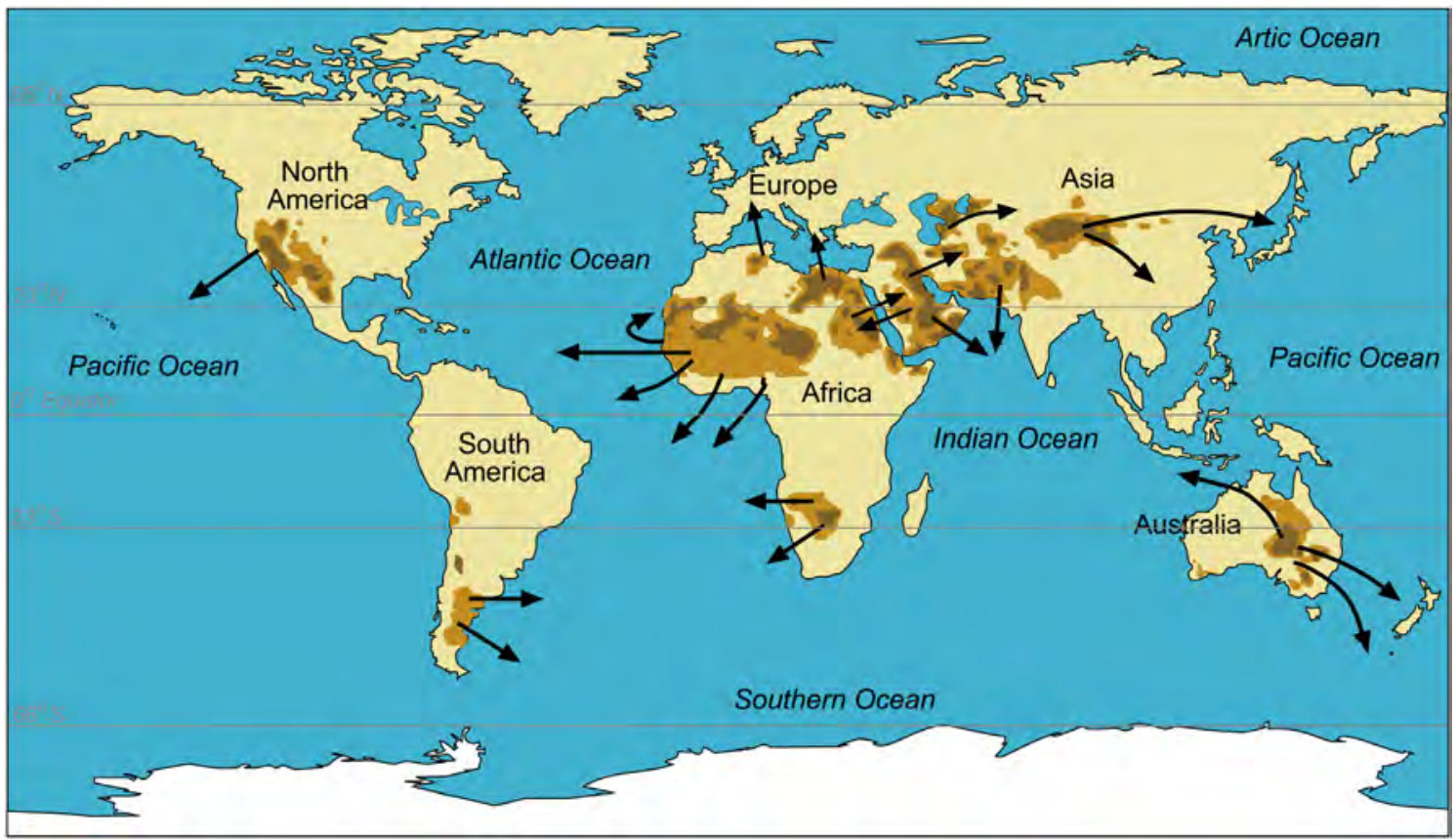

Figure 3 


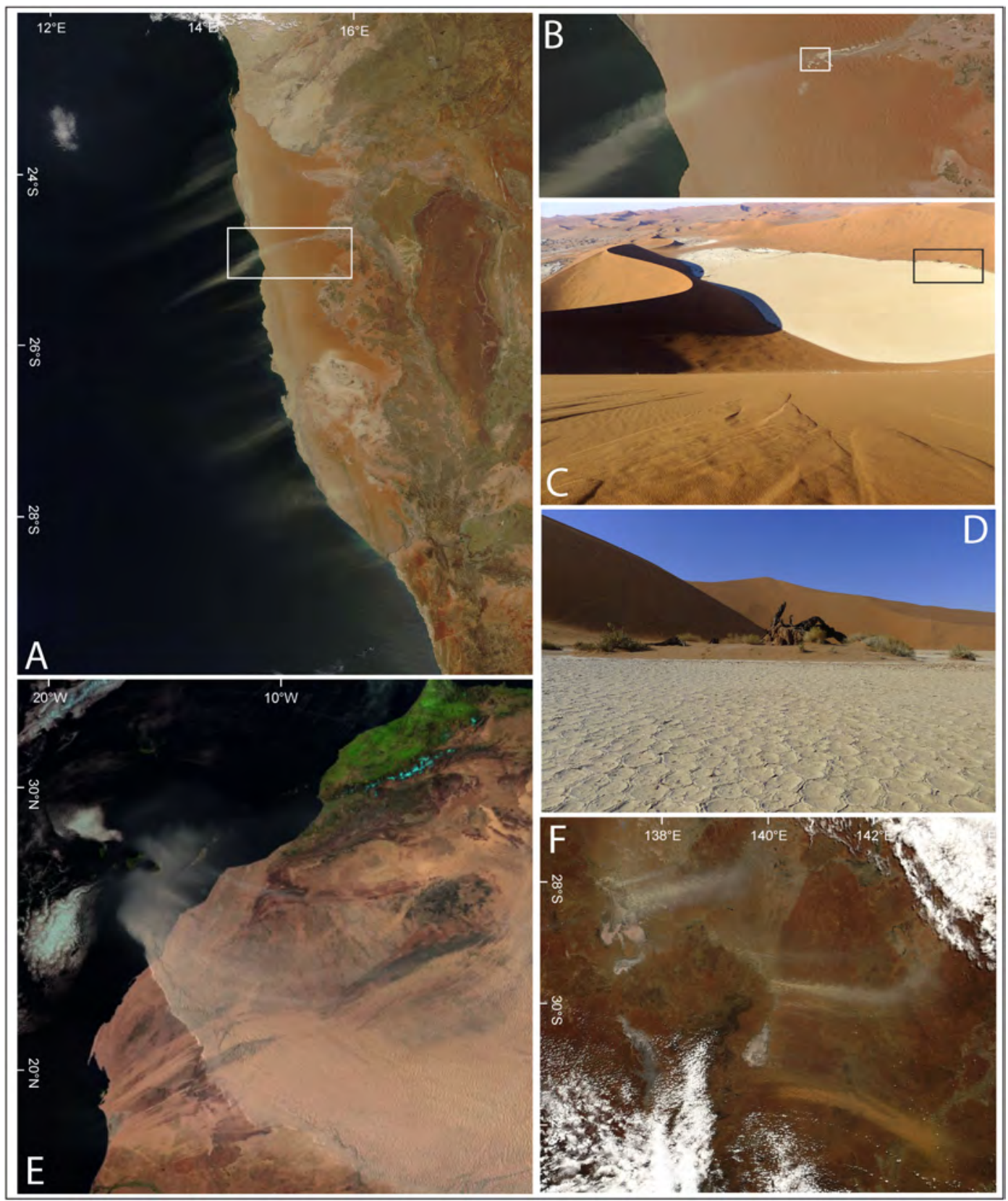

Figure 4 


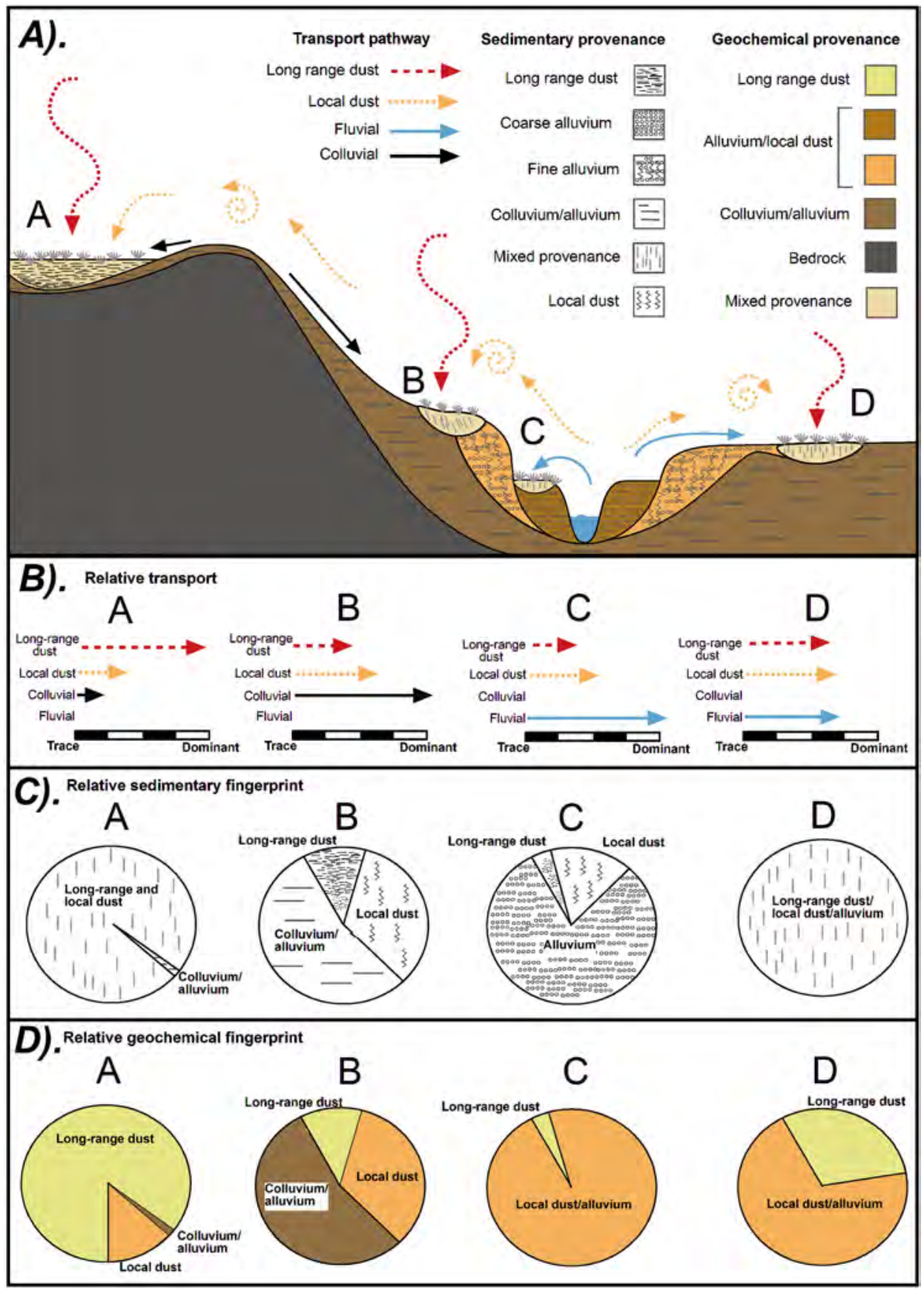



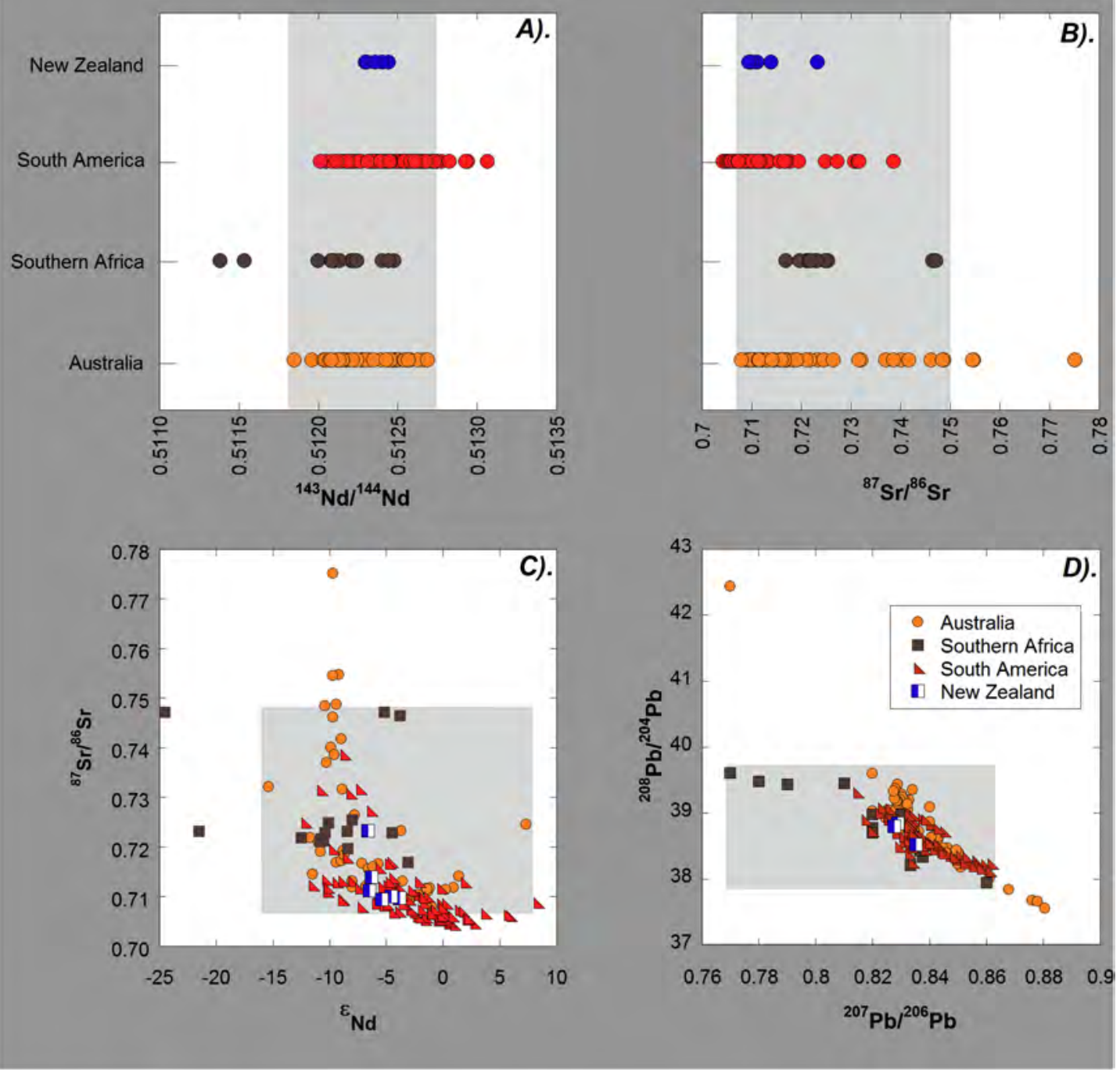

Figure 6 


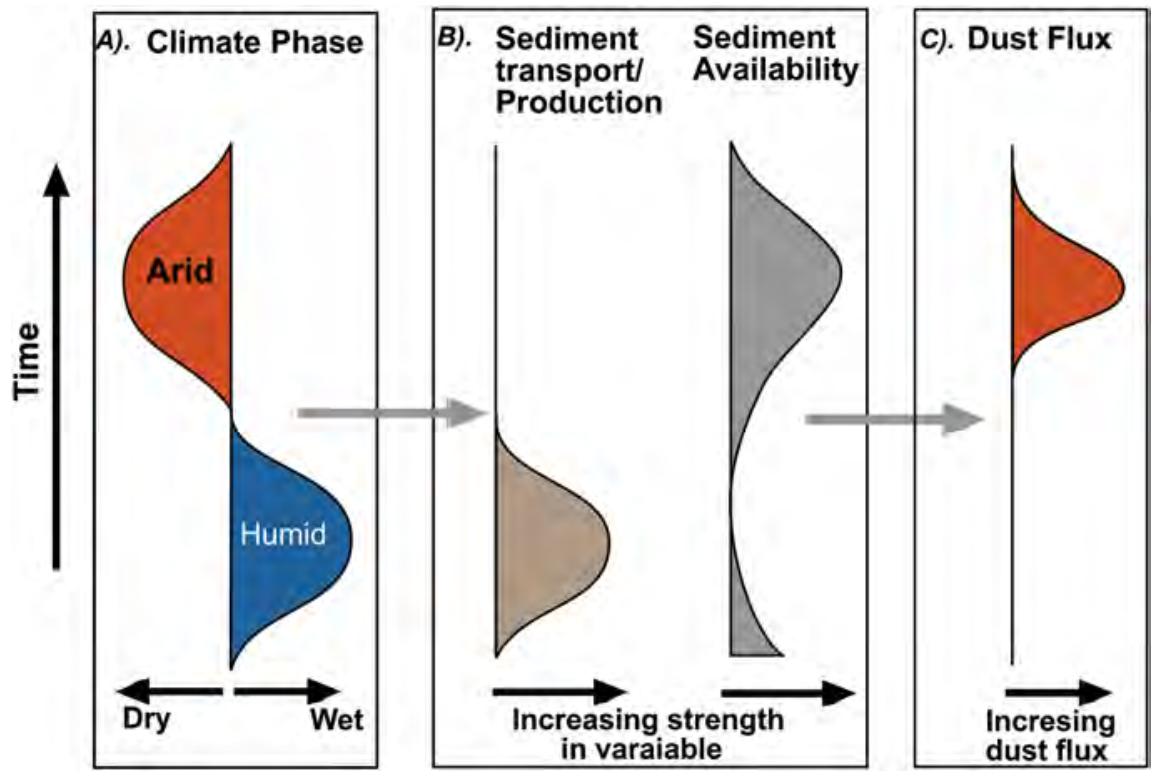

Figure 7 


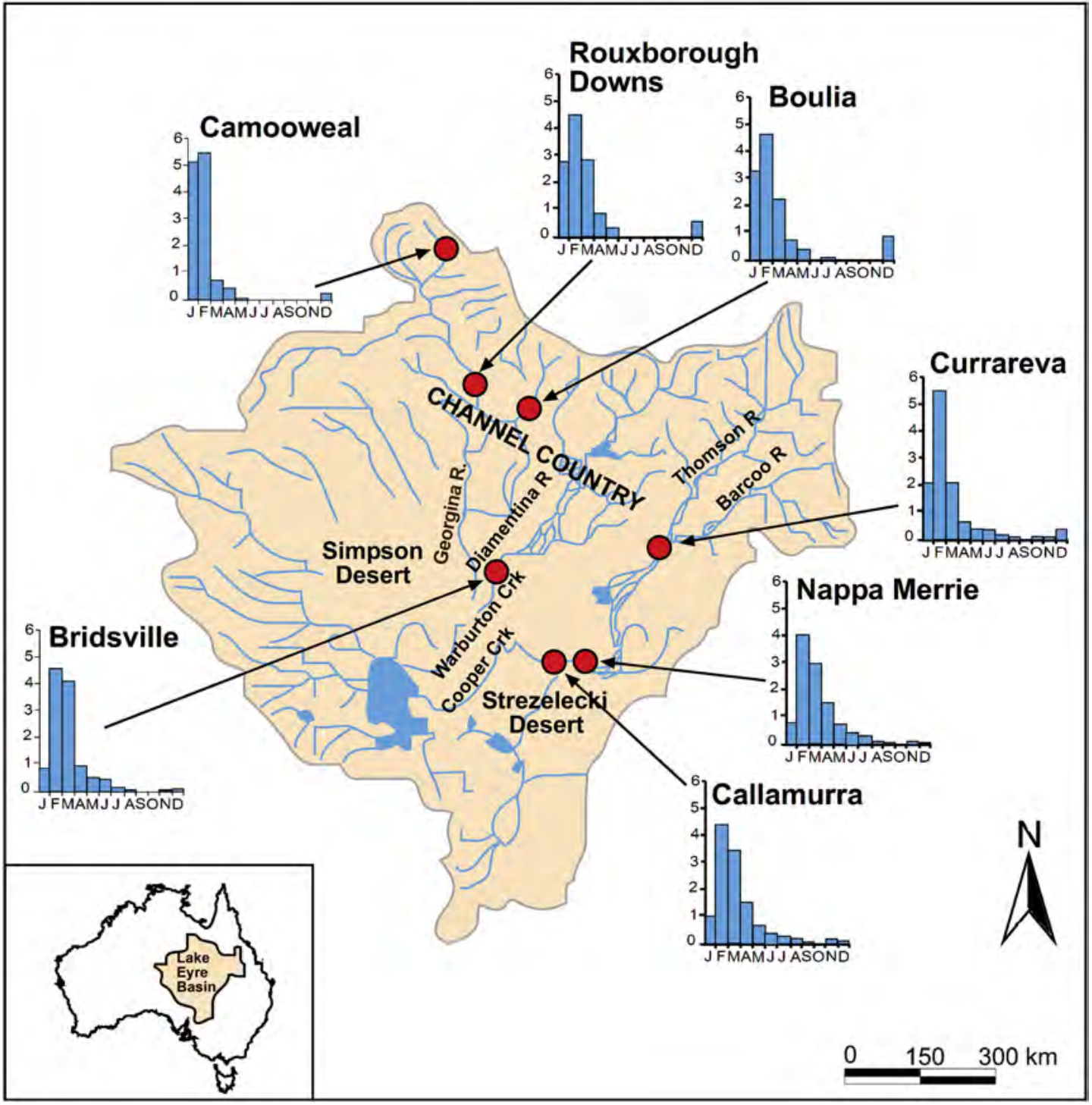

Figure 8 

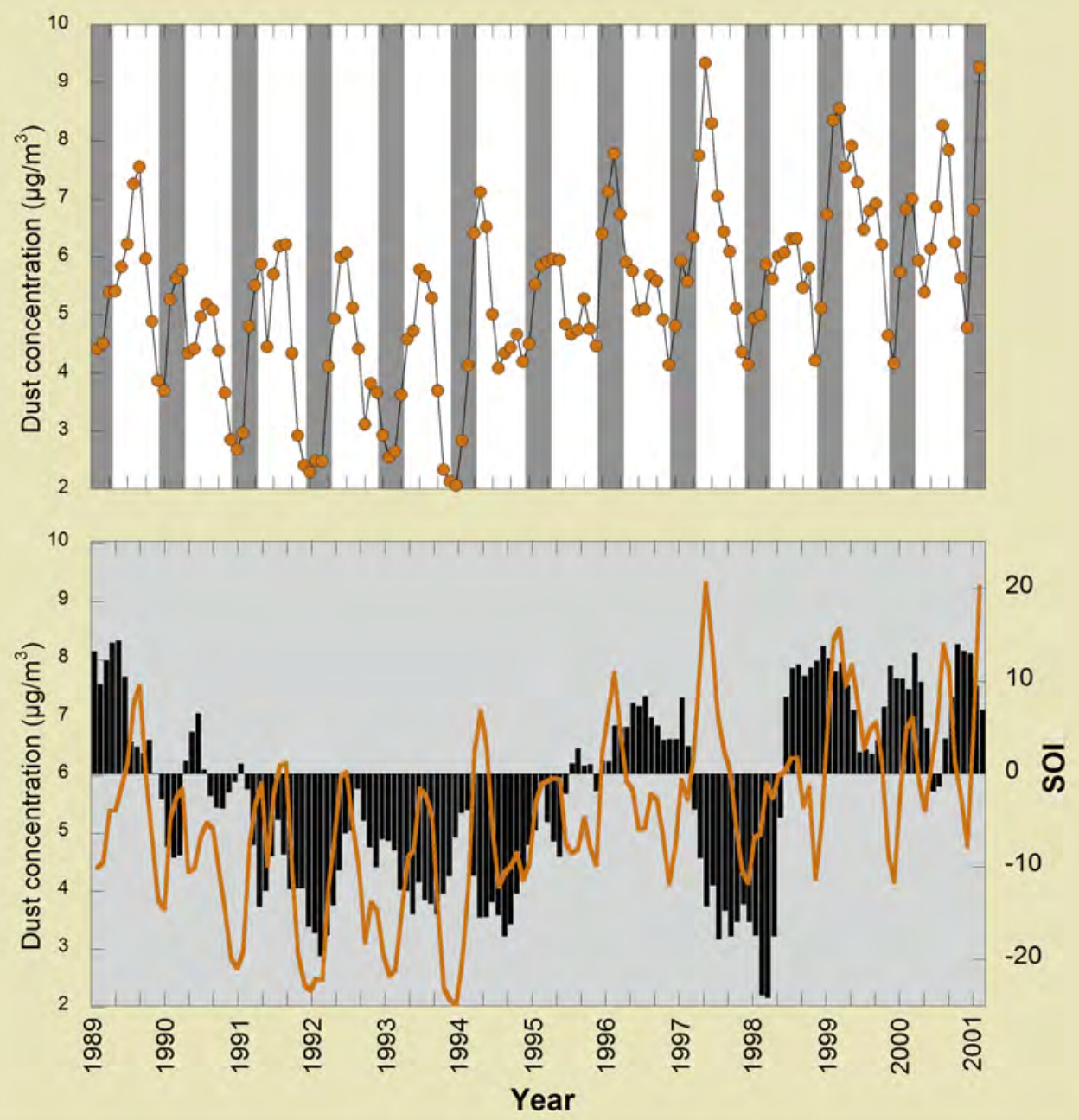

Figure 9 


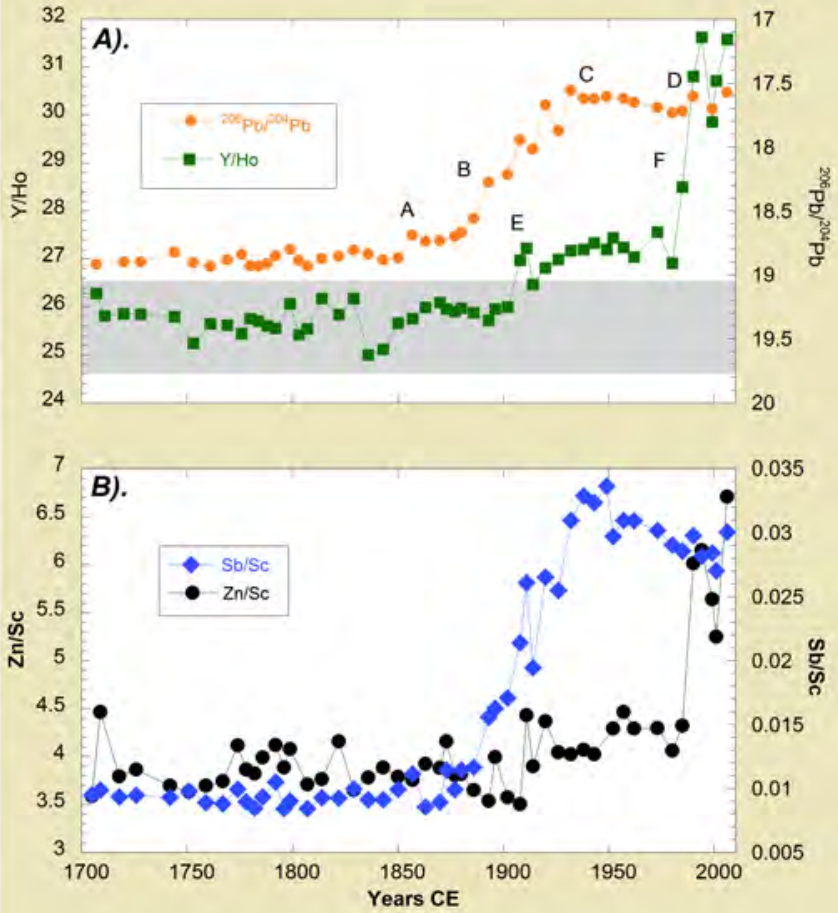

Figure 10 

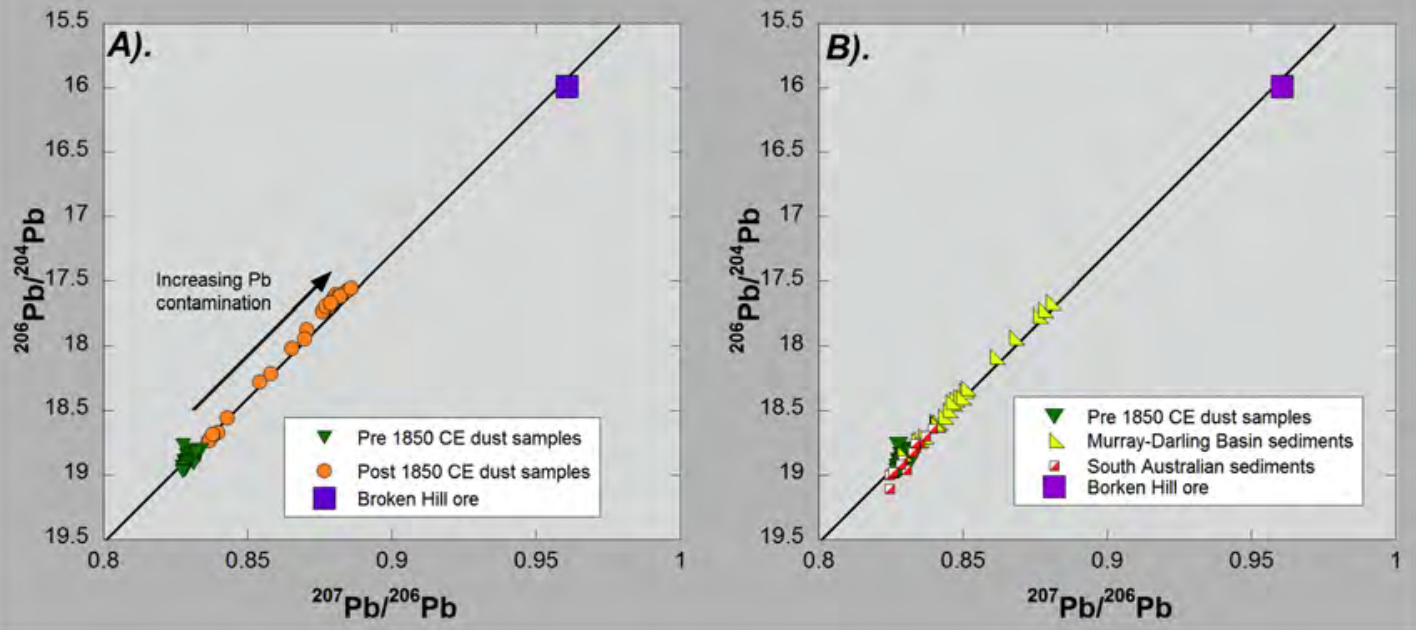

Figure 11 


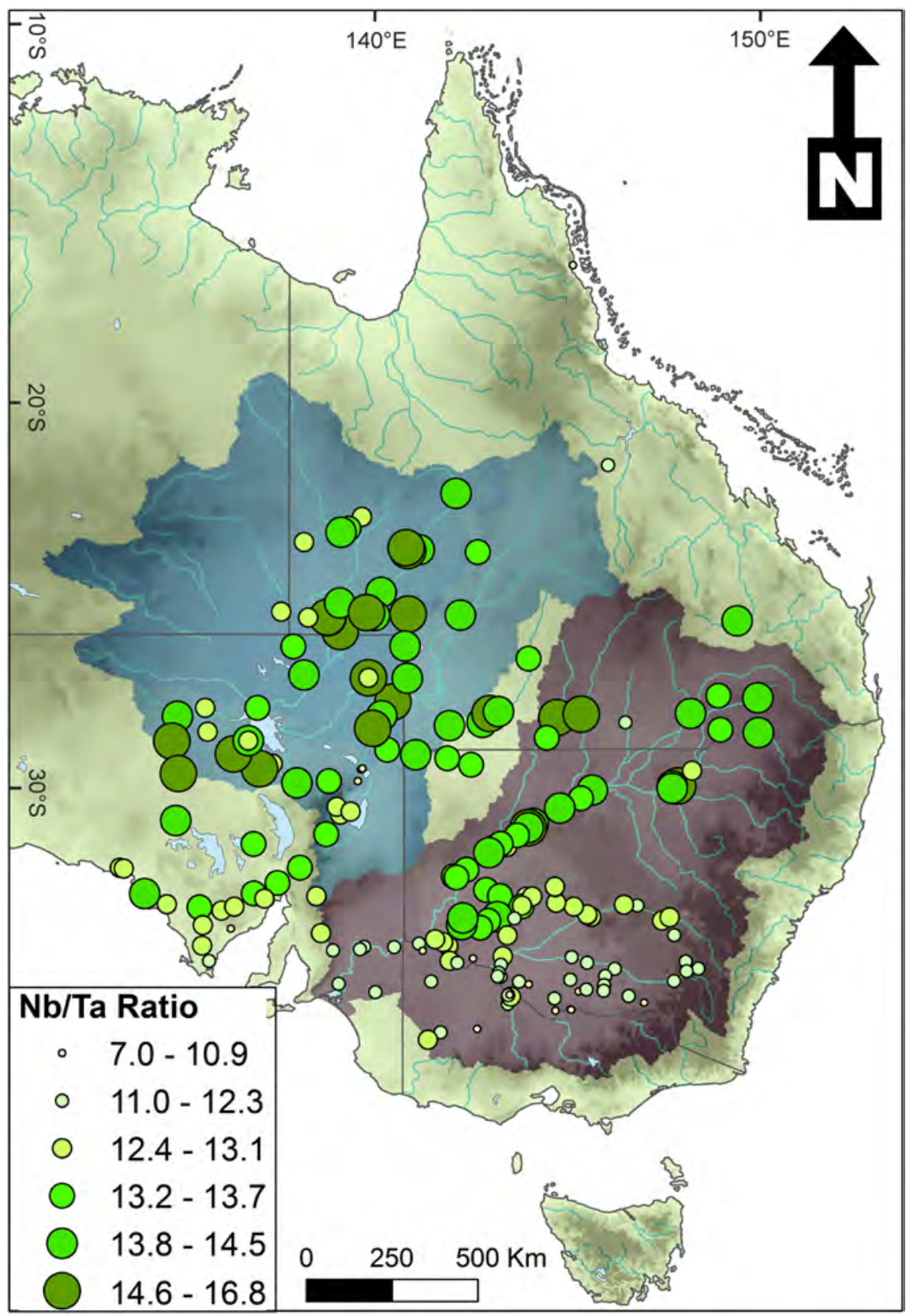



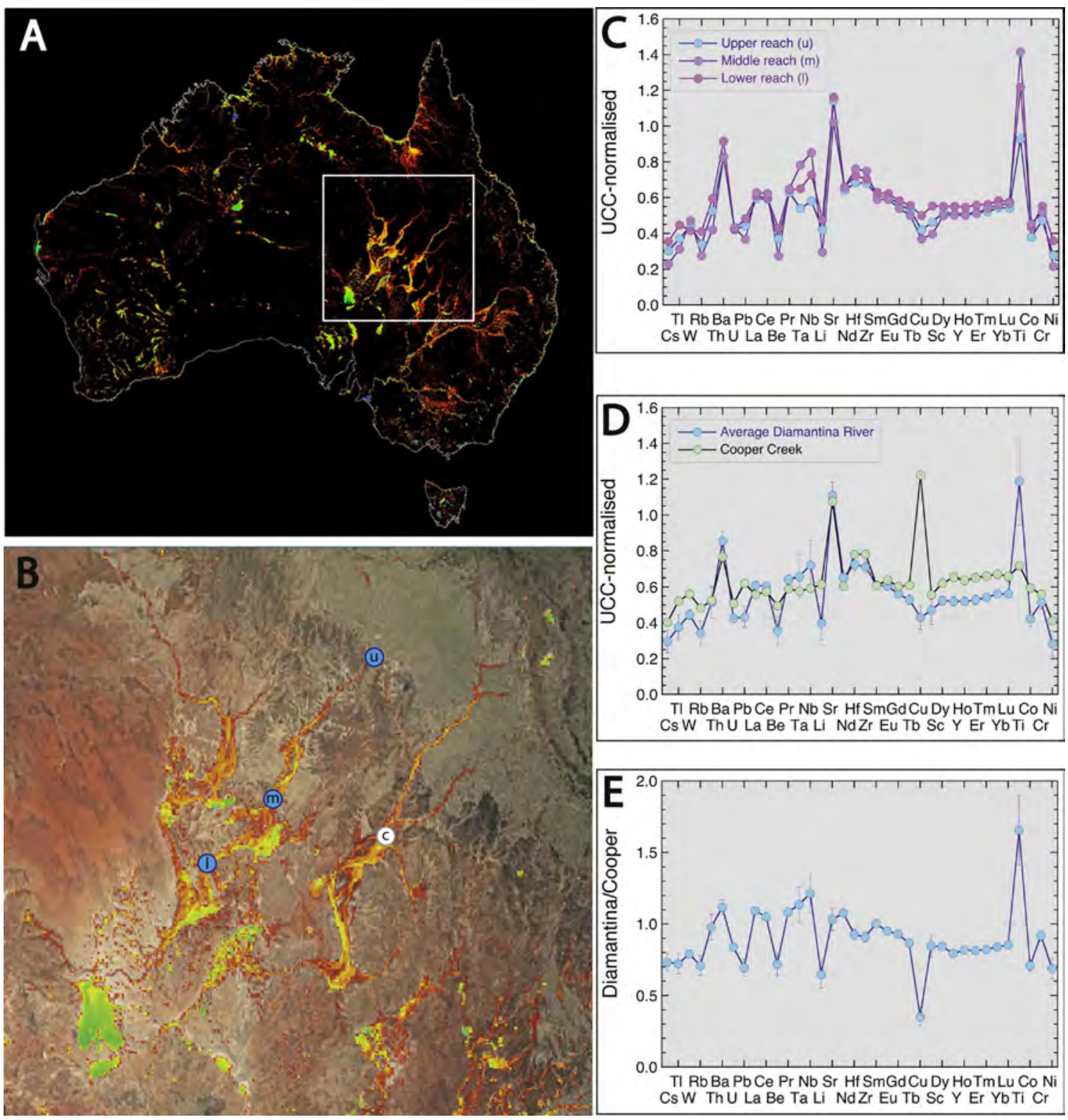

Figure 13 


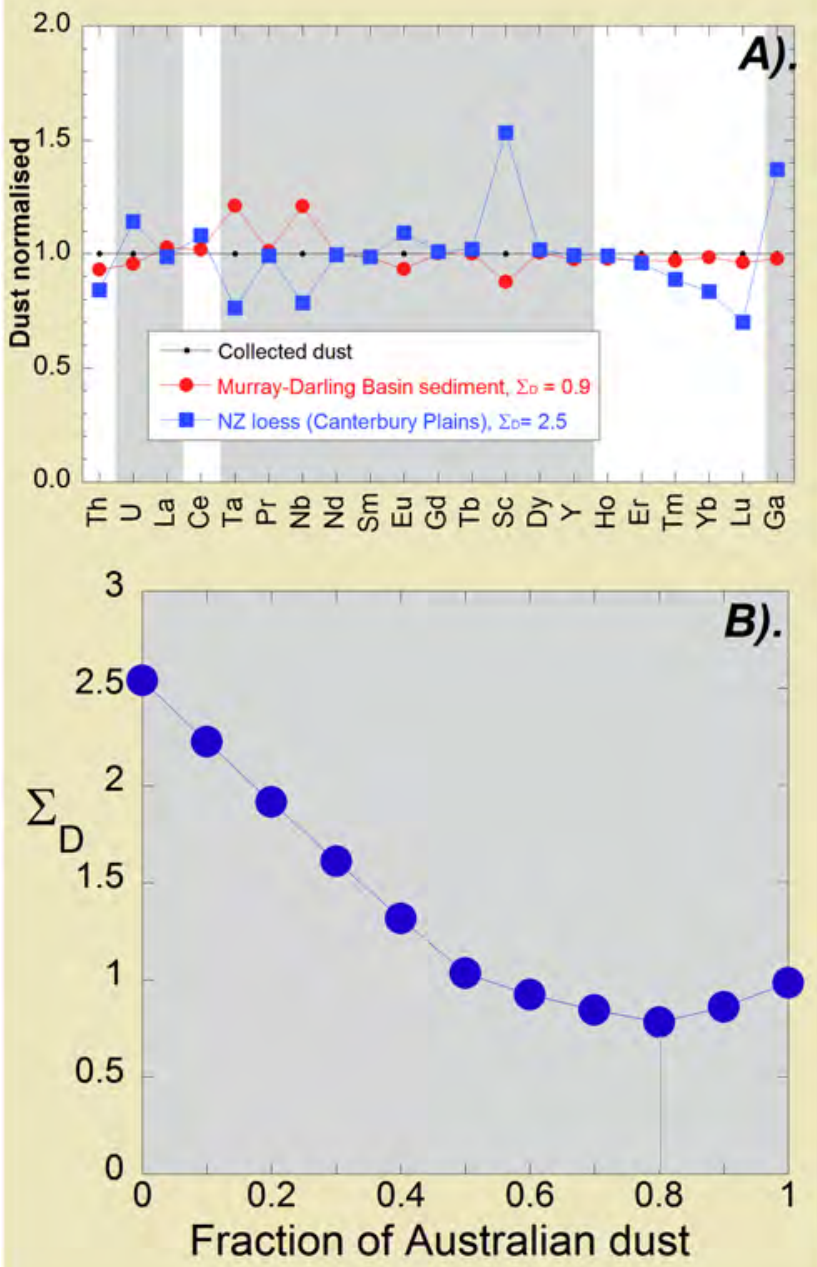

Figure 14 


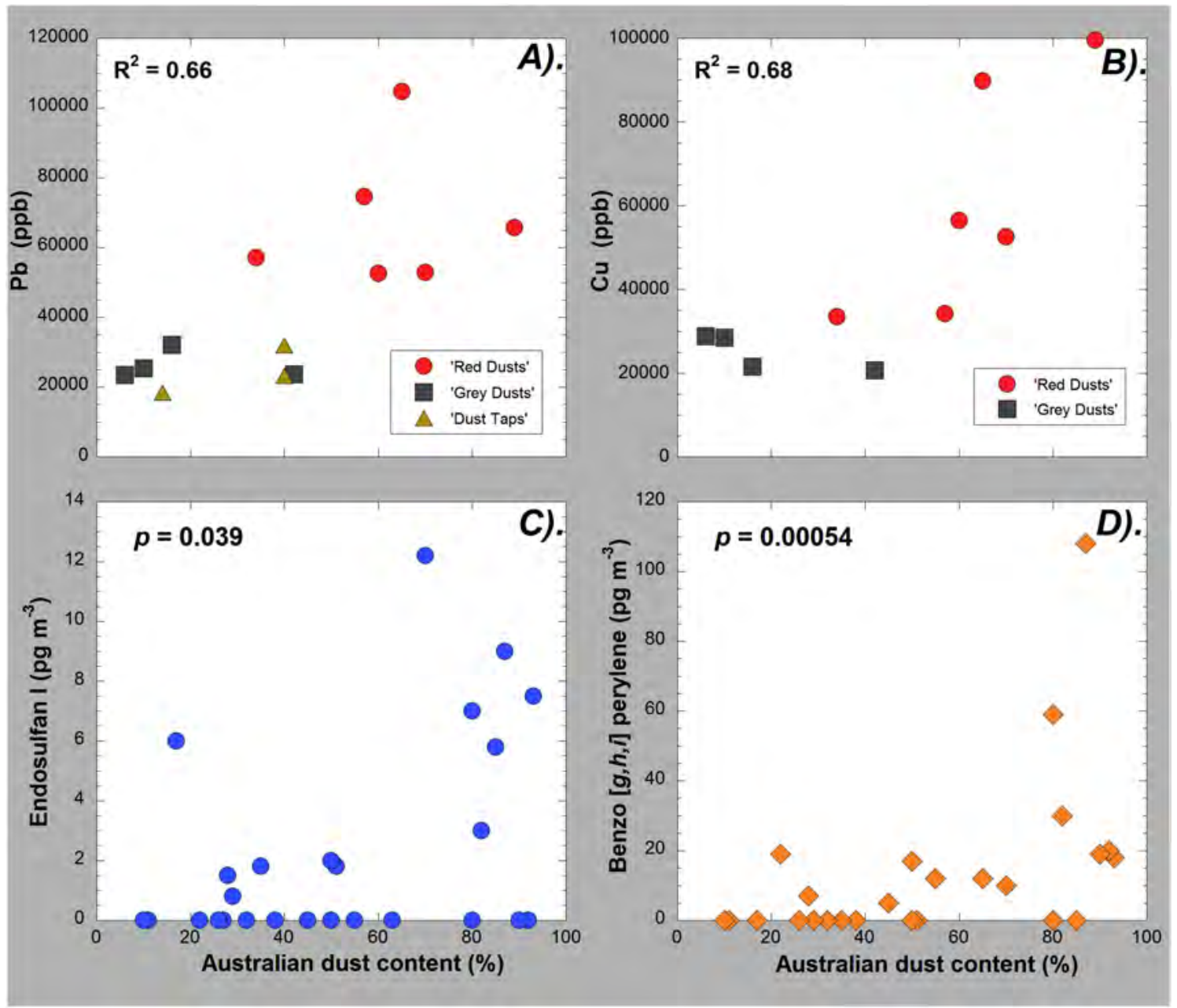

Figure 15 
Signature of

long-range dust

Signature of

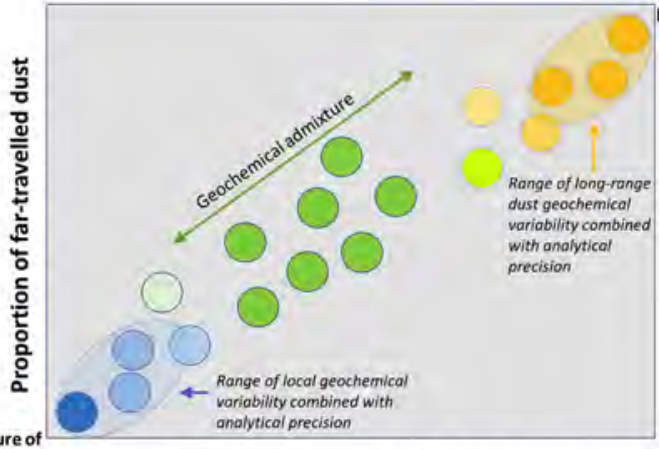

local sediment

Difference in geochemical signature

Figure 16 


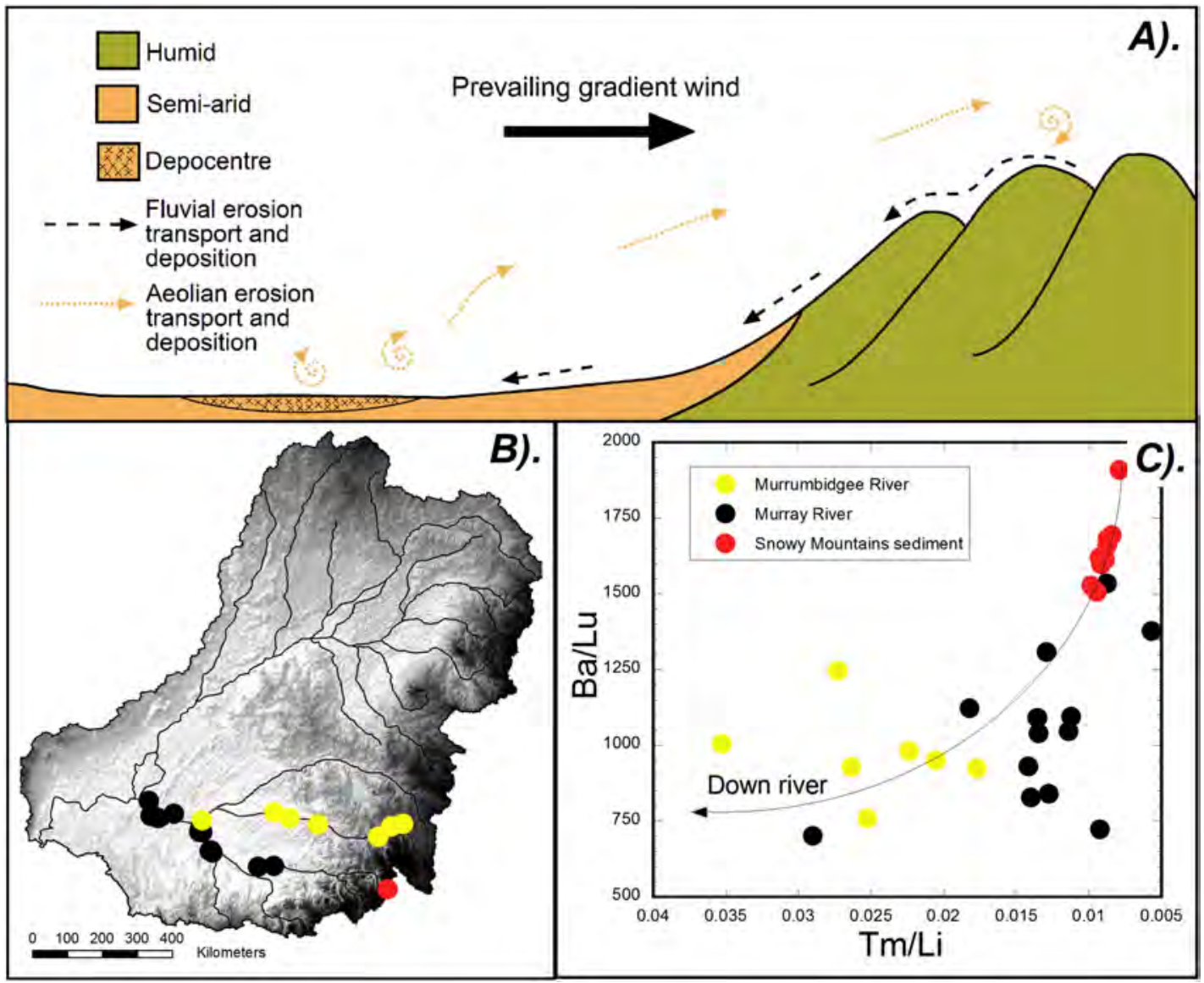

Figure 17 


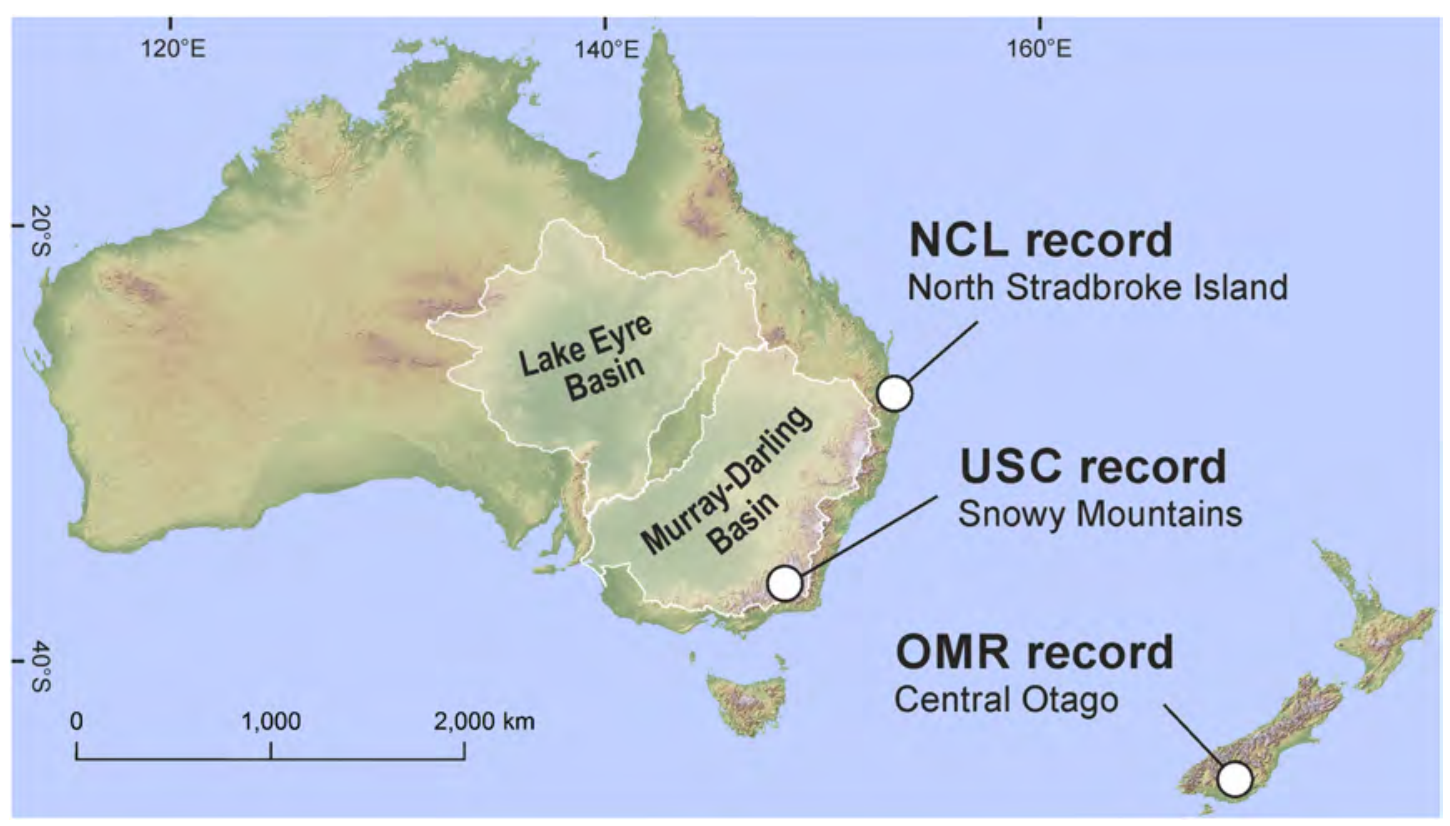

Figure 18 


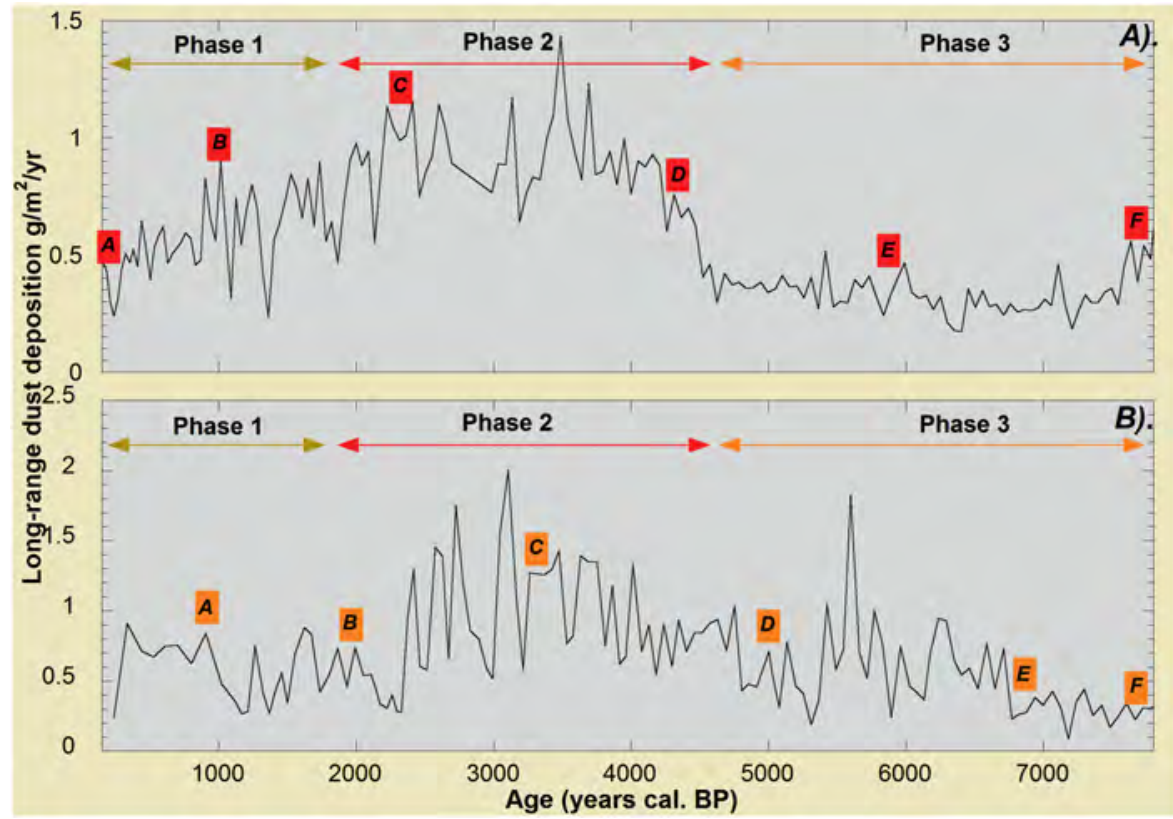

Figure 19 

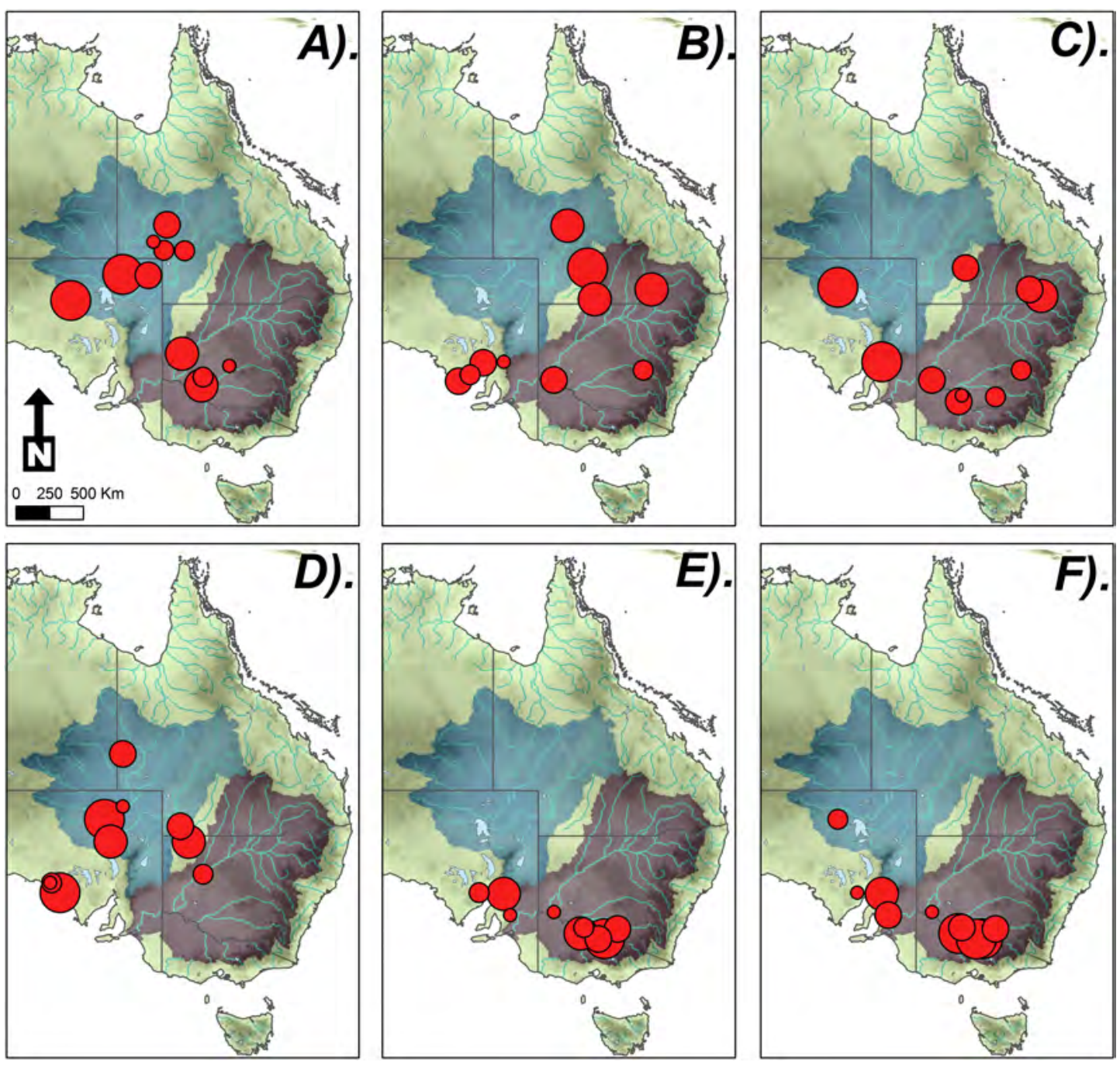

Figure 20 

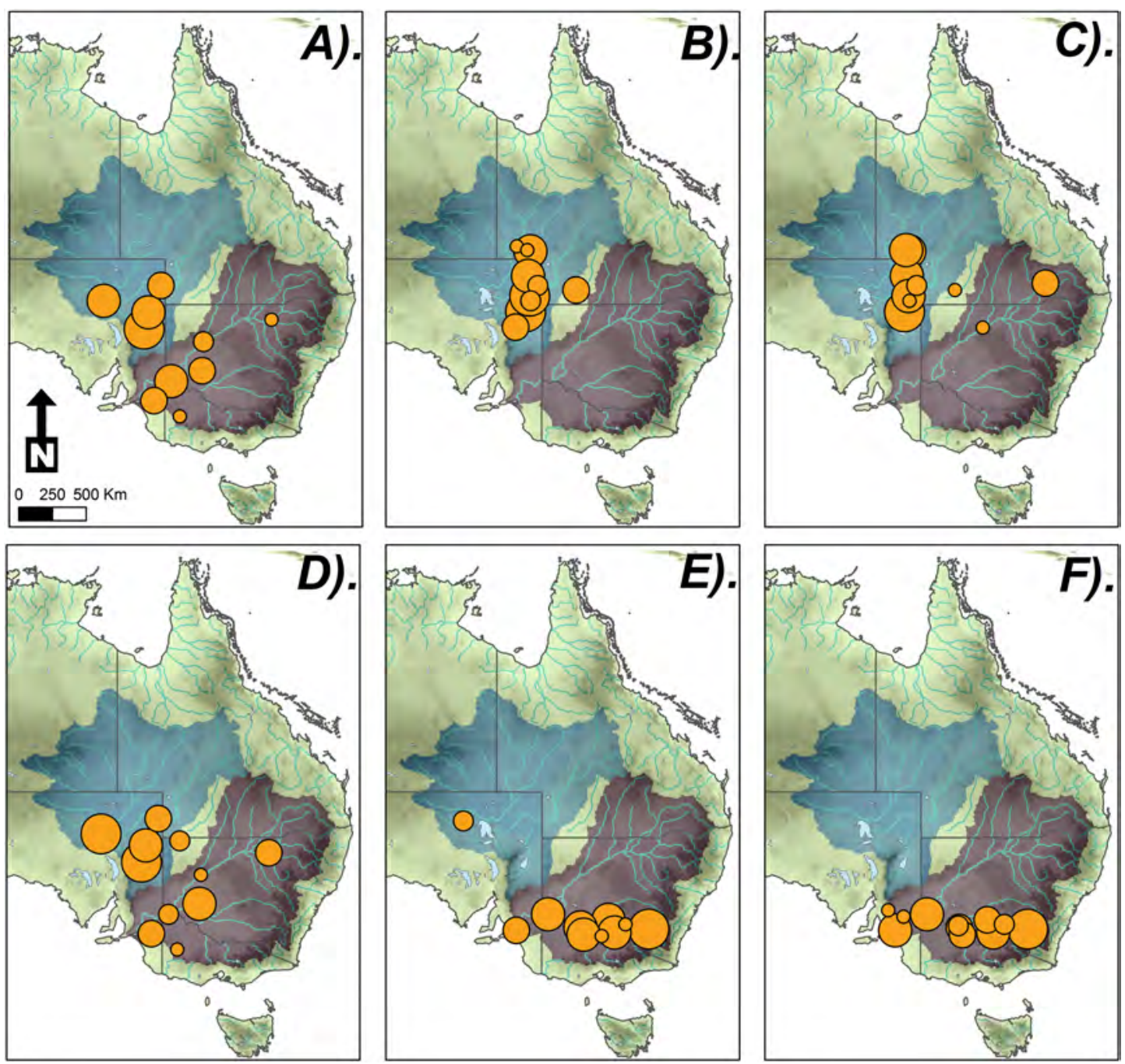

Figure 21 


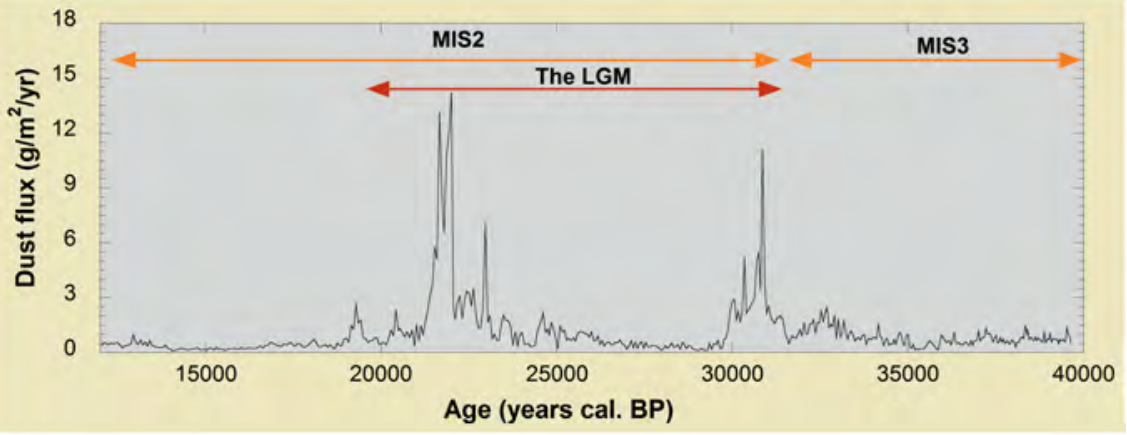

Figure 22 


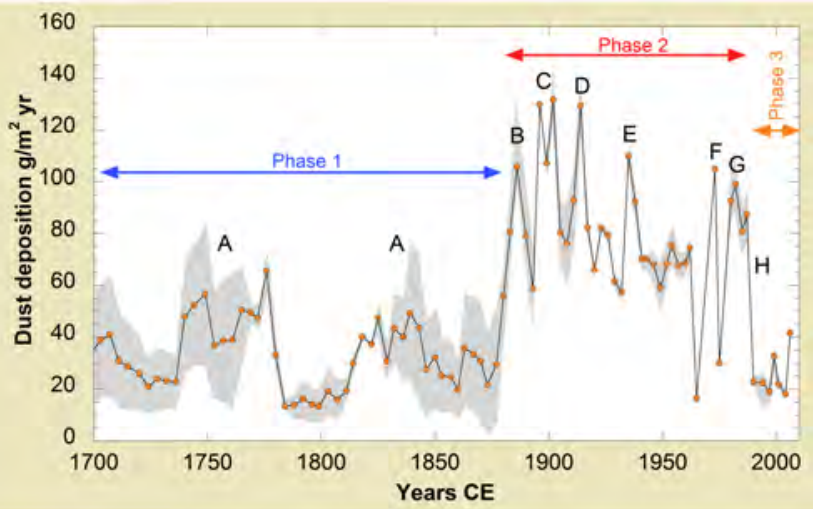

Figure 23 


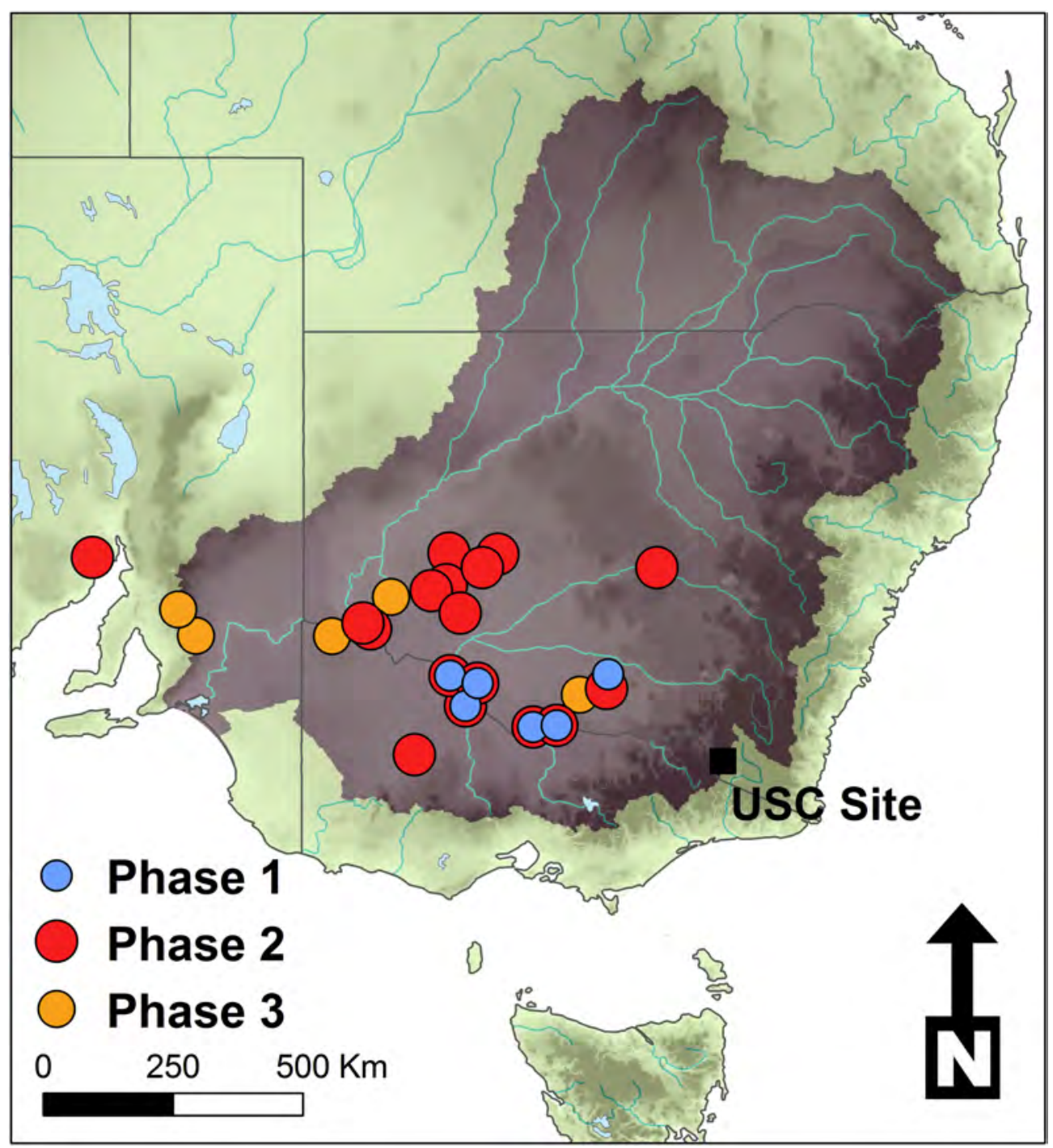

Figure 24 


\section{Accepted Manuscript}

Palaeo-dust records: A window to understanding past environments

Samuel K. Marx, Balz S. Kamber, Hamish A. McGowan, Lynda M. Petherick, Grant H. McTainsh, Nicola Stromose, James N. Hooper, Jan-Hendrik May

PII:

S0921-8181(17)30415-0

DOI: doi:10.1016/j.gloplacha.2018.03.001

Reference: GLOBAL 2746

To appear in:

Global and Planetary Change

Received date:

15 August 2017

Revised date:

2 March 2018

Accepted date:

5 March 2018

Please cite this article as: Samuel K. Marx, Balz S. Kamber, Hamish A. McGowan, Lynda M. Petherick, Grant H. McTainsh, Nicola Stromose, James N. Hooper, Jan-Hendrik May, Palaeo-dust records: A window to understanding past environments. The address for the corresponding author was captured as affiliation for all authors. Please check if appropriate. Global(2017), doi:10.1016/j.gloplacha.2018.03.001

This is a PDF file of an unedited manuscript that has been accepted for publication. As a service to our customers we are providing this early version of the manuscript. The manuscript will undergo copyediting, typesetting, and review of the resulting proof before it is published in its final form. Please note that during the production process errors may be discovered which could affect the content, and all legal disclaimers that apply to the journal pertain. 